Portland State University

PDXScholar

$5-20-2021$

\title{
Claiming Miscommunication to Justify Rape: The Role of Liking the Perpetrator
}

\author{
Alyssa Marie Glace Maryn \\ Portland State University
}

Follow this and additional works at: https://pdxscholar.library.pdx.edu/open_access_etds

Part of the Psychology Commons

Let us know how access to this document benefits you.

\section{Recommended Citation}

Maryn, Alyssa Marie Glace, "Claiming Miscommunication to Justify Rape: The Role of Liking the Perpetrator" (2021). Dissertations and Theses. Paper 5688.

https://doi.org/10.15760/etd.7561

This Dissertation is brought to you for free and open access. It has been accepted for inclusion in Dissertations and Theses by an authorized administrator of PDXScholar. Please contact us if we can make this document more accessible: pdxscholar@pdx.edu. 
Claiming Miscommunication to Justify Rape:

The Role of Liking the Perpetrator

by

Alyssa Marie Glace Maryn

A dissertation submitted in partial fulfillment of the requirements for the degree of

Doctor of Philosophy

in

Applied Psychology

Dissertation Committee:

Tessa Dover, Chair

Todd Bodner

Eric Mankowski

Emily Shafer

Portland State University

2021 
(C) 2021 Alyssa Marie Glace Maryn 
Abstract

In this dissertation, four experiments tested whether sharing an ingroup with a sexual violence perpetrator (vs not sharing an ingroup) makes individuals more likely to view the survivor's consent refusal as insufficient. Although most people communicate sexual consent indirectly and nonverbally (Hickman \& Muehlenhard, 1999; Kitzinger \& Frith, 1999), individuals often report that indirect and nonverbal consent refusals are an insufficient form of non-consent (O’Byrne et al., 2006, 2008). These claims of consent miscommunication might be used to justify instances of sexual violence when an individual is motivated to do so (Hansen et al., 2010). I hypothesize that sharing an ingroup identity with a perpetrator might motivate individuals to justify sexual violence, leading them to report that a survivor's communication of non-consent was unclear and insufficient. I also hypothesize that individuals with a higher preference for social hierarchy might display this effect even more strongly and that the relationship between perpetrator group membership and perceived survivor consent clarity would be mediated by situationally activated social rape scripts. Sharing a group with the perpetrator was associated with perceptions of poorer survivor consent clarity. However, this finding was qualified by insignificant results in three out of four studies. This effect was not stronger among those higher in preference for social hierarchy. Perceived peer norms supporting sexual aggression, but not rape myth acceptance, mediated the relationship between condition and perceived survivor consent clarity. The results of this dissertation suggest that perceptions of survivor consent clarity are impacted by factors outside the consent communication itself; this has implications for understanding victim blaming and improving third-party social support of sexual violence survivors. 


\section{Dedication}

For Boo, the best little dog in the whole world 


\section{Acknowledgments}

This dissertation would not have been possible without the support and guidance

of my advisor and chair, Dr. Tessa Dover, as well as the other members of my committee, Dr. Todd Bodner, Dr. Eric Mankowski, and Dr. Emily Shafer. I'd also like to thank my other research mentors, including but certainly not limited to Dr. Keith Kaufman. I am also deeply grateful to The Society for the Psychology of Women (Division 35 of the APA) for providing the funding that allowed me to conduct this research. Many thanks to my lab mates, cohort, and classmates, many of whom are also dear friends. I'd also be remiss not to thank my other friends, as well as my family and especially my parents for their unwavering support of my work and education. Finally, I cannot begin to express my gratitude to my wife, Aria. This would not have been possible without your support. 
Table of Contents

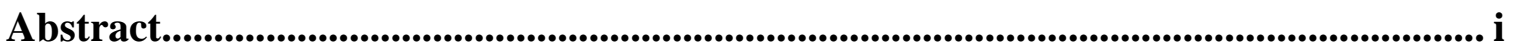

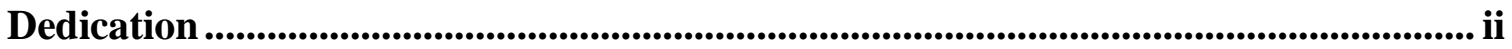

Acknowledgments .................................................................................................................... iii

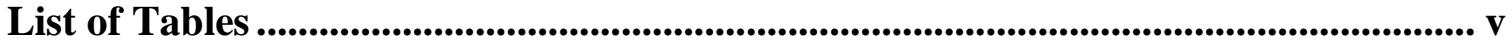

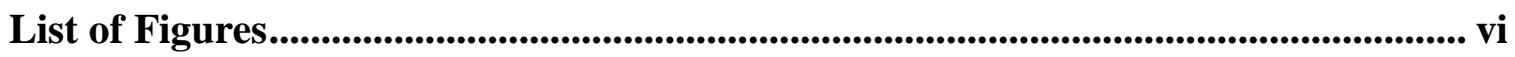

Chapter One - Introduction and Literature Review ...................................................... 1

Aversive Health Outcomes Associated with Sexual Violence ..................................... 2

The Importance of Defining Consent ......................................................................... 5

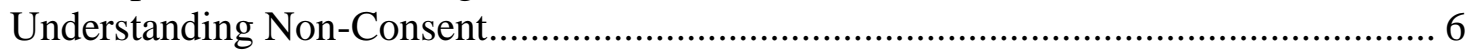

The Insufficiency of Miscommunication as a Cause of Sexual Violence .................... 9

Miscommunication Claims .................................................................................. 11

The Role of Power in Miscommunication Claims...................................................... 13

The Role of Gendered Scripts in Miscommunication Claims .................................... 16

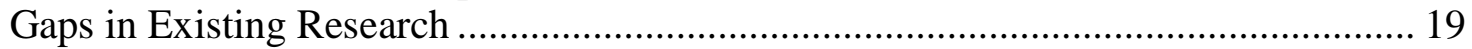

Research Questions .......................................................................................... 20

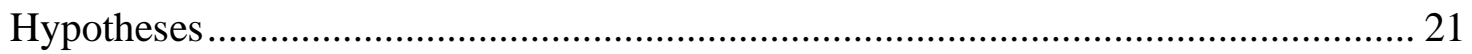

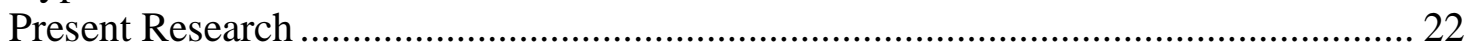

Chapter Two - Methods and Results....................................................................... 23

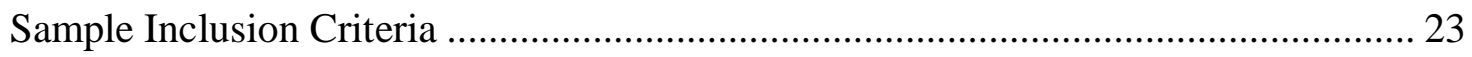

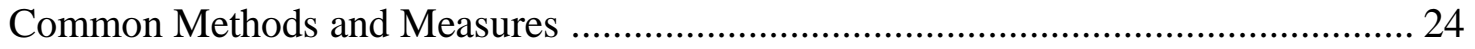

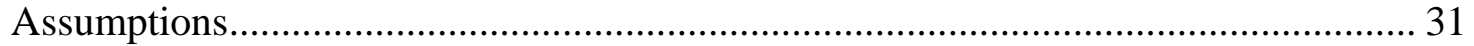

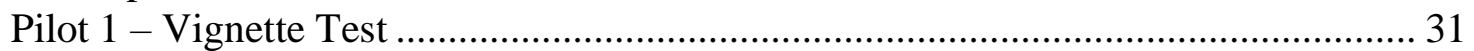

Pilot 2 - Manipulation Check ..................................................................................... 33

Pilot 3 - Updated Manipulation Check..................................................................... 35

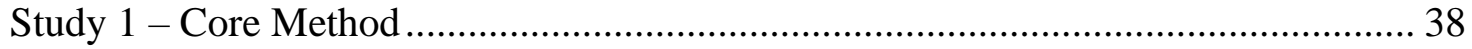

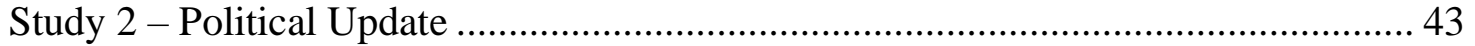

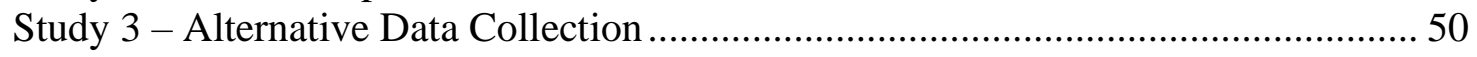

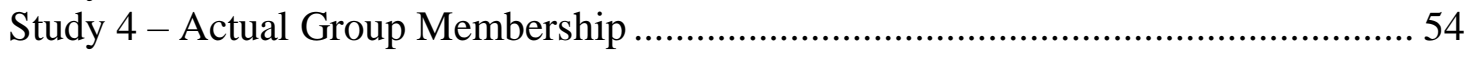

Chapter Three - Discussion.......................................................................................................60 60

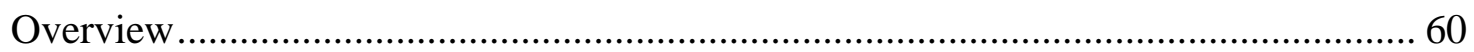

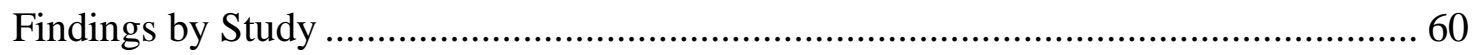

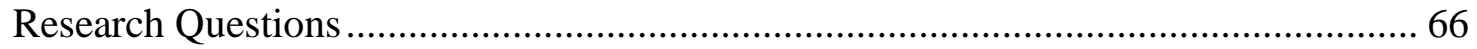

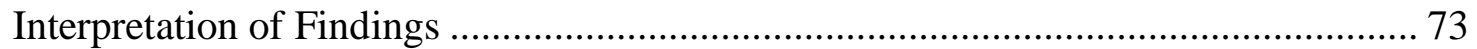

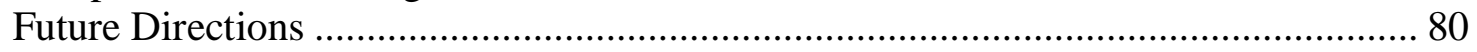

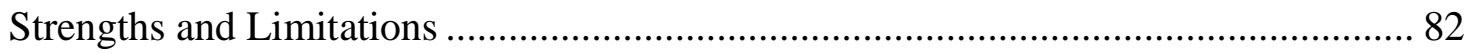

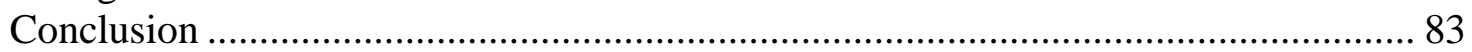

Tables and Figures ............................................................................................................................ 84

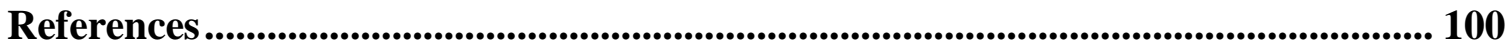

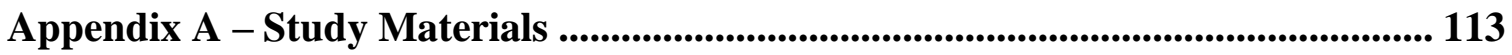

Appendix B - Tests of Model Assumptions ......................................................................... 140 


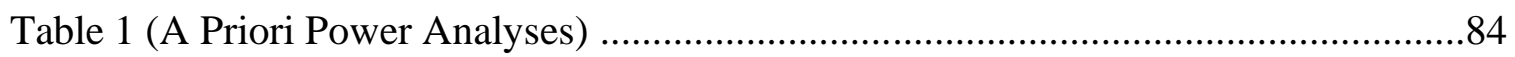

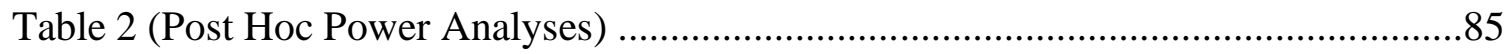

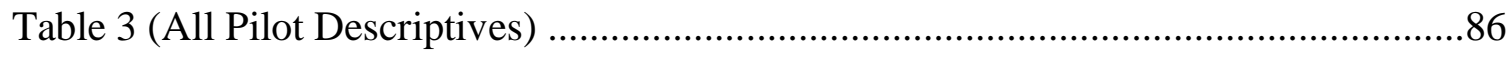

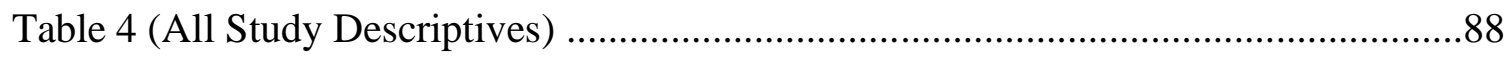

Table 5 (Pilot 1 Descriptives and Correlations) ........................................................90

Table 6 (Pilot 2 Descriptives and Correlations) ..................................................... 91

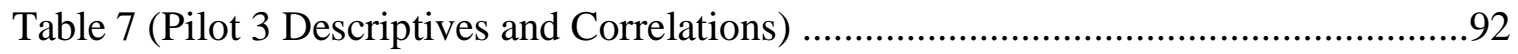

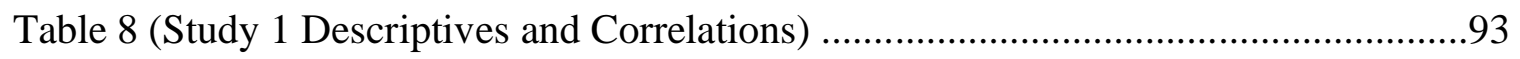

Table 9 (Study 2 Descriptives and Correlations) ...................................................94

Table 10 (Study 3 Descriptives and Correlations) …...............................................95

Table 11 (Study 4 Descriptives and Correlations) ..................................................96

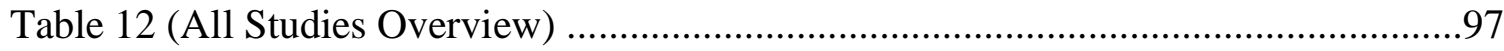




\section{List of Figures}

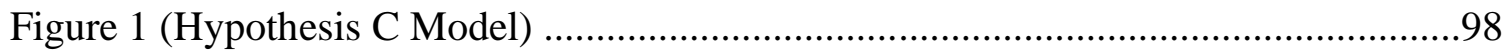

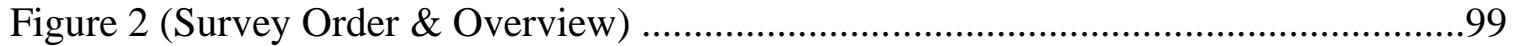




\section{Chapter One - Introduction and Literature Review}

"A young woman and a young man meet at a party, then proceed to tragically misunderstand each other's intentions - and they're drunk."- Malcolm Gladwell, Talking to Strangers

In 2015, two graduate students found Brock Turner raping an unconscious woman behind a dumpster in the middle of the night. Turner attempted to flee the scene, but one graduate student pinned him to the ground. Meanwhile, the other student checked the pulse of the woman, who was known as Emily Doe until she voluntarily identified herself years later as Chanel Miller. She would remain unconscious until hours later in the hospital. Despite Turner's multiple felony sexual assault convictions, Malcolm Gladwell calls his actions a tragic misunderstanding, as if the unconscious Miller should have just communicated a bit more clearly.

This example is only one instance of a larger cultural theme. Miscommunication is a commonly-cited cause of sexual violence, despite a growing body of evidence that suggests that miscommunication is a very unlikely cause of sexual violence (Beres et al., 2014; Hansen et al., 2010; Hickman \& Muehlenhard, 1999; Kitzinger \& Frith, 1999; O'Byrne et al., 2006, 2008). Claims of miscommunication diminish the harm caused by sexual assault and fail to hold perpetrators accountable for their actions.

The critical component of sexual consent is that it acts as a dividing line between sex and rape (Beres, 2007). Researchers have developed many varying criteria that establish what constitutes consent - and therefore what constitutes rape (Muehlenhard et 
al., 2016). Yet research definitions of consent do not align with the way individuals understand consent in their own lives (Beres, 2014). For example, young adults might report that consent operates differently in their own committed relationships, that consent is communicated nonverbally, and that they feel that the absence of resistance communicates consent (Beres, 2014). This conflicts with many research conceptualizations of affirmative consent, which consider the absence of resistance to be an insufficient indicator of consent and suggest that a verbal "yes" is the ideal consent communication (Jozkowski, 2015).

To adequately address sexual violence and its associated harms, it is essential to research how sexual consent is understood and communicated. In particular, it is crucial to identify how variability in the criteria used to establish clear and unambiguous consent might be exploited to justify sexually violent behavior. Perceptions of sexual consent communication might be impacted by factors outside of the consent communication itself. These factors may be used by third-party perceivers to determine whether a survivor's report of their own experiences is "legitimate." Based on this, these factors may determine whether or not a survivor receives critical social support.

Therefore, an understanding of external factors' influence on perceptions of consent clarity is important to efforts to support survivors of sexual violence.

\section{Aversive Health Outcomes Associated with Sexual Violence}

Sexual violence is a serious public health concern (García-Moreno et al., 2013). One in three US women will experience rape in her lifetime, as will one in one in six men (Smith et al., 2017). Research on the prevalence of sexual violence among gender 
minority individuals is lacking, but evidence indicates that these individuals experience sexual violence at even higher rates (Cantor et al., 2015).

Health outcomes associated with sexual violence victimization are well established. Survivors of sexual violence are at higher risk for depressive symptoms, anxiety, eating disorders, posttraumatic stress disorder, sleep disorders, suicide, reproductive cancer, difficulty walking, difficulty with daily activities, chronic pain, memory loss, dizziness, HIV, other STIs, low birth weight/premature births, substance use disorders, gastrointestinal problems, cardiopulmonary symptoms, fibromyalgia, migraines, painful menstruation, dyspareunia, and general poor health (Bonomi et al., 2007; Chen et al., 2010; Coker et al., 2009; Ellsberg et al., 2008; García-Moreno et al., 2013; Jina \& Thomas, 2013). Further, survivors of sexual violence might experience social disconnection and stigmatization related to their victimization experiences (Jina \& Thomas, 2013; Kennedy \& Prock, 2018).

In supporting survivor health and recovery, it is important to research the perceptions and responses of third parties to whom survivors may disclose their experiences. Social support, resources, and responses to survivors are critical to survivor health and recovery. At any point after experiencing sexual victimization, survivors might disclose their experiences to either formal (e.g., medical professionals, advocacy services, members of the criminal justice system) or informal (e.g., friends and family) sources of support. The responses that these disclosures are met with are often critical for survivor recovery. Unfortunately, the response that some survivors face from formal 
support resources can be so harmful that it is characterized as a further source of trauma or a "second rape" (Campbell, 2008).

Negative reactions to disclosures of sexual victimization from both formal and informal sources can lead to increased self-blame among survivors (Ahrens, 2006). This self-blame may then lead to increased symptoms of PTSD (Ullman et al., 2007). Survivors who experience negative reactions develop more symptoms of post-traumatic stress, anxiety, and depression in addition to having lower self-esteem (Borja et al., 2006; Halstead et al., 2017). These negative reactions can also keep survivors from making further disclosures, cutting off access to resources that would benefit the survivor in their recovery process and increasing rates of revictimization (Ahrens, 2006; Halstead et al., 2017).

Conversely, supportive reactions to survivor disclosures from both formal and informal sources are associated with increased posttraumatic growth and coping among survivors (Borja et al., 2006; Halstead et al., 2017). The provision of emotional support in response to survivor disclosures is associated with lower rates of revictimization (Mason et al., 2009). Positive responses to survivor disclosures are also associated with survivors' increased perceptions that they control their recovery process (Ullman \& Peter-Hagene, 2014).

The prevalence and adverse consequences of sexual violence make it clear that efforts are needed to prevent sexual violence and to support survivors. It is also clear that promoting supportive reactions and decreasing unsupportive reactions to disclosures of sexual violence are critical in supporting survivor recovery. This may be especially 
important to address among peer informal sources of support, as survivors are more likely to disclose to a friend than to other sources of support (Halstead et al., 2017). To implement such efforts, further research on how third-party perceivers conceptualize sexual consent and evaluate instances of sexual violence is warranted.

\section{The Importance of Defining Consent}

Without an operational understanding of sexual consent, it is impossible to define, research, legislate, prevent, and address sexual violence. This is due to its role as the dividing line between sex and rape (Beres, 2007). Therefore, sexual consent is a construct inherently imbued with legal and sociopolitical power. Discussions of the meaning, importance, and usefulness of the construct of sexual consent are complex, ongoing, and sometimes contentious (Muehlenhard et al., 2016). Attempts to prevent sexual violence have been hindered by inconsistent definitions and conceptualizations of sexual consent. Additionally, research in this area has focused on a limited population and often fails to examine consent outside of heterosex.

Research examining sexual violence and the way that individuals define and communicate sexual consent frequently rests on assumed ideas of what sexual consent is (Beres, 2007). As a result, inconsistent and sometimes problematic definitions of consent permeate the research literature, creating a significant barrier to the development of an integrated theory of consent. Generally speaking, consent is considered to be a freelygiven agreement to engage in sexual activity (Beres, 2014; Muehlenhard et al., 2016). However, ambiguity exists surrounding what constitutes a genuine freely-given agreement, and how it must be expressed and/or understood to be considered valid 
(Muehlenhard et al., 2016). While some past models of sexual consent have characterized consent as a discrete transaction, consent is better characterized as an ongoing negotiation process that occurs throughout a sexual encounter (Glace et al., 2020).

Within sexual encounters, the way that sexual consent is most often communicated is nuanced and nonverbal (Kitzinger \& Frith, 1999). When asked to describe their own sexual consent behaviors across general contexts (i.e., not specifically in situations involving coercion or violence), individuals generally report the use of nonverbal and/or indirect communication (Kitzinger \& Frith, 1999). This tendency is the case among men and women (Hickman \& Muehlenhard, 1999).

Young adults are frequently able to describe the indirect and nonverbal ways that they communicate consent with detail and nuance (Beres, 2010). Nonverbal cues might include a potential partner's body language and behaviors such as actively engaging in sexual activity (Beres, 2010). Verbal communication might still be indirect. Individuals looking to engage in sexual activity may ask their partner about contraceptive options (Beres, 2010). These are generally seen as acceptable and normative means of communicating sexual consent (Beres, 2010, 2014).

\section{Understanding Non-Consent}

However, the standards individuals apply to their own consent behavior (i.e., indirect, nonverbal) are not the standards that individuals tend to apply when considering rape. Individuals often perceive that the communication of non-consent must be simple, immediate, and forceful for an instance of sexual violence to "count" as genuine rape 
(O’Byrne et al., 2008). The level of forceful resistance required to align with common perceptions of what "true" non-consent means is almost impossibly high.

Many believe that a "real" instance of sexual violence has not occurred if the survivor does not have visible physical injuries sustained as a result of the assault (Gunby et al., 2013; Payne et al., 1999). Relatedly, social scripts that define rape dictate that rape must always involve physical force or extreme threats (e.g., being held at gunpoint; Gunby et al., 2013; Payne et al., 1999). Rape myths also suggest that rape is rarely perpetrated by intimate partners, in the survivor's neighborhood or home, or by middleclass men (Payne et al., 1999).

Rape scripts also state that "real" rape does not involve the consumption of alcohol and/or other drugs. These scripts include the idea that women who experience rape while drunk are responsible for their own victimization (Payne et al., 1999). Individuals may be reluctant to label an alcohol mediated rape as a "real" rape and be similarly resistant to holding perpetrators of alcohol mediated rapes accountable (Deming et al., 2013; Gunby et al., 2013). Individuals report that the meaning and communication of sexual consent are ambiguous in rapes involving the use of alcohol (Gunby et al., 2013). Many individuals feel that a survivor's voluntary consumption of alcohol inherently implies some degree of consent to sex, creating a misunderstanding in which the perpetrator is said to mistakenly believe that the survivor has given consent (Gunby et al., 2013). In cases where individuals see rape as a misunderstanding, they are often very resistant to holding perpetrators accountable, citing fears that the perpetrator's life would be ruined (Gunby et al., 2013). Alcohol consumption on the part of the perpetrator is also 
used to discount responsibility for sexual violence. Individuals may cite the perpetrator's intoxication to justify the perpetrator's behavior, claiming that the perpetrator could not fully understand what they were doing (Deming et al., 2013). Claims of consent miscommunication due to alcohol use represent another context in which "miscommunication" is invoked to minimize sexually violent behavior.

Rape scripts are not only present in the way that outsiders interpret sexual violence; these scripts play a role in the way survivors understand their own victimization. Kahn and colleagues (1994) found that survivors who reported less use of force during their experiences were less likely to acknowledge their own victimization. Individuals holding perceptions of rape that align more closely with rape scripts were also more likely to deny their own victimization (Kahn et al., 1994). A further effect might be found in cases where available rape scripts apply to a survivor's specific experiences. Women who endorse rape myths that match the characteristics of their own rape experience are less likely to acknowledge their own victimization (Peterson \& Muehlenhard, 2004). This is significant because it suggests that rape myths and scripts can be used to delegitimize survivor experiences, even by the survivor themselves.

Rape myths and scripts function to delineate "real" rape in which only the perpetrator is culpable from situations in which the survivor is blamed for their own victimization (Payne et al., 1999). Situations that align with these scripts are statistically rare and represent only a small subset of the forms that sexual assault and rape might take (Planty et al., 2013). The ways that survivors are expected to communicate their nonconsent within rape scripts (i.e., using sober, forceful, and direct physical resistance) are 
inconsistent with the ways that individuals report that they actually communicate consent (i.e., indirectly, nonverbally).

\section{The Insufficiency of Miscommunication as a Cause of Sexual Violence}

Interventions developed by researchers to prevent sexual violence may

inadvertently further the impact of rape scripts. Many consent education programs have focused on promoting effective consent communication (Borges et al., 2008). This emphasis on consent communication skills implies that consent misunderstanding causes sexual violence (Jozkowski, 2015). This public perception is reflected in the Gladwell quote describing an instance of rape as a "misunderstanding." Individuals are unwilling to hold perpetrators accountable when they perceive that an instance of rape is a misunderstanding and are more likely to blame survivors (Deming et al., 2013; Gunby et al., 2013). Blaming sexual violence on miscommunication inherently implies that if the survivor had said no louder, fought back better, or been clearer, then they would not have been victimized. This is reflective of neoliberal discourses, which state that an agentic woman would not be victimized. Research has suggested these discourses are associated with self-blame in survivors (Bay-Cheng \& Eliseo-Arras, 2008; Burkett \& Hamilton, 2012). Essentially, this is a rape myth that research must not perpetuate (Payne et al., 1999).

There are some differences in the way men and women communicate consent, suggesting that gender-based consent miscommunication is technically possible (Hickman \& Muehlenhard, 1999). However, the effect sizes associated with these gender differences are small (Hickman \& Muehlenhard, 1999). It is unlikely that the effect is 
strong enough to account for instances of sexual violence (Hickman \& Muehlenhard, 1999). When young adults are asked how they navigate desire differences (i.e., situations in which only one potential sexual partner desires sex, but sexual contact ultimately occurs), they do not report that miscommunications lead to unwanted or coerced sex (Beres et al., 2014). Young adults report many nuanced ways in which desire differences might be resolved, including further conversation, moving forward slowly, and the participant internally changing their mind, but miscommunication resulting in rape is not among them (Beres et al., 2014).

Beyond the fact that nonverbal, indirect consent communication is widely understood, research also indicates that young women face barriers to communicating non-consent directly. Young women might find it difficult to give a direct and verbal "no" when asked to consent to sex (Kitzinger \& Frith, 1999). First, pervasive gendered scripts of sexual consent pressure women to have sex regardless of their desires (Kitzinger \& Frith, 1999). Second, giving a direct "no" to any request is not socially normative, and this may be especially true for women (Kitzinger \& Frith, 1999). Social refusal is a multifaceted process defined by cultural rules and young women apply those rules when refusing sex (Kitzinger \& Frith, 1999).

Young men understand young women's indirect consent refusals. In research conducted by O'Byrne and colleagues (Hansen et al., 2010; O'Byrne et al., 2006, 2008) young men demonstrated their capacity to understand indirect and nonverbal social communication of non-consent. Further, young men indicated that such refusals are common and normal, as opposed to saying "no," which was seen as too blunt (O'Byrne et 
al., 2006). However, in cases of rape allegations, young men report that indirect refusals would lead to miscommunication, meaning that the perpetrator should not be held accountable (O’Byrne et al., 2008).

Sexual violence is not associated with misunderstanding consent but instead is associated with thinking that non-consensual sex is acceptable. Warren and colleagues' (2015) research found that rape myth acceptance, masculine norms, and perceived peer support for sexual violence predict sexual aggression. Further, the pathway from rape myth acceptance, masculine norms, and perceived peer support for sexual violence to sexual aggression is mediated by the degree to which one thinks that non-consensual sexual contact is acceptable (Warren et al., 2015).

Despite evidence that indirect consent refusals are a normative and wellunderstood mode of communication, and that miscommunication is not a cause of sexual violence, claims of consent miscommunication persist (Hansen et al., 2010). Specifically, individuals might cite a supposed miscommunication in cases of sexual coercion and rape (Hansen et al., 2010). This suggests that consent "miscommunication" might be evoked to diminish survivors' experiences and justify perpetrators' behavior (Hansen et al., 2010).

\section{Miscommunication Claims}

The existing literature suggests that normative consent communication is indirect and nonverbal. Further, it is unlikely that consent miscommunication is a cause of sexual violence. However, without the presence of direct verbal and physical resistance, many individuals discount instances of sexual violence as "just misunderstandings." These 
claims state that the survivor's consent communication was unclear, meaning that the perpetrator cannot be held responsible for their actions. The present research examined these miscommunication claims, and whether they are impacted by factors outside of the consent communication itself, such as the perceivers' feelings towards the perpetrator.

Specifically, the current research investigated whether individuals might be more motivated to justify the actions of a liked (vs. neutral or disliked) perpetrator, leading them to claim that the survivor's consent communication was unclear. This may have been influential in the Brock Turner case, as his role as a Stanford student and star swimmer was often suggested as evidence to support his character. Individuals might be more motivated to draw on gendered rape scripts and claim consent miscommunication to justify sexual violence in cases where they like or identify with the perpetrator. Group membership is related to liking and identification. Individuals are motivated to view groups they belong to as distinctly positive (Tajfel \& Turner, 1986). This results in ingroup favoritism, in which individuals show preference to those with whom they share a group identity (i.e., ingroup members; Tajfel \& Turner, 1986). People also tend to denigrate those who are outside of their group (i.e., outgroup members; Tajfel \& Turner, 1986). This preference has been demonstrated even in cases where group membership is arbitrarily assigned and lacks practical implications (Tajfel \& Turner, 1986). In other words, ingroup favoritism occurs even when the meaning of group identity is minimal (Tajfel \& Turner, 1986).

To test study hypotheses, the present research attempted to manipulate participant liking of a fictional perpetrator of sexual violence using a modified version of the 
minimal group classification paradigm. The minimal group paradigm involves assigning arbitrary or "minimal" group identities to individuals and examining the impact on a person's favoritism towards their own arbitrary group (Tajfel \& Turner, 1986). Individuals favor their own group even when group membership is inconsequential (Tajfel \& Turner, 1986). The present research used this technique to attempt to manipulate participants' liking of a perpetrator of sexual violence. While the traditional minimal group paradigm involves one's evaluation of an abstract ingroup and outgroup (Tajfel \& Turner, 1986), this research required an evaluation of a specific person (i.e., a perpetrator). For this reason, this research used a minimal group paradigm that was modified such that the participants evaluated a specific individual as opposed to the general idea of an ingroup.

The present research also investigated several factors that may influence this effect. More specifically, individuals high in preference for social hierarchy might be even more likely to justify instances of violence committed by a liked perpetrator. Additionally, this work explored whether sharing a group with a perpetrator might activate rape myths or norms which then justify faulting sexual violence survivors for perceived insufficiencies in their consent refusal. I review evidence about these moderators and mediators below.

\section{The Role of Power in Miscommunication Claims}

The motivation to diminish claims of sexual violence with which one has no involvement may be driven by attitudes supporting social hierarchies. Feminist understandings of sexual violence suggest that perpetrators' true motivation is power, not 
sexual desire (Wells \& Taylor, 2003). Further, one of the key mechanisms associated with the adverse outcomes that survivors experience is the disempowerment associated with the violation of one's consent (Wells \& Taylor, 2003). Research supporting this theory connects sexual aggression and related beliefs to more general attitudes supporting structural power hierarchies, such as system justification beliefs, belief in a just world, and social dominance orientation (Chapleau \& Oswald, 2014; Kelly et al., 2015; Landström et al., 2016; Ståhl et al., 2010; van den Bos \& Maas, 2009). The literature suggests that support for social hierarchy is associated with victim-blame when interpreting sexual violence experienced by others (Ståhl et al., 2010).

This may be especially true of support of systemic gender inequity. Higher gender-based system justification beliefs (i.e., modern sexism) are associated with greater rape myth acceptance and lower moral outrage in response to general injustice (Chapleau \& Oswald, 2014). Greater rape myth acceptance also predicts lower moral outrage in response to general injustice (Chapleau \& Oswald, 2014). Similarly, gender-related system justification predicts victim-blame against a survivor of sexual violence among men (Ståhl et al., 2010). However, among women, gender-related system justification only predicts victim-blame when participants are primed with complementary gender stereotypes about women (i.e., benevolent sexist stereotypes; Ståhl et al., 2010). Complementary stereotyping about women may lead women who are high in system justification to engage in more victim-blame (Ståhl et al., 2010).

Social dominance orientation is another attitude that demonstrates the relationship between preference for power imbalance and sexual violence. When men experience 
romantic rejection, those higher in social dominance orientation are more likely to blame the woman who rejected them and to engage in persistent and aggressive manipulation following the rejection (Kelly et al., 2015). Further, social dominance orientation is associated with higher hostile sexism, greater rape myth acceptance, higher belief that women should be disciplined, and more support for lowering the age of consent (Kelly et al., 2015).

The association between belief in a just world, rape myth acceptance, and victimblame is less clear-cut. This is likely related to the distinction between belief in a just world for self and belief in a just world for others. These are related but separate constructs (Lipkus et al., 1996). General belief in a just world is associated with increased victim-blame (Landström et al., 2016; van den Bos \& Maas, 2009) but not rape myth acceptance (Hammond et al., 2010). Increased belief in a just world for self has been associated with decreased rape myth acceptance (Hayes et al., 2013). However, in this same research belief in a just world for others was not significantly related to rape myth acceptance (Hayes et al., 2013). Belief in a just world for others may be more likely to be related to victim-blame and other attitudes that are generally supportive of sexual aggression.

Taken together, these results suggest that preference for social hierarchy is associated with more sexually violent attitudes and a higher propensity to blame survivors of sexual violence for their own victimization (Chapleau \& Oswald, 2014; Kelly et al., 2015; Ståhl et al., 2010). This aligns with theories that suggest that power motivation plays a key role in sexually violent behavior and the way that one 
conceptualizes sexual violence and consent (Wells \& Taylor, 2003). As such, I measured social dominance orientation and belief in a just world for others as moderators of the relationship between sharing a group with a perpetrator and perceived survivor consent clarity.

\section{The Role of Gendered Scripts in Miscommunication Claims}

Sharing a group with a perpetrator might activate gendered rape scripts and myths. Individuals might then rely on these gendered sexual scripts to justify sexual violence by citing consent miscommunication. Chapleau and Oswald (2010) suggest that situations that activate implicit power-sex associations (i.e., situations which involve the conflation of power and sex, such as rape) increase cognitions consistent with rape myths. Rape myths are gendered and associated with individuals' beliefs about sexual consent (Shafer et al., 2018). Therefore, exposure to situations that conflate power and sex might activate gendered rape myths, which might in turn influence perceptions of sexual consent.

Consent is gendered and impacted by sociocultural systems of power (Bay-Cheng \& Eliseo-Arras, 2008). The way individuals perceive and understand sexual consent is based on gender roles defined by gendered scripts and discourses. Sexual consent is often conceptualized as something that a woman gives to a man, and not vice versa (Hirsch et al., 2018). When individuals discuss consent, they predominantly focus on the ways that women give consent to men (Beres, 2014). They may also perceive consent as discrete, the bare minimum, and inapplicable to their relationships (Beres, 2014). This may have many problematic implications, including that it hinders men's ability to recognize 
coercive behaviors directed at them from women (Hirsch et al., 2018). Further, it positions women to act as gatekeepers who are responsible for resisting men's sometimes coercive sexual advances.

The idea that only women give consent is not the only problematic aspect of gendered scripts of sexual consent. There are many gendered double standards present in the way many young people conceptualize and communicate sexual consent (Jozkowski et al., 2017). Young women are degraded when they are perceived as having had sex too much or with too many partners (Jozkowski et al., 2017). However, young adults might also perceive some contexts in which a woman might "owe" a man sexual contact (Jozkowski et al., 2017). This produces no-win situations in which young women would be degraded whether or not they had sex.

Individuals might rely on gendered and neoliberal discourses in the consent negotiation process (Bay-Cheng \& Eliseo-Arras, 2008). Gendered discourses suggest that women should be sexually passive and pleasing to men, leading many women to feel pressured into having unwanted sex (Bay-Cheng \& Eliseo-Arras, 2008). After-the-fact, young women might feel pressured by neoliberal discourses which both value agency and posit victimization as the opposite of agency to hold themselves responsible for these experiences. Some researchers suggest that, in heterosexual consent negotiations, the gendered power gap between men and women might be insurmountable (Burkett \& Hamilton, 2012). They problematize the idea that a woman can ever give consent to a man that is truly free of the influence of gendered power structures (Burkett \& Hamilton, 2012). 
Many young men view obtaining sex as a conquest or competition with their potential sexual partners (Jozkowski et al., 2017). To this end, young men may exploit social norms surrounding sex and consent to facilitate situations in which women feel social pressure to have sex with them (Jozkowski et al., 2017). More specifically, young men may use deception and aggression to pressure women into having sex (Jozkowski \& Peterson, 2013). Women are often pressured to perform oral sex for men but the inverse is not the case (Jozkowski \& Peterson, 2013). Exposure to depictions of sexual coercion, which involve the conflation of sex and power, may increase endorsement of these gendered rape myths and subsequent perceptions of consent (Chapleau \& Oswald, 2010; Shafer et al., 2018). This effect may be especially present among those who are motivated to use these rape myths to protect an ingroup perpetrator. As such, I measured rape myth acceptance as a mediator of the relationship between sharing a group with a perpetrator and perceived survivor consent clarity.

A further consideration in this area is the role of social norms in impacting perceptions of consent and appropriate sexual behavior. These gendered scripts are socially constructed, and many individuals base their conceptualizations of sexual consent on discussions with their peers (Deming et al., 2013; Hirsch et al., 2018). A man's perception of his peers' support for sexual aggression predicts his likelihood of engaging in sexually aggressive behavior (Dardis et al., 2016). The activation of these gendered scripts might also be related to perceptions of peer support for sexual violence. Therefore, I also tested perceptions of peer support for sexual aggression as a mediator of 
the relationship between sharing a group membership with the perpetrator and perceived survivor consent clarity.

\section{Gaps in Existing Research}

The existing research includes several gaps and weaknesses which warrant further investigation. It has been demonstrated that miscommunication is not a cause of sexual violence, and also that miscommunication claims are used to justify sexually violent behaviors. The current research further investigated this phenomenon by examining potential motivations for consent communication claims. Further, there are some methodological limitations in the existing literature that the present research aimed to address.

\section{Missing Experimental Methods}

This research used experimental quantitative methods to examine consent miscommunication claims. The vast majority of research conducted in this area has been qualitative. This is likely due to the complex nature of the topic, as well as the relative lack of an integrated theory of sexual consent. While this past research has proven fruitful and has suggested many useful future directions, it cannot support causal inference.

Survivors are often victim-blamed when others perceive that their consent communication is insufficient. By understanding other factors that influence perceiver evaluations of survivors' consent, with the actual consent communication held constant, this narrative can be shifted away from victim-blame. Quantitative experimentation in this area is warranted. 
Limited Samples

The present research aimed to collect larger and more diverse samples than much of the existing literature. Perhaps associated with the previous limitation is that sample sizes in this research are predominantly small. This is especially true of the research covering potential misuse of miscommunication claims (O'Byrne et al., 2006, 2008). These samples are generally very homogenous. Research on sexual consent has a nearexclusive focus on heterosexual adolescents and emerging adults. While the gendered nature of sexual consent and the prevalence of date rape suggest that a heterosexual population engaged in dating should be a promising target of this research, this focus is highly detrimental to generalizability.

\section{Research Questions}

There are three research questions which this investigation aims to address.

\section{Research Question 1}

Does sharing a group with a sexual violence perpetrator lead third-party perceivers to report that the survivor's consent communication was unclear?

\section{Research Question 2}

Does individual preference for social hierarchy make a third-party perceiver more likely to report unclear survivor consent communication when the perceiver shares a group with the perpetrator? 


\section{Research Question 3}

Does sharing a group with a perpetrator lead third-party perceivers to report unclear survivor consent communication by activating cultural rape myths or norms associated with victim-blame?

\section{Hypotheses}

This research tested these Hypotheses A, B, and C, corresponding with Research Questions 1, 2, and 3, respectively.

\section{Hypothesis A}

When the perpetrator of an act of sexual violence is an ingroup member to the perceiver (vs. an outgroup member to the perceiver) the perceiver will report perceptions that the survivor's consent communication was less clear.

\section{Hypothesis B}

Preference for social hierarchy will moderate the relationship between perpetrator group membership and perceptions of survivor consent clarity, such that sharing a group membership with the perpetrator (vs not knowing the perpetrator's group membership) will have a stronger negative impact on perceived consent clarity among those high (vs. low) in preference for social hierarchy.

\section{Hypothesis $C$}

Global beliefs about sexual violence will mediate the relationship between perpetrator group membership and perceptions of survivor consent clarity. A model depicting Hypothesis $\mathrm{C}$ is shown in Figure 1. 
Present Research

In this dissertation, I conducted four studies that investigated these research questions and tested the above hypotheses. These studies consisted of online experiments in which participants were randomly assigned to read a vignette about an instance of sexual violence after being told that the perpetrator in the story was an ingroup member, was an outgroup member, or did not have a group membership. Participants' perceptions of the survivor's consent clarity (i.e., the extent to which they felt the survivor's consent communication was sufficient, precluding a misunderstanding) were measured after participants read the vignette. 


\section{Chapter Two - Methods and Results}

\section{Sample Inclusion Criteria}

For all studies, participants were required to be 18 or older and living in the United States. For all MTurk studies, once an individual had completed a study, they were ineligible to complete the subsequent studies. ${ }^{1}$ To be included in the final analyses, participants also had to pass attention and manipulation checks. The attention check included an item embedded in the consent clarity scale asking participants to leave the item blank. Participants who provided an answer to this item were excluded from analyses. The manipulation check entailed an item asking the participant if they remembered whether the perpetrator did or did not share their group. Participants who answered this item incorrectly or indicated that they were unsure were excluded from analyses.

For the Actual Group Membership study (Study 4), several more inclusion criteria were used. Participants were required to be Portland State University students. For data collected in the summer, participants were required to be enrolled in at least one course in the summer term and/or have enrolled in at least one class in the previous spring term. For data collected in the fall, participants were required to be enrolled in at least one course in the fall term.

\footnotetext{
${ }^{1}$ This was done using an external service (i.e., CloudResearch) so as to not damage participants' standing on the MTurk platform.
} 


\section{Common Methods and Measures}

\section{Core Method}

The core method was tested and developed in Pilots 1 through 3 and then used to test the hypotheses in Studies 1 through 4. In this method, participants first completed a measure of preference for social hierarchy. In Studies 1 and 2, this was a measure of social dominance orientation (Ho et al., 2015). In Studies 3 and 4, this was a measure of belief in a just world for others (Lipkus et al., 1996). I selected these two measures to examine whether perceptions of consent clarity and the relationship between group membership and perceptions of consent clarity are more strongly impacted by beliefs explicitly supporting social inequality generally or beliefs supporting the current social system which is characterized by social inequality.

Second, participants were randomly assigned to conditions in which I attempted to manipulate participants' liking of the perpetrator by manipulating group membership. In Studies 1 and 3, I used a modified minimal group paradigm (Tajfel \& Turner, 1986). Participants took a bogus "thinking type" test and were told they had a "logical" thinking type. They were then randomly assigned to conditions in which they were told that the perpetrator was either the same type of thinker (i.e., a fellow logical thinker; ingroup condition), the opposite type of thinker (i.e., a visual thinker; outgroup condition), or the perpetrator's thinking type was not mentioned (no group condition). In Studies 2 and 4, I relied on an actual group to which the participant belonged and randomly assigned participants to read about a perpetrator who shared this group, belonged to an outgroup, or was not assigned a group membership. All participants then completed a measure of 
baseline liking of the perpetrator before reading a study vignette which was identical across conditions for the given study. Vignettes are available in Appendix A, and Figure 2 depicts the order of the survey.

Third, participants filled out outcome measures including perceived consent clarity, perceptions of blame, liking towards the perpetrator, and perceptions that the event was rape and/or sexual assault. Participants also completed a manipulation check. They then completed a measure of global beliefs about sexual violence. In Studies 1 and 2, this was a measure of rape myth acceptance (Payne et al., 1999). In Studies 3 and 4, this was a measure of perceived peer norms supporting sexual aggression (Abbey et al., 2001). I selected these two measures to examine whether the relationship between group membership and perceptions of consent clarity was driven by one's own beliefs about sexual violence or one's perceptions of social norms around sexual violence. Another important consideration is that the measure of rape myth acceptance is gendered, referring only to male perpetrators and female survivors, while the measure of peer norms supporting sexual aggression is gender-neutral. Participants also provided demographic information. They were then debriefed and compensated based on the terms of that particular study. All MTurk data were collected using CloudResearch, a software used to access the MTurk platform (Litman et al., 2017).

\section{Core Measures}

Social Dominance Orientation. Social dominance orientation (SDO) was measured using the SDO-7 (Ho et al., 2015). This is a 16-item Likert-type scale rated on a scale from 1 (Strongly Oppose) to 7 (Strongly Favor). This measure was included in 
Study $1(\alpha=0.96)$ and Study $2(\alpha=0.96)$ and demonstrated excellent reliability in both cases. A sample item is "Some groups of people must be kept in their place." The full scale can be found in Appendix A.

Belief in a Just World for Others. Belief in a just world for others (BJW) was measured using the Belief in a Just World - Others scale (Lipkus et al., 1996). This is an 8-item Likert-type scale rated on a scale from 1 (Strongly Disagree) to 6 (Strongly Agree). This measure was included in Study $3(\alpha=0.92)$ and Study $4(\alpha=0.87)$ and demonstrated good to great reliability in both cases. A sample item is "I feel that when people meet with misfortune, they have brought it on themselves." The full scale can be found in Appendix A.

Baseline Liking of the Perpetrator. Baseline liking of the perpetrator was measured using a single Likert-type item rated on a scale from 1 (Strongly Disagree) to 6 (Strongly Agree) asking participants to evaluate the statement "I like Alan." ${ }^{2}$ This measure was included in all studies except Pilot 1 and Pilot 2.

Perceived Consent Clarity. Perceived consent clarity was measured using a scale developed for this dissertation. This scale included 8 Likert-type items rated on a scale from 1 (Strongly Disagree) to 6 (Strongly Agree). The scale was used in Pilot 1 ( $\alpha=0.89)$, Pilot 2 ( $\alpha=0.89)$, Pilot 3 ( $\alpha=0.91)$, Study $1(\alpha=0.91)$, Study $2(\alpha=0.89)$, Study $3(\alpha=0.86)$, and Study $4(\alpha=0.83)$. The scale demonstrated good to great reliability in all studies. A sample item is "It makes sense that Alan would think that Sandy ${ }^{3}$ wanted to

\footnotetext{
${ }^{2}$ Alan is the name of the perpetrator in the vignette.

${ }^{3}$ Sandy is the name of the survivor in the vignette.
} 
have sex [R].” An attention check was embedded within this scale, which asked participants to leave the item blank if they were attentively reading the scale. This item was included in the scale in every study, except for Study 3, which used separate quality control checks. All scale items can be found in Appendix A.

Manipulation Check. Two manipulation check items were included in this survey. One item asked participants to recall the group to which the perpetrator belonged while the other asked participants to recall whether they shared a group with the perpetrator. The latter was found to be a more conservative and relevant indication of manipulation success and therefore was used to determine inclusion in the sample. These items were included in all surveys except Pilot 1 , for which they were inapplicable.

Rape Myth Acceptance. Rape myth acceptance was measured using the Illinois Rape Myth Acceptance Scale - Short Form (IRMAS; Payne et al., 1999). This is a 17item Likert-type scale rated on a scale from 1 (Not at all Agree) to 7 (Very Much Agree). This measure was included in Study $1(\alpha=0.96)$ and Study $2(\alpha=0.95)$ and demonstrated excellent reliability in both cases. A sample item is "If a woman doesn't physically fight back, you can't really say that it was rape." The full scale can be found in Appendix A.

Perceived Rape-Supportive Peer Norms. Perceived rape-supportive peer norms were measured using the Peer Attitudes Towards Sexual Aggression Scale (Abbey et al., 2001). This is a 5-item Likert-type scale rated on a scale from 1 (Not at all) to 5 (Very Much). This measure was included in Study $3(\alpha=0.89)$ and Study $4(\alpha=0.62)$. This scale demonstrated good reliability in Study 3, but sub-par reliability in Study 4. A sample item 
is "How much would your friends approve of forcing someone to have sex?" The full scale can be found in Appendix A.

Demographics. Collected demographics included gender, race/ethnicity, education, employment status, marital status, income, and trans status, and sexual orientation. These demographics were collected in every study.

\section{Supplementary Measures}

These measures were included in the core method as potential explanatory factors but were not used in any hypothesis tests.

Victim and Perpetrator Blame. Victim and perpetrator-blame were measured using two sliding scales asking participants to rate the percent (0-100) of blame they would assign to the perpetrator and blame they would assign to the survivor. These scales were not locked to $100 \%$, so a participant could assign percentages of blame that might add up to more or less than $100 \%$. This measure was included in all studies.

Liking of the Perpetrator. Liking of the perpetrator was measured using the same item as the baseline liking of the perpetrator measure. The sole difference was that this item was measured after participants read the vignette which described the perpetrator's sexual offending behavior and asked if the participant liked Alan "from this story." This measure was included in all studies.

Perceptions of Sexual Assault and Rape. Perceptions of sexual assault and rape were measured using two Likert-type items rated on a scale from 1 (Strongly Disagree) to 6 (Strongly Agree) asking participants to evaluate the statements "What Alan did to 
Sandy is sexual assault" and "What Alan did to Sandy is rape." These measures were included in all studies.

\section{Core Hypotheses}

For this research, I propose several core hypotheses to be tested in different iterations across Studies 1 through 4 . These are described in detail at the end of the previous chapter.

\section{Core Analyses}

Preliminary Analyses. In all studies that included a measure of baseline liking of the perpetrator, T-Test or ANOVA analyses, depending on the number of conditions, were used to determine if baseline liking of the perpetrator differed significantly by condition. When the study included more than two conditions, post hoc Tukey tests were used to test differences between conditions. These tests were conducted as manipulation checks. The correlation between baseline liking of the perpetrator and perceived consent clarity was also calculated and tested for significance.

Hypothesis A. In all studies, T-Test or ANOVA analyses, depending on the number of conditions, were used to determine if perceived consent clarity differed significantly by condition. When the study included more than two conditions, post hoc Tukey tests were used to test differences between conditions.

Hypothesis B. When a study included a measure of preference for social hierarchy (i.e., Studies 1 through 4), that measure was tested as a moderator of the relationship between condition and perceived consent clarity. In all moderation models, all predictor variables were standardized. When studies included more than two 
conditions, two dummy-coded variables were used representing the ingroup vs. no group comparison and the outgroup vs. no group comparison. Stepwise linear regression was used to test this potential moderation effect. First, in the step 1 model, condition (dummy coded in the case of three conditions) and the preference for social hierarchy variables were entered into the model predicting perceived consent clarity. Then, in the step 2 model, the interaction term was added into the model. Two interaction terms (i.e., ingroup vs. no group comparison x preference for social hierarchy, outgroup vs. no group comparison x preference for social hierarchy) were entered into the model in cases with two dummy coded variables. If an interaction term was found to be significant, simple slopes were calculated to probe the effect.

Hypothesis C. When a study included a measure of global beliefs about sexual violence (i.e., Studies 1 through 4), that measure was tested as a mediator of the relationship between condition and perceived consent clarity. When studies included more than two conditions, two dummy-coded variables were used representing ingroup vs. no group comparison and outgroup vs. no group comparison. I used linear regression based on Baron and Kenny's (1986) steps to calculate mediation effects.

In the step 1 models, I predicted perceived consent clarity based on the condition variable(s). In the step 2 models, I predicted the global beliefs about sexual violence variable based on the condition variable(s). In the step 3 models, I predicted perceived consent clarity based on the global beliefs about sexual violence variable. Finally, in the step 4 models, I predicted perceived consent clarity based on the condition variable(s) and the global beliefs about sexual violence variable. 
Following these steps, I computed bootstrapped indices of direct and indirect effects using the mediation package in R (Tingley et al., 2014).

\section{Assumptions}

I tested model assumptions for each analysis. In many cases, q-q plots and Shapiro-Wilk tests indicated some degree of non-normality in the residuals. Because the general linear model is robust to non-normal residuals, I proceeded with the analyses as

planned. Documentation of my tests of model assumptions can be found in Appendix B. A priori power analyses indicated that a sample of 1548 would be sufficient to detect a small effect and a sample of 252 would be sufficient to detect a medium effect. These power analyses were based on the analyses used to test Hypothesis A as these were the analyses that required the largest sample sizes. A priori and post hoc power analyses can be found in Table 1 and Table 2 .

Pilot 1 - Vignette Test

\section{Research Questions}

I conducted this pilot test to examine participant responses to three potential study vignettes. I examined whether the mean and standard deviation of perceived consent clarity would differ substantially by vignette, to inform which vignette to use for the remainder of the pilots and studies that comprise this dissertation.

\section{Survey Measures}

Vignettes. All vignettes described the same instance of date rape (see Appendix A). Vignette 1 ends without the survivor responding to her victimization, vignette 2 ends with the survivor calling her friend to ask for support, and vignette 3 ends with the 
survivor calling her friend to warn others to stay away from the perpetrator. I tested these variations based on past research which suggests that a survivor's reporting decisions impact how they are perceived (Ellison \& Munro, 2008; Glace \& Dover, 2020).

Included Measures. This study included measures of perceived consent clarity, victim and perpetrator blame and responsibility (i.e., the victim and perpetrator blame measure using the word "responsibility" instead), liking of the perpetrator, perceptions of sexual assault and rape, and demographic items.

\section{Data Collection}

Because this pilot was solely testing participant responses to Vignette 1, Vignette 2, and Vignette 3, the core method was not used. Instead, participants were randomly assigned to read one of the three vignettes and filled out the included measures. No ingroup/outgroup manipulation was used in this pilot test.

\section{Sample Makeup}

I collected a sample of 106 participants using CloudResearch to access Amazon's Mechanical Turk Platform. After eliminating participants who failed the attention check, the total sample size was 96. Sample demographics are shown in Table 3.

\section{Descriptives}

The majority of the sample reported fairly high perceived consent clarity $(M=4.28)$ and reported that the majority of the blame $(M=79.72 \%)$ and responsibility $(\mathrm{M}=80.78 \%)$ was with the perpetrator, while less blame $(\mathrm{M}=27.66 \%)$ and responsibility $(M=29.21 \%)$ were assigned to the survivor. Participants largely did not like the perpetrator $(\mathrm{M}=2.05)$ and tended to feel that the incident was both sexual assault $(\mathrm{M}=4.8)$ 
and rape $(\mathrm{M}=4.44)$, though they did report lower perceptions that the incident was rape versus sexual assault. Correlations and descriptives are available in Table 5.

Results

Consent clarity did not differ by vignette $\left[F(2,90)=0.11, \mathrm{p}=0.9, \eta^{2}=0.002\right]$, indicating that the iteration of the vignette did not significantly impact participant perceptions of consent clarity. Further, Levene's test of homogeneity of variances indicated that the variance of consent clarity did not differ significantly by vignette $[F(2,90)=1.00, \mathrm{p}=0.37]$.

\section{Conclusion}

I found no reason to believe that which vignette was used would substantially impact perceptions of consent clarity. Therefore, Vignette 2 was chosen for use in future studies, as it represented a moderate option as compared to Vignettes 1 and 3.

\section{Pilot 2 - Manipulation Check}

\section{Research Questions}

I conducted this pilot test to test the proposed experimental manipulation. I wanted to assess whether a minimal group paradigm manipulating shared group membership with a perpetrator could successfully impact participant perceptions of survivor consent clarity. Specifically, I was interested in examining whether manipulating shared group membership with a perpetrator could lead participants to defend an ingroup perpetrator by claiming that the survivor's refusal of consent was insufficiently clear.

\section{Survey Measures}

Vignette. All participants in this study read Vignette 2. 
Included Measures. This study included measures of perceived consent clarity, victim and perpetrator blame, liking of the perpetrator, perceptions of sexual assault and rape, manipulation checks, and demographic items.

\section{Data Collection}

Procedures in Pilot 2 largely followed the core method, with some differences. This pilot included no "no group" control condition, only ingroup and outgroup conditions. This was done to allow for a smaller sample size consistent with a pilot study. Further, this study did not include measures of preference for social hierarchy, baseline liking of the perpetrator, nor global beliefs about sexual violence. Other procedures remained the same.

\section{Sample Makeup}

I collected a sample of 210 participants using CloudResearch to access Amazon's Mechanical Turk Platform. After eliminating participants who failed the included attention check and/or the manipulation check, the total sample size was 160. Sample demographics are shown in Table 3.

\section{Descriptives}

Similar to the first pilot, participants generally rated perceived consent clarity as high $(\mathrm{M}=4.65)$ and blamed the perpetrator $(\mathrm{M}=86.9 \%)$ much more than the survivor $(\mathrm{M}=17.8 \%)$. Still, there was substantial variance in victim-blame $(\mathrm{SD}=23.33 \%)$ and many participants reported perceptions that a sizeable amount of blame laid with the survivor. Most participants did not like the perpetrator $(\mathrm{M}=1.81)$ and reported perceptions that the 
incident was both sexual assault $(\mathrm{M}=5.13)$ and rape $(\mathrm{M}=4.91)$. Descriptives and correlations can be found in Table 6 .

Results

Consent clarity did not differ by condition [t(155)=-1.02, $\mathrm{p}=0.31, \mathrm{~d}=0.17]$, indicating that sharing a group with the perpetrator did not significantly impact participant perceptions of consent clarity.

\section{Conclusion}

This pilot found no significant effects. This may be an indicator that the manipulation failed. In response, I designed a third pilot test to examine a modified version of the experimental manipulation.

Pilot 3 - Updated Manipulation Check

\section{Rationale}

The results of Pilot 2 suggested that the experimental manipulation failed to produce the intended effect. Participants may have perceived that people with the same thinking type also exhibit the same behaviors. Those in the ingroup condition may have reacted negatively to the implication that an ingroup member, and by extension themselves, might perpetrate sexual violence. To examine whether this may have been the case, I made several changes. Vignette 2 was slightly altered to be described as slightly more alcohol-mediated, as past research has suggested that alcohol-mediated sexual violence is associated with more victim-blame (Grubb \& Turner, 2012). The updated vignette was titled Vignette 4 (see Appendix A). Additionally, the experimental manipulation was changed in an attempt to manipulate perpetrator liking more directly. 
Specifically, participants were instructed to imagine and write about an imaginary person (i.e., the perpetrator) who they liked or disliked. Finally, I added a baseline measure of liking in which participants reported the extent to which they liked the perpetrator before reading the vignette. This manipulation check was included to directly assess whether the manipulation influenced liking before any information about sexual violence was presented.

\section{Research Questions}

I conducted this pilot to examine whether encouraging participants to imagine liking a perpetrator would impact their perceptions of an instance of sexual violence. Specifically, I aimed to examine whether imagining a liked perpetrator would lead participants to defend the perpetrator by claiming that the survivor's consent quality was less clear.

\section{Survey Measures}

Vignette. All participants in this study read Vignette 4.

Included Measures. This study included measures of baseline liking of the perpetrator, perceived consent clarity, victim and perpetrator blame, liking of the perpetrator, perceptions of sexual assault and rape, manipulation checks, and demographic items.

\section{Data Collection}

Pilot 3 included several differences from the core method. Instead of a group manipulation, participants were randomly assigned to conditions in which they were told to imagine and write about how they either liked (liking condition) or disliked (disliking 
condition) the perpetrator. Similar to Pilot 2, this study included no "no group" condition, measure of preference for social hierarchy, nor measure of global beliefs about sexual violence. Other procedures remained the same.

\section{Sample Makeup}

I collected a sample of 239 participants using CloudResearch to access Amazon's Mechanical Turk Platform. After eliminating participants who failed the included attention check and/or the manipulation check, the total sample size was 189. Sample demographics are shown in Table 3.

\section{Descriptives}

Baseline liking of the perpetrator was fairly split $(\mathrm{M}=3.31)$ likely due to demand effects. As previously observed, perceptions of consent clarity were generally high $(M=4.62)$ and participants blamed the perpetrator $(M=86.78 \%)$ more than the survivor $(\mathrm{M}=18.98 \%)$. Participants did not like the perpetrator $(\mathrm{M}=1.66)$ and most often perceived that the incident was both sexual assault $(M=5.16)$ and rape $(M=5.01)$. Descriptives and correlations can be found in Table 7.

\section{Results}

Preliminary Analyses. Baseline self-reported liking of the perpetrator differed significantly by condition $[\mathrm{t}(186)=22.00, \mathrm{p}<0.001, \mathrm{~d}=3.21]$. Participants in the liking condition $(M=5.07)$ reported liking the perpetrator significantly more than participants in the disliking condition $(\mathrm{M}=1.79)$. This was likely strongly influenced by demand effects.

Main Analyses. Consent clarity did not differ significantly by condition [t(185)=$0.16, \mathrm{p}=0.88, \mathrm{~d}=0.02]$. Further, the mean and standard deviation of the perceptions of 
consent clarity measure did not differ substantially between Pilot $2(\mathrm{M}=4.65, \mathrm{SD}=1.02)$ and Pilot $3(\mathrm{M}=4.62, \mathrm{SD}=1.08)$.

\section{Conclusion}

The manipulation used in Pilot 3 had no effect at all. This may have been due to its lack of sophistication and experimental realism. Because of the complete failure of this manipulation, the original manipulation was used for Study 1. Vignette 4 was kept and used for future studies in hopes that the alcohol use described in this vignette would help to alleviate concerns about range restriction in the perceived consent clarity variable. The methods and analyses used in Studies 1-4 were then based on the findings of these three pilot studies.

\section{Study 1 - Core Method}

\section{Hypotheses}

This study tested the core hypotheses.

\section{Survey Measures}

Vignettes. All participants in this study read Vignette 4.

Included Measures. This study included measures of baseline liking of the perpetrator, perceived consent clarity, victim and perpetrator blame, liking of the perpetrator, perceptions of sexual assault and rape, manipulation checks, and demographic items. The measure of preference for social hierarchy in Study 1 assessed social dominance orientation (Ho et al., 2015) and the measure of global beliefs about sexual violence assessed rape myth acceptance (Payne et al., 1999). 
Data Collection

Study 1 used the core method, using the modified minimal group manipulation, with no alterations.

\section{Sample Makeup}

I collected a sample of 449 participants using CloudResearch to access Amazon's Mechanical Turk Platform. After eliminating participants who failed the included attention check and/or the manipulation check, the total sample size was 313. Sample demographics are shown in Table 4.

\section{Descriptives}

Participants reported fairly low levels of social dominance orientation ( $M=2.51)$ and rape myth acceptance $(M=1.93)$. They also reported fairly high perceptions of consent clarity $(M=4.65)$ and once again blamed the perpetrator $(M=88.81 \%)$ more than the survivor $(\mathrm{M}=16.67 \%)$. While baseline liking of the perpetrator was fairly high $(\mathrm{M}=4.13)$ this liking plummeted after reading the vignette $(\mathrm{M}=1.59)$. Participants also reported overall beliefs that the incident qualified as both sexual assault $(M=5.15)$ and rape $(M=5.04)$. Descriptives and correlations can be found in Table 8 .

\section{Results}

Preliminary Analyses. Baseline liking of the perpetrator differed by condition $\left[F(2,310)=9.16, \mathrm{p}<0.001, \eta^{2}=0.06\right]$ such that participants in the no group condition $(M=3.77)$ liked the perpetrator significantly less than participants in the ingroup condition $(\mathrm{M}=4.30, \mathrm{p}<0.001)$ and participants in the outgroup condition $(\mathrm{M}=4.18, \mathrm{p}=0.005)$. Baseline liking did not differ significantly between the ingroup and outgroup conditions 
$(\mathrm{p}=0.48)$, indicating that the experimental manipulation did not have its intended effect. Further, baseline liking was not significantly correlated with perceptions of consent clarity $[\mathrm{r}(310)=-0.07, \mathrm{p}=0.2]$.

Hypotheses A. Consent clarity did not differ by condition $[F(2,309)=0.17$, $\left.\mathrm{p}=0.85, \eta^{2}=0.001\right]$. Consent clarity did not differ between the ingroup condition $(\mathrm{M}=$ 4.68) and the outgroup condition $(M=4.61, \mathrm{p}=0.84)$, the ingroup condition and the no group condition $(\mathrm{M}=4.66, \mathrm{p}=0.99)$, nor the outgroup condition and the no group condition ( $\mathrm{p}=0.93)$. Hypothesis A was not supported in Study 1.

Hypothesis B. Social dominance orientation was tested as a potential moderator of the relationship between condition and perceived consent clarity. The step 1 model was significant $\left[F(3,295)=20.32, \mathrm{p}<0.001, \mathrm{R}^{2}=0.17\right]$. As previously found, consent clarity did not differ between the ingroup condition and the no group condition $[b=0.04$, $\mathrm{SE}=0.07, \mathrm{t}(295)=0.56, \mathrm{p}=0.57]$ nor the outgroup condition and the no group condition $[b=0.01, S E=0.07, t(295)=0.19, p=0.85]$. Social dominance orientation was a significant negative predictor of perceived consent clarity $[b=-0.43, S E=0.06, t(295)=-7.79$, $\mathrm{p}<0.001]$. When the interaction terms were added into the step 2 model, they did not significantly increase the variance explained by the model $\left(\Delta \mathrm{R}^{2}=0.002, \mathrm{p}=0.73\right)$. Further, the interaction terms were not significant [ingroup condition vs no group condition: $b=-$ $0.01, \mathrm{SE}=0.07, \mathrm{t}(293)=-0.15, \mathrm{p}=0.88$; outgroup condition vs no group condition: $\mathrm{b}=-0.05$, $\mathrm{SE}=0.07, \mathrm{t}(293)=-0.72, \mathrm{p}=0.47]$. Hypothesis B was not supported in Study 1.

Hypothesis C. Rape myth acceptance was tested as a potential mediator of the relationship between condition and perceived consent clarity. The step 1 model was not 
significant $\left[F(2,298)=0.25, \mathrm{p}=0.78, \mathrm{R}^{2}=0.002\right]$. As suggested previously, sharing an ingroup with the perpetrator (versus not knowing the perpetrator's group) was not associated with consent clarity $[\mathrm{b}=0.06, \mathrm{SE}=0.14, \mathrm{t}(298)=0.43, \mathrm{p}=0.67]$ nor was having an outgroup relationship with the perpetrator (versus not knowing the perpetrator's group) $[b=-0.03, S E=0.14, t(298)=-0.18, p=0.86]$.

The step 2 model was marginally significant but explained very little variance $\left[F(2,298)=2.83, \mathrm{p}=0.06, \mathrm{R}^{2}=0.01\right]$. Rape myth acceptance did not differ between the ingroup condition and the no group condition $[\mathrm{b}=0.05, \mathrm{SE}=0.1, \mathrm{t}(298)=0.51, \mathrm{p}=0.61]$. However, the outgroup condition vs no group condition comparison was a significant predictor of rape myth acceptance $[\mathrm{b}=0.22, \mathrm{SE}=0.1, \mathrm{t}(298)=2.16, \mathrm{p}=0.03]$ such that being in the outgroup condition was associated with higher levels of rape myth acceptance (as compared to the no group condition).

The step 3 model was significant and explained a substantial amount of model variance $\left[F(1,299)=235.1, \mathrm{p}<0.001, \mathrm{R}^{2}=0.44\right]$. Rape myth acceptance was a significant negative predictor of consent clarity $[b=-0.95, S E=0.06, t(299)=-15.33, p<0.001]$, such that higher rape myth acceptance was associated with lower perceived consent clarity.

The step 4 model was significant and explained a substantial amount of model variance $\left[F(3,297)=79.52, \mathrm{p}<0.001, \mathrm{R}^{2}=0.45\right]$. As before, consent clarity did not differ between ingroup condition and no group condition $[b=0.11, \mathrm{SE}=0.11, \mathrm{t}(297)=1.03$, $\mathrm{p}=0.3]$ nor outgroup condition and no group condition $[\mathrm{b}=0.18, \mathrm{SE}=0.11, \mathrm{t}(297)=1.68$, $\mathrm{p}=0.09]$. Rape myth acceptance remained a strongly negative significant predictor of consent clarity $[b=-0.96, S E=0.06, t(297)=-15.42, p<0.001]$. 
Average causal mediation effects (ACME) and average direct effects (ADE) were calculated for the ingroup and outgroup conditions. For the ingroup condition, neither the indirect $[\mathrm{ACME}=-0.05, \mathrm{LLCI}=-0.21, \mathrm{ULCI}=0.11, \mathrm{p}=0.57]$ nor direct $[\mathrm{ADE}=0.11$, $\mathrm{LLCI}=-0.11, \mathrm{ULCI}=0.32, \mathrm{p}=0.31]$ effects were significant. For the outgroup condition, the indirect effect was significant $[\mathrm{ACME}=-0.21, \mathrm{LLCI}=-0.38, \mathrm{ULCI}=-0.04, \mathrm{p}=0.2]$, but the direct effect was not $[\mathrm{ADE}=0.18, \mathrm{LLCI}=-0.03, \mathrm{ULCI}=0.42, \mathrm{p}=0.1]$. Despite this significant finding, the lack of a significant impact of outgroup condition on consent clarity means that there is insufficient evidence to support the hypothesis that rape myth acceptance mediates the relationship between condition and consent clarity. Hypothesis $\mathrm{C}$ was not supported in Study 1.

\section{Conclusion}

None of the main hypotheses in Study 1 were supported. This is consistent with manipulation failure, as implied in the pilot studies. The manipulation failed to produce the intended changes in baseline liking of the perpetrator such that the anticipated effect could not be tested. The minimal group effect may have failed to produce a substantial amount of liking. This is an especially important consideration given that the level of liking produced would need to persist through a rape allegation. In Study 2, I implemented an updated manipulation based on political beliefs, a real-world factor known to influence liking (Bruchmann et al., 2018). 
Study 2 - Political Update

\section{Rationale}

The minimal group paradigm used in Pilot 2 and Study 1, as well as the more straightforward manipulation used in Pilot 3, failed to produce the anticipated effects. Based on this, I tested another updated manipulation in which the ingroup, outgroup, and no group conditions were defined by shared, opposing, or unstated political affiliations. Related to this update, I also added several measures of political beliefs to the survey.

\section{Hypotheses}

This study tested the core hypotheses.

\section{Survey Measures}

Vignette. All participants in this study read Vignette 4.

Included Measures. This study included measures of baseline liking of the perpetrator, perceived consent clarity, victim and perpetrator blame, liking of the perpetrator, perceptions of sexual assault and rape, manipulation checks, and demographic items. The measure of preference for social hierarchy in Study 2 assessed social dominance orientation (Ho et al., 2015) and the measure of global beliefs about sexual violence assessed rape myth acceptance (Payne et al., 1999).

Political Orientation. Several measures of political orientation and beliefs were included in Study 2 alone, related to the updated manipulation. As part of the study manipulation, participants selected which of the two major American political parties (Democrats, Republicans) they most often agreed with (i.e., their political party). These political parties were chosen because participants were limited to adults living in the 
United States and because the ingroup/outgroup distinction required a binary choice. Participants also selected their most important party platform issue from a list available in Appendix A. Additionally, participants reported how strongly they supported their selected political party (degree of political affiliation) on a slider with possible values from 0 to 100. Finally, participants reported how conservative or liberal their general political views were on a scale from 1 (very conservative) to 7 (very liberal).

\section{Data Collection}

Study 2 used the core method, including the actual group manipulation, with some alterations. Participants completed the demographics section, including the political orientation items first, before the measure of preference for social hierarchy. As the manipulation, participants were then were randomly assigned to read about a person (later described as the perpetrator) who actively advocated around the participant's chosen political issue, either on behalf of the same party as the participant (ingroup condition), the opposing political party (outgroup condition), or was not described as engaging in any type of political advocacy (no group condition). Political party and political issue were piped in based on that participant's answers to the political orientation items. This information replaced the description of the perpetrator as a minimal ingroup, outgroup, or no group member. Other procedures remained the same.

\section{Sample Makeup}

I collected a sample of 419 participants using CloudResearch to access Amazon's Mechanical Turk Platform. After eliminating participants who failed the included 
attention check and/or the manipulation check, the total sample size was 336. Sample demographics are shown in Table 4.

\section{Descriptives}

Participants were low in rape myth acceptance $(M=1.90)$ and social dominance orientation $(\mathrm{M}=2.32)$ and also trended towards being liberal $(\mathrm{M}=4.71)$. Perceptions of consent clarity were generally high, as previously observed $(M=4.61)$, and participants blamed the perpetrator $(M=89.51 \%)$ more than the survivor $(M=15.7 \%)$. While baseline liking was split $(M=3.70)$, liking after reading the vignette was low $(M=1.49)$.

Participants also generally believed that the incident was sexual assault $(M=5.24)$ and rape $(M=5.10)$. Further descriptives and correlations can be found in Table 9.

\section{Results}

Preliminary Analyses. Baseline liking was predicted based on condition, controlling for political party and degree of political affiliation. The main effect of condition was significant $\left[F(2,331)=76.99, \mathrm{p}<0.001\right.$, partial $\left.\eta^{2}=0.32\right]$. Baseline liking in the ingroup condition ( $\mathrm{M}=4.55)$ was significantly higher than baseline liking in the no group condition $(\mathrm{M}=3.7, \mathrm{p}<0.001)$ and in the outgroup condition $(\mathrm{M}=2.90, \mathrm{p}<0.001)$. Further, baseline liking was significantly higher in the no group condition than the outgroup condition $(\mathrm{p}<0.001)$. Baseline liking did not differ significantly by political party $\left[F(1,331)=1.52, \mathrm{p}=0.22\right.$, partial $\left.\eta^{2}<0.001\right]$ or degree of political affiliation party $[F(1,331)=0.98, \mathrm{p}=0.32]$. Further, baseline liking of the perpetrator was not significantly correlated with perceptions of consent clarity [r(329)=-0.03, $\mathrm{p}=0.56]$. 
Hypothesis A. Consent clarity was predicted based on condition, controlling for political party and degree of political affiliation. The main effect of condition was not significant $\left[F(2,326)=1.45, \mathrm{p}=0.24\right.$, partial $\left.\eta^{2}=0.009\right]$. There were no significant differences in perceived consent clarity between the ingroup condition $(M=4.65)$ and the outgroup condition $(\mathrm{M}=4.50, \mathrm{p}=0.46)$, the ingroup condition and the no group condition $(\mathrm{M}=4.71, \mathrm{p}=0.88)$, nor the no group condition and the outgroup condition $(\mathrm{p}=0.24)$. Hypothesis A was not supported in Study 2. However, consent clarity did differ significantly by political party $\left[F(1,326)=23.27, \mathrm{p}<0.001\right.$, partial $\left.\eta^{2}=0.07\right]$. Republicans $(\mathrm{M}=4.21)$ reported significantly lower perceptions of consent clarity than Democrats $(\mathrm{M}=4.79)$. Consent clarity was also only marginally impacted by degree of political affiliation $[F(1,326)=3.86, \mathrm{p}=0.05]$.

Hypothesis B. I tested social dominance orientation as a moderator of the relationship between condition and perceived consent clarity, controlling for political party and degree of political affiliation. The step 1 model was significant $[F(5,318)=$ 14.94, $\left.\mathrm{p}<0.001, \mathrm{R}^{2}=0.19\right]$. Neither the ingroup condition vs no group condition comparison $[\mathrm{b}=-0.02, \mathrm{SE}=0.06, \mathrm{t}(318)=-0.26, \mathrm{p}=0.79]$, the outgroup condition vs no group condition comparison $[\mathrm{b}=-0.06, \mathrm{SE}=0.06, \mathrm{t}(318)=-0.9, \mathrm{p}=0.37]$, political party $[\mathrm{b}=-$ $0.03, \mathrm{SE}=0.06, \mathrm{t}(318)=-0.53, \mathrm{p}=0.6]$, nor degree of political affiliation $[\mathrm{b}=0.08, \mathrm{SE}=0.05$, $\mathrm{t}(318)=1.54, \mathrm{p}=0.13]$ were significant predictors of consent clarity. However, social dominance orientation was a significant negative predictor of consent clarity $[b=-0.41$ $\mathrm{SE}=0.06, \mathrm{t}(318)=-6.47, \mathrm{p}<0.001]$. Being higher in social dominance orientation was associated with lower perceived consent clarity. 
The step 2 model explained significantly more variance $\left(\Delta \mathrm{R}^{2}=0.02, \mathrm{p}=0.008\right)$. The interaction between condition and social dominance orientation was significant for the outgroup condition vs no group condition comparison $[b=-0.19, \mathrm{SE}=0.06, \mathrm{t}(316)=-3.11$, $\mathrm{p}=0.002]$ and but was not significant for the ingroup condition vs no group condition comparison $[\mathrm{b}=-0.11, \mathrm{SE}=0.06, \mathrm{t}(316)=-1.76, \mathrm{p}=0.08]$. Hypothesis $\mathrm{B}$ was not supported in Study 2. Among those high (+1SD) in social dominance orientation, being in the outgroup condition (versus the no group condition) was associated with significantly poorer perceptions of consent clarity $[\mathrm{b}=-0.25, \mathrm{SE}=0.09, \mathrm{t}(316)=-2.84, \mathrm{p}=0.004]$. Among those low (-1SD) in social dominance orientation, consent clarity did not differ between the outgroup condition and the no group condition $[b=0.13, S E=0.09, t(316)=1.53$, $\mathrm{p}=0.13]$

Hypothesis C. I tested the indirect effect of condition on consent clarity through rape myth acceptance, controlling for political party and degree of political affiliation.

The step 1 model was significant $\left[F(4,326)=7.51, \mathrm{p}<0.001, \mathrm{R}^{2}=0.08\right]$. As previously found, neither the ingroup condition vs no group condition comparison $[b=-$ $0.03, \mathrm{SE}=0.06, \mathrm{t}(326)=-0.44, \mathrm{p}=0.66]$ nor the outgroup condition vs no group condition comparison $[\mathrm{b}=-0.08, \mathrm{SE}=0.06, \mathrm{t}(326)=-1.35, \mathrm{p}=0.18]$ were significant predictors of consent clarity. However, political party was a significant predictor of consent clarity $[b=-0.24, S E=0.05, t(326)=-4.62 p<0.001]$, such that being a Republican predicted significantly lower consent clarity. Further, degree of political affiliation was a marginally significant predictor of consent clarity $[b=0.1, S E=0.05, t(326)=1.96, p=0.05]$, 
such that feeling more strongly connected to one's political party was associated with perceptions of higher consent clarity.

The step 2 model was significant $\left[F(4,321)=8.42, \mathrm{p}<0.001, \mathrm{R}^{2}=0.09\right]$. Rape myth acceptance did not differ between the ingroup condition and the no group condition $[\mathrm{b}=0.04, \mathrm{SE}=0.05, \mathrm{t}(321)=0.84, \mathrm{p}=0.4]$. However, the outgroup condition vs no group condition comparison was a significant predictor of rape myth acceptance $[b=0.1$, $\mathrm{SE}=0.05, \mathrm{t}(321)=2.19, \mathrm{p}=0.03]$ such that being in the outgroup condition was associated with higher levels of rape myth acceptance. Political party was a significant predictor of rape myth acceptance $[\mathrm{b}=0.2, \mathrm{SE}=0.04, \mathrm{t}(321)=4.97, \mathrm{p}<0.001]$, such that being a Republican predicted significantly higher rape myth acceptance. Degree of political affiliation was not a significant predictor of consent clarity $[b=-0.04, S E=0.04, t(321)=-$ $1.07, \mathrm{p}=0.29]$.

The step 3 model was significant $\left[F(1,324)=264.4, \mathrm{p}<0.001, \mathrm{R}^{2}=0.45\right]$. Rape myth acceptance was a significant negative predictor of consent clarity $[b=-0.9, S E=0.06$, $\mathrm{t}(324)=-16.26, \mathrm{p}<0.001]$, such that high rape myth acceptance was associated with lower perceived consent clarity.

The step 4 model was significant and explained a substantial amount of model variance $\left[F(5,320)=54.72, \mathrm{p}<0.001, \mathrm{R}^{2}=0.46\right]$. Neither the ingroup condition vs no group condition comparison $[\mathrm{b}=0.01, \mathrm{SE}=0.05, \mathrm{t}(320)=0.2, \mathrm{p}=0.84]$ nor the outgroup condition vs no group condition comparison $[\mathrm{b}=0.004, \mathrm{SE}=0.05, \mathrm{t}(320)=0.08, \mathrm{p}=0.94]$ were significant predictors of consent clarity. Rape myth acceptance remained a strongly negative significant predictor of consent clarity $[b=-0.86, S E=0.06, t(320)=-14.9$, 
$\mathrm{p}<0.001]$. Political party was no longer a significant predictor of consent clarity $[\mathrm{b}=-0.08$, $\mathrm{SE}=0.04, \mathrm{t}(320)=-1.84, \mathrm{p}=0.07]$. Further, degree of political affiliation was not a significant predictor of consent clarity $[b=0.07, S E=0.04, t(320)=1.72, p=0.09]$

Average causal mediation effects (ACME) and average direct effects (ADE) were calculated for the ingroup and outgroup conditions. For the ingroup condition, neither the indirect $[\mathrm{ACME}=-0.03, \mathrm{LLCI}=-0.10, \mathrm{ULCI}=0.04, \mathrm{p}=0.33]$ nor $\operatorname{direct}[\mathrm{ADE}=0.01$, $\mathrm{LLCI}=-0.09, \mathrm{ULCI}=0.11, \mathrm{p}=0.84]$ effects were significant. For the outgroup condition, the indirect effect was significant $[\mathrm{ACME}=-0.09, \mathrm{LLCI}=-0.16, \mathrm{ULCI}=-0.02, \mathrm{p}=0.01]$ but the direct effect was not $[\mathrm{ADE}=0.004, \mathrm{LLCI}=-0.10, \mathrm{ULCI}=0.11, \mathrm{p}=0.9]$. Despite this significant finding, the lack of a significant impact of outgroup condition on consent clarity means that there is insufficient evidence to support the hypothesis that rape myth acceptance mediates the relationship between condition and consent clarity. Hypothesis $\mathrm{C}$ was not supported in Study 2.

\section{Conclusion}

In this study, the manipulation did appear to produce the intended effect on liking. However, this effect did not carry through to impact perceptions of survivor consent clarity. This may be because the inclusion of political party masked the effect. However, it is also possible that poor data quality contributed to the continued null results. All studies up to this point were conducted on MTurk, which has been shown to have inconsistent data quality (Chmielewski \& Kucker, 2020). As a result, I pursued alternative methods of data collection for Studies 3 and 4. 
Study 3 - Alternative Data Collection

\section{Rationale}

Poor data quality may have contributed to the null and inconsistent results found in the previous studies. To test this possibility, I collected another round of data (i.e., Study 3) through Qualtrics' paneling service. This recruitment service is a panel aggregator, which recruits participants from a variety of research panels and imposes more stringent data quality checks. This approach was taken to determine whether poor data quality impacted the results of previous studies. Due to budgetary constraints associated with the increased cost of this service, the planned sample size was decreased to 300 , and the no group condition was eliminated to compensate for the associated decrease in statistical power. Related to the null effects found from social dominance orientation as a moderator and rape myth acceptance as a mediator, measures of belief in a just world for others and perceived rape-supportive peer norms were collected instead, respectively.

\section{Hypotheses}

This study tested the core hypotheses. However, Hypothesis B was amended because the comparison group described in Hypothesis B is the no group condition. Study 3 did not include a no group condition. Therefore, this study tested the interaction between preference for social hierarchy and the ingroup vs outgroup comparison variable.

\section{Survey Measures}

Vignette. All participants in this study read Vignette 4. 
Included Measures. This study included measures of baseline liking of the perpetrator, perceived consent clarity, victim and perpetrator blame, liking of the perpetrator, perceptions of sexual assault and rape, manipulation checks, and demographic items. The measure of preference for social hierarchy in Study 3 assessed belief in a just world for others (Lipkus et al., 1996) and the measure of global beliefs about sexual violence assessed peer norms supporting sexual aggression (Abbey et al., 2001). Additionally, the perceived consent clarity measure did not include the usual attentional check item, as it was replaced by quality checks in the data collection platform.

\section{Data Collection}

Study 3 used the core method, except for the elimination of the no group condition.

\section{Sample Makeup}

I collected a sample of 315 participants using Qualtrics’ Paneling services. After eliminating participants who failed Qualtrics' data quality checks and/or the manipulation check, the total sample size was 217. Sample demographics are shown in Table 4.

\section{Descriptives}

Participant belief in a just world for others was moderate overall $(\mathrm{M}=3.44)$, but perceptions of peer norms supporting sexual violence were low $(M=1.74)$. Perceptions of consent clarity were high $(M=4.18)$ as was baseline liking of the perpetrator $(M=4.35)$. Liking of the perpetrator was lower after reading the vignette $(M=2.17)$ though the drop was less pronounced than in earlier iterations. Participants blamed the perpetrator 
$(\mathrm{M}=82.98 \%)$ more than the survivor $(\mathrm{M}=31.91 \%)$, though victim-blame was noticeably higher than was found in previous iterations. Participants did still generally report that the incident could be classified as sexual assault $(M=5.01)$ and rape $(M=4.77)$. Further descriptives and correlations can be found in Table 10.

\section{Results}

Preliminary Analyses. Baseline liking varied significantly by condition [t $(215)=$ 2.68, $\mathrm{p}=0.008, \mathrm{~d}=0.36]$, such that liking was significantly higher in the ingroup condition $(M=4.52)$ than in the outgroup condition $(M=4.17)$. This indicates that the experimental manipulation did have its intended effect. Further, baseline liking of the perpetrator and perceptions of consent clarity were significantly negatively correlated $[\mathrm{r}(214)=-0.14$, $\mathrm{p}=0.04]$, such that higher baseline liking of the perpetrator was associated with lower perceptions of consent clarity.

Hypothesis A. Consent clarity differed significantly by condition $[\mathrm{t}(214)=-2.39$, $\mathrm{p}=0.02, \mathrm{~d}=-0.33$, such that consent clarity was significantly lower in the ingroup condition $(M=4.01)$ than in the outgroup condition $(M=4.36)$. Hypothesis A was supported in Study 3.

Hypothesis B. Belief in a just world for others was tested as a moderator of the relationship between condition and perceived consent clarity. The step 1 model was significant $\left[F(2,213)=16.66, \mathrm{p}<0.001, \mathrm{R}^{2}=0.14\right]$. When controlling for belief in a just world for others, condition (higher $=$ outgroup) was no longer a significant predictor of perceived consent clarity $[\mathrm{b}=0.11, \mathrm{SE}=0.07, \mathrm{t}(213)=1.62, \mathrm{p}=0.11]$. However, belief in a just world for others was a significant predictor of perceived consent clarity $[b=-0.37$, 
$\mathrm{SE}=0.07, \mathrm{t}(213)=-5.19, \mathrm{p}<0.001]$. Higher belief in a just world for others was associated with lower perceived consent clarity.

The step 2 model did not explain significantly more variance $\left(\Delta R^{2}=0.002\right.$, $\mathrm{p}=0.48)$. The interaction term was not significant $[\mathrm{b}=0.05, \mathrm{SE}=0.08, \mathrm{t}(212)=0.71$, $\mathrm{p}=0.48]$. Hypothesis B was not supported in Study 3.

Hypotheses C. Perception of peer norms supporting sexual violence was tested as a mediator of the relationship between condition and perceptions of consent clarity. The step 1 model was significant $\left[F(1,214)=5.71, \mathrm{p}=0.02, \mathrm{R}^{2}=0.03\right]$. As noted previously, condition (higher $=$ outgroup) was a significant predictor of perceived consent clarity $[\mathrm{b}=0.33, \mathrm{SE}=0.14, \mathrm{t}(214)=2.39, \mathrm{p}=0.02]$.

The step 2 model was also significant $\left[F(1,214)=7.86, \mathrm{p}=0.006, \mathrm{R}^{2}=0.04\right]$. Condition was also a significant predictor of perceived peer norms supporting sexual violence $[b=-0.37, S E=0.13, t(214)=-2.8, p=0.005]$. Perceived peer norms supporting sexual violence were significantly higher in the ingroup condition $(M=1.92)$ than in the outgroup condition $(\mathrm{M}=1.52)$.

The step 3 model was also significant $\left[F(1,214)=63.1, \mathrm{p}<0.001, \mathrm{R}^{2}=0.23\right]$. Perceived peer norms supporting sexual violence was a significant negative predictor of consent clarity $[\mathrm{b}=-0.5, \mathrm{SE}=0.06, \mathrm{t}(214)=-7.94, \mathrm{p}<0.001]$.

Finally, the step 4 model was also significant $[F(2,213)=32.35, \mathrm{p}<0.001$, $\left.\mathrm{R}^{2}=0.23\right]$. When controlling for perceived peer norms supporting sexual violence, condition was no longer a significant predictor of consent clarity $[b=0.15, S E=0.13$, 
$\mathrm{t}(213)=1.21, \mathrm{p}=0.23]$. However, peer norms supporting sexual violence was a significant predictor of consent clarity $[\mathrm{b}=-0.49, \mathrm{SE}=0.06, \mathrm{t}(213)=-7.58, \mathrm{p}<0.001]$.

Bootstrapped indices of indirect effects support a full mediation effect, as the indirect effect was significant $(\mathrm{ACME}=0.18, \mathrm{LLCI}=0.05, \mathrm{ULCI}=0.31, \mathrm{p}=0.004)$ and the direct effect was not $(\mathrm{ADE}=0.15, \mathrm{LLCI}=-0.09, \mathrm{ULCI}=0.41, \mathrm{p}=0.20)$. Hypothesis $\mathrm{C}$ was supported in Study 3.

\section{Conclusion}

The results found in Study 3 were consistent with Hypotheses A and C. Data quality may have contributed to the null results found in previous studies. This result warranted a further study from another alternative data collection avenue.

\section{Study 4 - Actual Group Membership}

\section{Rationale}

To better assess how this effect might operate based on real group membership without the complicating factor of political affiliation, I collected data from a more specific population (i.e., Portland State University students) and based my manipulation on this actual group identity. This study was conducted to further assess how claims of consent miscommunication are impacted by actual (i.e., not minimal) shared group identity. Due to this smaller population, recruitment was limited. I aimed for a sample of 200 participants who provided usable data. I once again collected measures of belief in a just world for others and perceived rape-supportive peer norms.

\section{Hypotheses}

This study tested the core hypotheses. 
Survey Measures

Vignette. All participants in this study read Vignette 4.

Included Measures. This study included measures of baseline liking of the perpetrator, perceived consent clarity, victim and perpetrator blame, liking of the perpetrator, perceptions of sexual assault and rape, manipulation checks, and demographic items. The measure of preference for social hierarchy in Study 4 assessed belief in a just world for others (Lipkus et al., 1996) and the measure of global beliefs about sexual violence assessed peer norms supporting sexual aggression (Abbey et al., 2001).

\section{Data Collection}

Study 4 used some inclusion criteria that were not used in previous studies. Survey-takers who reported they were 18 years of age or older and currently enrolled in a course at Portland State University (or, if during the summer, were enrolled in the preceding spring term) were directed into the survey. All others were ineligible to participate.

Study 4 also included several departures from the core method. Participants were randomly assigned to read about a person (later described as the perpetrator) who either attended the same university as the participant (i.e., Portland State University; ingroup condition), a nearby similar-status university (i.e., Oregon State University; outgroup condition), or was not described as attending a university (no group condition). This information replaced the description of the partner's minimal group membership. 
Sample Makeup

I recruited participants using an existing university participant pool, and by asking psychology professors to promote this participant pool to their students. I collected a sample of 454 participants, 306 of whom met the initial criteria and agreed to participate. After eliminating participants who failed attention checks and/or the manipulation check, the total sample size was 232. Sample demographics are shown in Table 4.

\section{Descriptives}

Participants in Study 4 were college students on a liberal campus in a liberal city. As such, there was little variance in some variables as participant beliefs skewed in this direction. Participant belief in a just world for others was fairly low $(\mathrm{M}=2.6)$ and perceptions of peer norms supporting sexual violence were exceptionally low ( $M=1.19)$. Perceptions of consent clarity were high $(M=5.06)$. Participants' baseline liking of the perpetrator was moderate $(\mathrm{M}=3.63)$. Even still, participants' liking of the perpetrator was drastically lower after reading the vignette $(M=1.19)$. Participants nearly exclusively blamed the perpetrator $(\mathrm{M}=96.58 \%)$ and rarely blamed the survivor $(\mathrm{M}=11.63 \%)$. Participants overwhelmingly reported that the incident could be classified as sexual assault ( $M=5.52)$ and rape $(M=5.42)$. Further descriptives and correlations can be found in Table 11.

\section{Results}

Preliminary Analyses. Baseline liking did not vary significantly by condition $\left[F(2,219)=1.72, \mathrm{p}=0.18, \eta^{2}=0.02\right]$. Liking did not differ between the ingroup condition $(\mathrm{M}=3.52)$ and the outgroup condition $(\mathrm{M}=3.75, \mathrm{p}=0.16)$, the ingroup condition and the no 
group condition $(\mathrm{M}=3.63, \mathrm{p}=0.64)$, nor the no group condition and the outgroup condition $(\mathrm{p}=0.67)$. This indicates that the experimental manipulation may not have had its intended effect. Further, baseline liking of the perpetrator and perceived consent clarity were significantly positively correlated $[\mathrm{r}(217)=0.16, \mathrm{p}=0.02]$. This suggests that the manipulation may have had the opposite of the intended effect.

Hypothesis A. Consent clarity did not differ significantly by condition $\left[F(2,226)=0.21, \mathrm{p}=0.81, \eta^{2}=0.002\right]$. Consent clarity did not differ between the ingroup condition ( $M=5.08)$ and the outgroup condition $(M=5.07, p=1)$, the ingroup condition and the no group condition $(\mathrm{M}=5.01, \mathrm{p}=0.81)$, nor the outgroup condition and the no group condition $(\mathrm{p}=0.86)$. Hypothesis A was not supported in Study 4.

Hypothesis B. Belief in a just world for others was tested as a moderator of the relationship between condition and perceived consent clarity. The step 1 model was significant $\left[F(3,222)=4.08, \mathrm{p}=0.008, \mathrm{R}^{2}=0.05\right]$. Neither the ingroup condition vs no group condition comparison $[\mathrm{b}=0.03, \mathrm{SE}=0.06, \mathrm{t}(222)=0.48, \mathrm{p}=0.63]$ nor the outgroup condition vs no group condition comparison $[\mathrm{b}=0.003, \mathrm{SE}=0.06, \mathrm{t}(222)=0.06, \mathrm{p}=0.95]$ were significant predictors of consent clarity. However, belief in a just world for others was a significant negative predictor of perceived consent clarity $[b=-0.17, S E=0.05, t(222)=-$ 3.48, $\mathrm{p}=0.001]$. Higher belief in a just world for others was associated with lower perceived consent clarity.

The step 2 model did not explain any additional variance $\left(\Delta \mathrm{R}^{2}=0.005, \mathrm{p}=0.54\right)$. The interaction term was not significant for ingroup condition vs no group condition 
$[b=0.06, S E=0.06, t(220)=1.02, p=0.31]$ nor outgroup condition vs no group condition $[b=0.01, S E=0.06, t(220)=0.24, p=0.81]$. Hypothesis B was not supported in Study 4.

Hypothesis C. Perceived peer norms supporting sexual violence was tested as a mediator of the relationship between condition and perceptions of consent clarity.

The step 1 model was not significant $\left[F(2,225)=0.09, \mathrm{p}=0.91, \mathrm{R}^{2}=0.001\right]$. Neither the ingroup condition vs no group condition comparison $[b=0.03, \mathrm{SE}=0.08, \mathrm{t}(225)=0.41$, $p=0.68]$ nor the outgroup condition vs no group condition comparison $[b=0.02, S E=0.08$, $t(225)=0.33, p=0.75]$ were significant predictors of consent clarity.

Additionally, the step 2 model was not significant $[F(2,225)=0.05, \mathrm{p}=0.95$, $\left.\mathrm{R}^{2}<0.001\right]$. Neither the ingroup condition vs no group condition comparison $[b=0.02$, $\mathrm{SE}=0.08, \mathrm{t}(225)=0.32, \mathrm{p}=0.75]$ nor the outgroup condition vs no group condition comparison $[\mathrm{b}=0.02, \mathrm{SE}=0.08, \mathrm{t}(225)=0.20, \mathrm{p}=0.84]$ were significant predictors of peer norms supporting sexual violence.

The step 3 model was significant $\left[F(1,226)=7.32, \mathrm{p}=0.007, \mathrm{R}^{2}=0.03\right]$. Perceived peer norms supporting sexual violence was a significant negative predictor of consent clarity $[b=-0.17, \mathrm{SE}=0.06, \mathrm{t}(226)=-2.71, \mathrm{p}=0.007]$.

Finally, the step 4 model was marginally significant $[F(3,224)=2.5, \mathrm{p}=0.06$, $\left.\mathrm{R}^{2}=0.03\right]$. Neither the ingroup condition vs no group condition comparison $[b=0.04$, $\mathrm{SE}=0.07, \mathrm{t}(224)=0.47, \mathrm{p}=0.64]$ nor the outgroup condition vs no group condition comparison $[\mathrm{b}=0.03, \mathrm{SE}=0.07, \mathrm{t}(224)=0.37, \mathrm{p}=0.71]$ were significant predictors of consent clarity. However, peer norms supporting sexual violence remained a significant predictor of consent clarity $[\mathrm{b}=-0.18, \mathrm{SE}=0.06, \mathrm{t}(224)=-2.71, \mathrm{p}=0.007]$. 
Bootstrapped indices of direct and indirect effects were not significant for the ingroup condition $(\mathrm{ACME}=-0.004, \mathrm{LLCI}=-0.03, \mathrm{ULCI}=0.03, \mathrm{p}=0.74 ; \mathrm{ADE}=0.04$, $\mathrm{LLCI}=-0.11, \mathrm{ULCI}=0.18, \mathrm{p}=0.63)$ nor the outgroup condition $(\mathrm{ACME}=-0.003, \mathrm{LLCI}=$ $-0.03, \mathrm{ULCI}=0.02, \mathrm{p}=0.79 ; \mathrm{ADE}=0.03, \mathrm{LLCI}=-0.11, \mathrm{ULCI}=0.17, \mathrm{p}=0.67)$.

Hypothesis C was not supported in Study 4.

\section{Conclusion}

Study 4 found virtually no support for study hypotheses. This may be due to range restriction and limited variance in study variables. However, this is also consistent with the findings of all studies except Study 3. 


\section{Chapter Three - Discussion}

\section{Overview}

I hypothesized that sharing a group membership with a perpetrator of sexual violence would be associated with third-party individuals' perceptions that the survivor's consent communication was less clear (vs outgroup perpetrators). I further hypothesized that this relationship would be moderated by preference for social hierarchy, such that greater support for social hierarchy would exacerbate the effect of sharing a group with a perpetrator (vs a no group perpetrator). Finally, I hypothesized that this relationship would be mediated by rape-supportive attitudes, such that sharing a group with a perpetrator (vs an outgroup or no group perpetrator) would predict higher rape supportive attitudes, which would, in turn, predict lower perceived survivor consent clarity.

The majority of the findings in this research were null, and often inconsistent with study hypotheses. First I will interpret the findings of each study. Second, I will discuss how these findings answered or failed to answer the three research questions asked in this series of studies. Third, I will provide a general discussion of my findings and consider potential explanations for the results. Fourth, I will discuss future directions and approaches that might be used to explicate study results. Finally, I will describe the strengths and limitations of this research.

\section{Findings by Study}

This research included a series of studies that examined the impact of sharing a group membership with a perpetrator of sexual violence on perceptions of survivor consent clarity. These studies also tested various indicators of preference for social 
hierarchy as moderators of this effect and various beliefs about sexual violence as mediators of this effect. The results of all hypothesis tests are summarized in Table 12.

\section{Study 1}

In Study 1, participants' baseline liking of the perpetrator did not significantly differ between ingroup and outgroup perpetrators but was significantly lower in the no group control condition. Simply perceiving that the perpetrator had taken the same test as they had may have induced participants to like the perpetrator more. Alternatively, participants might have felt discomfort evaluating a person about whom they had no information in the no group condition. This result is indicative of a manipulation failure.

There was no significant effect of perpetrator group membership on perceptions of survivor consent clarity. This is unsurprising given that the manipulation did not have its intended effect. Further, participants' baseline feelings of liking towards the perpetrator were not significantly associated with perceptions of the survivor's consent clarity. Study 1 offers no reason to believe that claims of consent miscommunication differ based on whether one likes or shares a group membership with the perpetrator.

Further, the impact of the experimental condition did not differ based on social dominance orientation. This also is likely because the manipulation did not work as intended. However, holding attitudes that favor social dominance predicted perceptions that the survivor's consent communication was less clear. Social dominance orientation is associated with sexual aggression, hostile sexism, rape myth acceptance, support for lowering the age of consent, and the belief that women should be punished (Kelly et al., 
2015). This result adds to the body of evidence that suggests that support for group inequality is associated with support for sexual aggression.

Similar to social dominance orientation, rape myth acceptance was a significant negative predictor of perceptions of survivor consent clarity. This is especially unsurprising given that claims of consent miscommunication are essentially the endorsement of a rape myth. Although this is not a novel finding, this strong relationship supports the validity of the measure of perceptions of survivor consent clarity used in this research. One unexpected finding of this research was that participants who read about an outgroup member committing an act of sexual violence (vs. those who read about a perpetrator with no group membership) reported higher levels of rape myth acceptance. This effect was in the opposite of the hypothesized direction and will be discussed in the section covering Research Question 3.

\section{Study 2}

In Study 2, participants' baseline liking of the perpetrator was highest when the perpetrator was a political ingroup member and lowest when the perpetrator was a political outgroup member. The no group condition formed a middle group, and all group differences were statistically significant. Manipulating political group membership was an effective way to manipulate liking, as has been indicated in past research (Bruchmann et al., 2018). The Study 2 manipulation was an apparent success.

However, the manipulation's impact on liking did not translate to an impact on perceptions of survivor consent clarity. Perceptions of survivor consent clarity were also uncorrelated with baseline liking of the perpetrator. Republicans (vs Democrats) did 
report significantly lower perceptions of consent clarity. Conservatism has been associated with victim-blame directed at sexual violence survivors (Lambert \& Raichle, 2000; Walker et al., 1993) which is consistent with these findings.

Similar to Study 1, in Study 2, being higher in social dominance orientation was associated with perceptions of poorer consent clarity. In Study 2, for those high in social dominance orientation, being in the outgroup condition (vs the no group condition) predicted perceptions of less clear consent communication from the survivor. This effect is the opposite of what was hypothesized. It is possible that manipulating the perpetrator's group membership might also inadvertently manipulate the survivor's group membership. Perceptions of the survivor in the outgroup condition as an outgroup member might explain this effect, as individuals high in social dominance orientation might be more likely to victim-blame a survivor that they see as an outgroup member. As will be discussed, several findings that conflicted with study hypotheses may have resulted from an inadvertent manipulation of the perceived group membership of the survivor in addition to the perpetrator.

Once again, rape myth acceptance was significantly higher in the outgroup condition (vs the no group condition) and was a significant negative predictor of consent clarity. One additional finding was that rape myth acceptance was higher among Republicans, which is consistent with past research (Lambert \& Raichle, 2000; Walker et al., 1993). 


\section{Study 3}

Study 3 was unique in that it included no control condition and that it found substantially more support for proposed hypotheses. Participants in the ingroup condition reported significantly higher baseline liking for the perpetrator than participants in the outgroup condition. Further, liking the perpetrator more at baseline was associated with perceptions of less clear survivor consent communication. In Study 3, participants who read about an ingroup perpetrator reported that the survivor's consent communication was significantly less clear than participants who read about an outgroup perpetrator. This finding is consistent with Hypothesis A.

Belief in a just world for others was a significant negative predictor of perceptions of consent clarity. Similar to social dominance orientation, beliefs that the current social system is fair or justifiable have been associated with rape myth acceptance and victimblame (Chapleau \& Oswald, 2014; Ståhl et al., 2010). The findings of this research corroborate these results and support the validity of the perceptions of consent clarity measure. However, there was once again no significant interaction between experimental condition and preference for social hierarchy.

Participants who shared an ingroup with the perpetrator reported significantly higher perceptions that their peers supported sexual aggression. Subsequently, perceptions that one's peers supported sexual aggression predicted perceptions that the survivor's consent communication was less clear. The indirect effect was significant. This finding speaks to Research Question 3 and will be discussed further in that section. 


\section{Study 4}

The data in Study 4 suffered from very little variance, often resulting from floor or ceiling effects. The mean of perceived consent clarity in Study 4 was the highest of all four studies and was very near the highest possible value on the scale (Mean=5.06, Mode $=6$ out of a possible 6 ). Additionally, means of both perceptions of peer norms supporting sexual aggression and belief in a just world for others were lower than those found in Study 3. There are several potential reasons for this range restriction, which is likely due to some characteristics of the sample and the population from which it was taken. Participants in Study 4 were students at an urban university in a progressive city where social norms might strongly oppose rape-supportive attitudes. Additionally, the sample in Study 4 skewed towards women (73\%) more so than other studies. Women are also less likely than men to hold rape-supportive attitudes across cultures and contexts (Emmers-Sommer, 2014; Stephens et al., 2016). This may have meant that this sample overall was less likely to justify the perpetrator's actions in any circumstance. Finally, students on this campus are required to participate in anti-sexual violence training consistent with Title IX of the United States Educational Amendments of 1972. The effectiveness of these training programs in impacting behavior is questionable (Vladutiu et al., 2011) but still may have taught students the "right way" to talk about consent.

Neither baseline liking of the perpetrator nor perceptions of consent clarity differed by experimental condition. Baseline liking of the perpetrator positively correlated with perceptions of consent clarity, which was the opposite of the anticipated effect. Participants who liked the perpetrator more at baseline may have reacted more 
negatively to the vignette and thus defended the survivor more strongly. It is also possible that liking the perpetrator may have translated to liking the survivor, creating the same effect. This may be especially true in a sample comprised of mainly women, to whom an initially-trusted ingroup perpetrator might cause more threat than an outgroup perpetrator of whom they were initially wary. Belief in a just world for others and peer norms supporting sexual aggression were both significant negative predictors of perceived consent clarity once again. No significant moderation or mediation effects were found.

\section{Research Questions}

The ability of these studies to speak to the relevant research questions is qualified by apparent manipulation failures and inconsistent or null effects. The modified minimal group manipulation did not work (i.e., failed to impact participants' baseline liking of the perpetrator) in Study 1 but did work in Study 3. Given that the data used in Study 3 included significantly more stringent quality control checks, poor data quality may have contributed to the manipulation failure seen in Study 1. This concern is likely compounded by the sociopolitical context. Data for all studies were collected during the COVID-19 pandemic, during which many Americans were unemployed. The platform used for data collection in Study 1 (Amazon's Mechanical Turk) is an easy-to-access source of income, which the Study 3 data collection platform (Qualtrics' paneling service) is more difficult to access and offers incentive points instead of money. This unanticipated public health crisis may have resulted in higher than usual levels of inattentive responding on MTurk specifically. 
However, this data quality concern is contradicted by the fact that the actual group manipulation used in Study 2, which also used data from MTurk, did impact participants' baseline liking of the perpetrator. The manipulation used in Study 2 may have been stronger than the modified minimal group manipulation. Meanwhile, the actual group manipulation used in Study 4 did not significantly impact participants' baseline liking of the perpetrator. Study 4 data were collected from volunteers and not through the MTurk platform. Many variables in this dataset had limited variance, which may have hindered the detection of any impact of the experimental manipulation.

\section{Research Question 1}

Research Question 1 asked if liking/identifying with a sexual violence perpetrator would lead third-party perceivers to report that the survivor's consent communication was unclear. Results found in Study 3 indicated that third-party perceivers do report that a survivor's consent communication was less clear when they share a group with the perpetrator. Perceptions of consent clarity seem to be influenced by factors that had nothing to do with the consent communication itself, which was held constant across conditions. Therefore, it is likely that claims of consent miscommunication are sometimes at least partially divorced from the consent communication itself. This finding has implications for theoretical and applied understandings of victim-blame and perceptions of sexual violence.

However, these results should be interpreted with caution, as all three of the other studies did not find significant differences in consent clarity based on experimental condition. The significant results found in Study 3 may be the result of a Type I error. 
However, some characteristic of Study 3 may have facilitated the detection of significant results that were masked in the other three studies. Study 3 included the most stringent data quality checks, was the only study that did not include a control condition, and was one of only two studies that showed evidence of manipulation effectiveness.

Participants in Study 2 did report a pattern of baseline liking of the perpetrator consistent with manipulation success. However, this same pattern did not hold when examining the effect of sharing a group with the perpetrator on perceptions of survivor consent clarity, which was non-significant in Study 2. Concerning Research Question 1, the results of this series of studies are inconclusive.

\section{Research Question 2}

Research Question 2 asked whether a third-party perceiver's preference for social hierarchy might make them more likely to report unclear survivor consent communication when the perceiver likes/identifies with the perpetrator. The measures of preferences for social hierarchy used in this research included social dominance orientation and belief in a just world for others. For both variables and across all studies, no evidence was found to suggest that a higher preference for social hierarchy would lead a third-party perceiver to report poorer survivor consent communication when the perpetrator was an ingroup member. The effect proposed in Research Question 2 was unsupported.

There were several other significant findings in this area. In Study 2, the outgroup versus no group comparison variable interacted significantly with social dominance orientation. However, this effect was in the opposite direction. Among those high in 
social dominance orientation, being in the outgroup condition was associated with perceptions of significantly worse consent clarity than being in the no group condition. It was anticipated that individuals high in social dominance orientation would have even more negative feelings towards an outgroup perpetrator and would thus be more willing to see the perpetrator as a sex offender and the survivor's consent refusal as clearer. However, the opposite effect was observed. For those high in social dominance orientation, having an outgroup relationship with the perpetrator (vs no group relationship) was associated with perceptions that the survivor's consent communication was less clear. It is possible that, in this among other cases, the group manipulation inadvertently manipulated perceptions of survivor group membership in addition to perpetrator group membership. Those high in social dominance orientation might have been especially punitive towards survivors whom they perceived as outgroup members. Additionally, across all studies, higher preference for social hierarchy was predictive of poorer perceived consent clarity. This finding is consistent with past research that has demonstrated the association between preference for social hierarchy (e.g., social dominance orientation, system-justifying beliefs) and sexual aggression, rape myth acceptance, and other rape-supportive attitudes (Chapleau \& Oswald, 2014; Kelly et al., 2015; Ståhl et al., 2010). Feminist theories of sexual violence state that a core motive of sexual aggression is power (Wells \& Taylor, 2003). It follows that beliefs that support a power-imbalanced social hierarchy would relate to rape-supportive and victimblaming attitudes. Past research has found such an association with rape-supportive attitudes for social dominance orientation (Kelly et al., 2015) and system-justifying 
beliefs (Chapleau \& Oswald, 2014; Ståhl et al., 2010). This research extends these findings to include belief in a just world for others, a closely related construct.

\section{Research Question 3}

Research Question 3 asked whether liking/identifying with a perpetrator leads to perceived unclear survivor consent communication by activating cultural rape myths or norms associated with victim-blame. Studies 1 and 2 measured rape myth acceptance as a potential mediator of the relationship between perpetrator group membership and perceived survivor consent clarity; neither found support for this proposed effect. These studies also found no support for the effect of perpetrator group membership on perceptions of consent clarity at all, precluding a potential mediation effect.

However, one finding which was the opposite of the anticipated effect is that participants in the outgroup condition reported significantly higher rape myth acceptance than participants in the no group condition. Theoretically, I anticipated that third-party perceivers of an outgroup perpetrator would be less likely to defend the perpetrator's actions and might even decrease their support for rape myths to denigrate an outgroup perpetrator. However, outgroup membership was associated with an increase in rape myth acceptance as compared to the control condition in Study 1 and Study 2.

The Illinois Rape Myth Acceptance Scale does include a subscale titled "Rape is a deviant event" which measures beliefs that rape is only committed by deviant outgroup men (Payne et al., 1999). This may have increased after individuals read about an outgroup perpetrator. However, follow-up tests indicated that scores on this specific subscale did not differ between the outgroup and no group conditions. This subscale did 
not explain the observed effect. An alternative explanation, as has been the case for many findings that contradict the proposed hypotheses, is that the manipulation inadvertently manipulated survivor group membership as well. In this case, reading about an outgroup survivor might lead to higher rape myth acceptance as participants were more likely to engage in victim-blame when it was directed at a perceived outgroup member. In this case specifically, this may have been exacerbated by the gendered nature of the rape myth acceptance measure. Many of the items on this measure ask the participant to evaluate a female rape survivor. This may have encouraged participants to focus their evaluation on the survivor and, in reaching for a basis on which to evaluate a person they knew very little about, applied the information that they were provided about the male perpetrator's group membership to her.

In Studies 3 and 4, I tested a different measure of global beliefs about sexual violence (i.e., perceived peer norms supporting sexual aggression) as a potential mediator of the relationship between perpetrator group membership and perceptions of survivor consent clarity. While there were no significant findings in Study 4, the results in Study 3 supported a full mediation effect. Specifically, participants in the ingroup condition reported significantly higher perceived peer norms supporting sexual aggression than participants in the outgroup condition. This is unsurprising given that the vignette described an ingroup member, ostensibly a peer, committing an act of sexual aggression. Additionally, those who perceived that their peers were more supportive of sexual aggression also reported perceptions that the survivor's consent communication was less 
clear. The indirect effect of condition on consent clarity was significant while the index of the direct effect in the same model was not, supporting a full mediation effect.

This finding suggests an alternative explanation for the relationship between perpetrator group membership and perceptions of consent clarity. Instead of liking or identifying with a perpetrator, sharing a group with a perpetrator might induce perceptions that sexual aggression is normal. This altered perception of social norms might then lead perceivers to justify sexually aggressive behavior by claiming consent miscommunication. Social norms are known to influence sexually aggressive attitudes and behaviors. Men who perceive that obtaining consent and intervening in potential sexual assaults are socially-supported are self-reportedly more likely to engage in these behaviors (Fabiano et al., 2003). Additionally, men who were given false feedback suggesting that their peers held more rape-supportive views were more likely to report that they would engage in sexually aggressive behavior (Berkowitz, 2010). Participants who claim higher levels of miscommunication when the perpetrator is an ingroup member might do so because they are more likely to believe that sexual aggression is socially acceptable.

Study 4 did not find support for this effect. This suggests that the results of Study 3 should be interpreted with caution, especially since the ingroup perpetrator in Study 4 was described even more explicitly as a peer (i.e., a student attending the same university as the participant). However, there were significant problems with the peer norms supporting sexual aggression variable in Study 4. The variable suffered from a strong floor effect (M=1.19, a minimum score of 1$)$ and the reliability of this scale in Study 4 
was poor. Additionally, Study 4 did not find support for Hypothesis A, and this effect was dependent on that finding.

Additionally, rape myth acceptance and peer norms supporting sexual aggression were negatively associated with perceptions of consent clarity across studies. This supports the convergent validity of the perceptions of consent clarity scale.

\section{Interpretation of Findings}

Study 3 found support for Hypotheses A and C. These results would suggest that individuals may claim consent miscommunication to justify sexually violent behavior, as has been suggested in previous qualitative research (Hansen et al., 2010). However, instead of the proposed model based on liking or identifying with the perpetrator, this effect may instead occur due to the rape-supportive norms facilitated by perceiving that an ingroup member, peer, or liked other has perpetrated sexual violence. Perceptions of social norms impact an individual's rape-related attitudes and behaviors (Berkowitz, 2010; Fabiano et al., 2003). These results suggest that such norms may also lead individuals to engage in victim-blame by claiming poorer consent communication.

However, Study 3 was the only study that supported any of the proposed core hypotheses. While there are many potential explanations for these findings, Study 3 results may be the result of a Type I error and should be interpreted with great caution. Additional research is required to further investigate these research questions. Below I explore potential interpretations of the null findings. 
Poor Data Quality

As previously mentioned, poor data quality related to inattentive responding might have prevented the detection of significant findings. Studies 1 and 2 were collected using Amazon's Mechanical Turk; this platform may suffer from data quality concerns, especially related to inattentive responding (Chmielewski \& Kucker, 2020; Fleischer et al., 2015). Some research suggests that MTurk workers may be uniquely skilled at identifying attention check items and scales and may attend selectively to these items while responding inattentively to others (Barends \& de Vries, 2019). MTurk workers are incentivized to respond carefully to attention check items, for which some requesters will deny payment, and as quickly as possible to other items. Participants on other data collection platforms are not incentivized in the same way. This may have allowed for a disproportionate number of inattentive responses in the MTurk samples to pass the attention and manipulation checks.

Average participant completion times also suggest less attentive responding on MTurk as compared to the other platforms. The average time participants took to complete the study was roughly 100 seconds shorter in the studies using the MTurk data collection platform (Study 1 mean= 619 seconds; Study 2 mean $=616$ seconds) than the study using the Qualtrics data collection platform (Study 3 mean $=720$ seconds) and drastically shorter than the completion time in the student sample (Study 4 mean $=1769$ seconds). This was the case even though the length of the survey was shorter in Studies 3 and 4. Where Studies 1 and 2 included measures of Social Dominance Orientation (16 items) and Rape Myth Acceptance (17 items), Studies 3 and 4 used measures of Belief in 
a Just World for Others (8 items) and Peer Norms Supporting Sexual Aggression (5 items). That participants in Studies 1 and 2 took less time to respond to a higher number of items suggests less careful responding and poorer data quality in those studies.

Study 3, which included the most stringent quality control checks in addition to using another data collection platform, did find support for two out of three core study hypotheses. However, concerns related to MTurk data quality do not account for the null results found in Study 4, which used data collected from volunteers in an existing participant pool and had a very high average response time. However, the survey in Study 4 was set such that participants were given a longer time to complete the survey before it was automatically recorded. The higher average in this study could be partially explained by several outliers who seem to have completed the survey but failed to click the final "submit" button to immediately record their responses. Study 4 data might be compromised in some other way, potentially by the comparatively high degree of range restriction.

\section{Manipulation Concerns}

Study manipulations may have failed or created an effect that was the opposite of the intended manipulation. While minimal group manipulations are effective at inducing favoritism, my modifications to the technique (i.e., describing a specific ingroup or outgroup member with individual characteristics) might have weakened its effect (Balliet et al., 2014; Tajfel \& Turner, 1986). While actual group manipulations have also been shown to be effective (Balliet et al., 2014), they may not be so effective that their impact persists after learning highly socially undesirable information (i.e., being a sex offender) 
about a group member. Main effect (i.e., Hypothesis A) analyses were repeated with participants who failed the manipulation checks included with almost no impact on the results. The sole exception is that the significant finding in Study 3 became marginal, though it trended in the same direction. This manipulation may have impacted liking the perpetrator and identifying with the perpetrator differently, creating problems observing the intended effect.

Another potential concern is that the manipulation may have also inadvertently manipulated perceptions of the survivor's group membership. While the manipulation did explicitly state that the group membership of the survivor was unknown, participants may not have attended to this information. The impact on perceptions of the survivor's group identity may have persisted regardless of this statement simply through association with the perpetrator. Because of this, participant interpretations might be based on the perceived group membership of the survivor instead of or in addition to the perceived group membership of the perpetrator. Individuals report less support for sexual violence survivors who belong to an outgroup (Page \& Whitt, 2020). Decreased support for the survivor in the outgroup condition would explain several unexpected findings in Studies 1, 2, and 4. First, it would explain the findings in Studies 1 and 2 that rape myth acceptance was higher in the outgroup condition than the no group condition. Second, it would explain the findings that in Study 2, those high in social dominance orientation, being in the outgroup condition was associated with lower consent clarity than being in the no group condition. Finally, it could also explain why baseline liking was positively correlated with perceptions of consent clarity in Study 4. 


\section{Role of Participant Gender}

The experimental manipulation may have worked differently based on participant gender. In a context where gender is highly salient, other group memberships may be less psychologically impactful than one's gender group. Therefore, women and nonbinary individuals may not see an ingroup male perpetrator as a full ingroup member, and men may not perceive an outgroup male perpetrator as a full outgroup member. This effect may have created a situation where manipulation effectiveness differed by gender, potentially hindering the detection of any significant effects.

Gender was examined as a moderator to further probe this potential explanation. Participant gender was a significant predictor of perceived consent clarity in Studies 1 and 3, such that non-men (i.e., women and nonbinary participants) reported significantly higher perceived consent clarity than men $[(\mathrm{S} 1 ; \mathrm{b}=0.13, \mathrm{SE}=0.05, \mathrm{p}=0.02) ;(\mathrm{S} 3 ; \mathrm{b}=0.64$, $\mathrm{SE}=0.19, \mathrm{p}=0.007)]$. In Study 2, gender was a marginally significant predictor of consent clarity in the same direction $(\mathrm{S} 2 ; \mathrm{b}=0.16, \mathrm{SE}=0.09, \mathrm{p}=0.07)$. In Study 4, gender was not a significant predictor of perceived consent clarity $(S 4 ; b=0.06, S E=0.06$, $\mathrm{p}=0.34$ ). Non-men generally reported higher perceived consent clarity than men.

Gender did not moderate the relationship between condition and perceived consent clarity in Studies 2 (Ingroup vs No Group $b=-0.17, \mathrm{SE}=0.11, \mathrm{p}=0.11$; Outgroup vs No Group; $b=0.04, \mathrm{SE}=0.11, \mathrm{p}=0.68), 3(\mathrm{~S} 3$ Outgroup vs Ingroup $\mathrm{b}=-0.09, \mathrm{SE}=$ $0.11, \mathrm{p}=0.42$ ), and 4 (Ingroup vs No Group $\mathrm{b}=0.02, \mathrm{SE}=0.07, \mathrm{p}=0.8$; Outgroup vs No Group $b=-0.006, \mathrm{SE}=0.07, \mathrm{p}=0.93)$. In Study 1, gender did not moderate the relationship between the Outgroup vs No Group comparison and consent clarity $(b=-0.08, S E=0.07$, 
$\mathrm{p}=0.25$ ). However, gender was a marginally significant moderator of the relationship between the Ingroup vs No Group comparison and consent clarity $(b=-0.13, S E=0.07$, $\mathrm{p}=0.06$ ). Among non-men, being in the Ingroup condition vs the No Group condition was associated with marginally lower perceived consent clarity. Still, the results regarding the impact of participant gender on this relationship are inconclusive.

It is also possible that other measures and materials in this research may have been interpreted differently based on participant gender. A common criticism of the miscommunication model of sexual violence is that it implies that women's methods of communication are deficient (Hansen et al., 2010). The way that individuals perceive and make claims of consent miscommunication may differ significantly by gender. Some study materials, specifically the vignettes and the perceptions of consent clarity scale, were developed for this research, have not been otherwise validated, and therefore may not be equally valid across genders.

\section{Differing Ingroup Standards}

The reasoning behind attempting to manipulate group membership with the perpetrator was the assumption that sharing a group with the perpetrator and/or liking the perpetrator would induce participant motivation to defend the perpetrator. This assumption may have been incorrect. Individuals may only be willing to justify the harmful behavior of ingroup leaders instead of ingroup members (Abrams et al., 2013). Immoral behavior by ingroup members might lead to feelings of shame and harsher judgment to protect the image of the ingroup (Fousiani et al., 2019; Gausel \& Brown, 2012). This negative reaction might be even further heightened by the extra stigma 
associated with sexual offending creating an even larger threat to the ingroup. There is still some research that finds that less blame is attributed to ingroup members than outgroup members (Halabi et al., 2015) but this tendency might be hindered by transgressions as severe as committing rape.

\section{Reduced Perceptions of Ambiguity}

A rape myth that some might rely on to justify sexual violence is that women often lie about their experiences of rape (Payne et al., 1999). However, participants in this research are provided only the vignette describing the instance of sexual violence as a basis for their judgment. As such, they lose this potential justification for the perpetrator's behavior. Actual allegations of sexual aggression generally entail multiple perspectives which might facilitate claims of ambiguity. In essence, the participants might have been unable to diminish the instance of sexual violence because they were told explicitly that it had happened and were given no access to any further information.

\section{Alternative Mechanisms}

Claims of miscommunication have been identified as tools that individuals might use to justify sexual violence (Hansen et al., 2010; O’Byrne et al., 2006, 2008). The present research did not test whether this effect occurs at all, but instead whether it occurs disproportionately among individuals who share a group membership with the survivor. Many other explanations and contexts might motivate individuals to engage in rapejustification using claims of consent miscommunication. Results in Study 3 suggest that seeing sexual aggression as acceptable among one's peers might be a better explanation for miscommunication claims. 


\section{Future Directions}

The null results found in the majority of this research underscore the need for future research to investigate these research questions. Several directions are implicated.

First, steps might be taken to increase the psychological realism of the research. It is unlikely that the psychological processes evoked by evaluating a one-dimensional fictional perpetrator of sexual violence are the same processes that drive perceivers' reactions to real-world instances of sexual violence. Alternative experimental manipulations might more closely approximate the psychological processes behind the proposed effect in real-world settings. These might include providing more detailed information about a perpetrator on which a participant might base their evaluation, such as showing each participant a video clip of the perpetrator talking about some unrelated topic. A further consideration is that real-world claims of consent miscommunication are not made based on a clearly defined vignette. Another alternative approach might involve introducing ambiguity about the nature of an instance of sexual violence by providing participants with a conflicting perspective from the perpetrator's point of view. This may more closely reflect the complicated information that real-world third-party perceivers often receive in addition to creating more variance in participant responses. Further, natural experiments might be better able to address the conflation of liking a perpetrator and identifying with a perpetrator that occurred in this research. Perceivers who initially liked a celebrity perpetrator before learning about an offense might be compared to those who initially disliked a celebrity perpetrator. Of course, this research would likely face barriers related to difficulties obtaining a true baseline measurement. 
Second, perceivers' evaluations of a perpetrator may not be the driving factor behind consent miscommunication claims. In this case, testing other motivations for miscommunication claims might prove enlightening. Inducing feelings of system threat has been suggested as a potential method of manipulating victim-blame which might be considered (Ståhl et al., 2010). Future research might compare claims of consent miscommunication based on feelings of system threat both within and between participants. The results of Study 3 suggest that social norms might be an important mechanism. Providing different types of social norm feedback might impact claims of consent miscommunication. Future researchers might provide a sample of male participants with manipulated norm feedback about the sexual violence-related attitudes of other men and test the impact of this manipulation on perceptions of consent clarity. Other mechanisms might include priming certain gender beliefs/stereotypes or manipulating feelings of threat to the self.

Third, exploratory and theory-building research about consent miscommunication claims, the situations in which they are made, and their impact on survivors might prove useful. More exploratory work in this area is warranted to develop a more comprehensive understanding of the phenomenon of interest. Future research might entail broad, descriptive surveys examining a variety of attitudes and perceptions related to this topic. Additionally, exploratory research with survivors specifically might provide more indepth knowledge about how consent miscommunication claims impact recovery. This might also involve descriptive surveys which focus on survivor's experiences of social reactions to disclosure and their health and well-being. This information could be used to 
apply these findings in ways that could promote more supportive social responses to disclosures of sexual violence and facilitate survivor recovery.

Fourth, future research may consider the role of participant gender in more depth. It is likely that women make consent miscommunication claims, which often imply that women's patterns of communication are deficient (Hansen et al., 2010), differently and in different contexts than men and people of other genders. It is likely impossible to entirely extract gendered concerns from research on such a gendered topic. Liking, perceptions of shared interests and group memberships, and evaluation of perpetrators do not occur in a gender-neutral context. Future research may benefit from more carefully attending to the subject as well as the object of miscommunication claims. This might involve collecting single-gender samples, developing and validating measures and materials across genders, and/or testing factorial designs that treat participant gender as a predictive factor.

\section{Strengths and Limitations}

Some several strengths and limitations should be considered in interpreting the results of this research.

This research involves multiple conceptual replications, using a variety of methodologies and measures and collecting data from several different populations. Further, the experimental design of this research, including the random assignment, allows for a higher level of internal validity than would be available in a typical crosssectional survey. Of course, this experimental control is diminished by the online context, as it does not offer the same ability to control extraneous variables as a laboratory setting. 
The strengths of this research are undercut by the inconsistent and largely null results. A substantial limitation is the lack of external validity and psychological realism in this research. It is unlikely that these findings reflect the way that these psychological processes occur in the real world, as the experimental manipulation was unable to create such processes. Additionally, the populations from which samples were drawn (online survey-takers from MTurk and Qualtrics, university students) are limited, and these results may not generalize to other populations and contexts. Another consideration is the impact of social desirability on the measures utilized in this research. While the measures were intentionally written to be subtle, the subject matter of this research is highly sensitive, and any self-report measures in this area often produce blunt results. Future research might consider using more sophisticated or implicit measures to examine this phenomenon.

\section{Conclusion}

Study 3 found results that support the idea that liking or identifying with the perpetrator of an instance of sexual violence results in increased claims of consent miscommunication. However, the other three studies revealed inconsistent and largely null results, limiting the impactions of this research. Future research that is higher in psychological realism is warranted in further explorations of this area. 


\section{Tables and Figures}

\section{Table 1}

A Priori Power Analyses

\begin{tabular}{lcccc}
\multicolumn{2}{c}{ Sample for 0.95 power } & Small Effect & Medium Effect & Large Effect \\
\hline Hypothesis A & & 1548 & 252 & 102 \\
Hypothesis B & Step 1 & 863 & 119 & 54 \\
& Step 2 & 995 & 138 & 63 \\
Hypothesis C & Step 1 \& 2 & 776 & 68 & 48 \\
& Step 3 & 652 & 44 & 40 \\
& Step 4 & 863 & 119 & 54 \\
\hline \multicolumn{2}{l}{ Small Effect: $f=0.1, f^{2}=0.02 ;$ Medium Effect: $f=0.25, f^{2}=0.15 ;$ Large Effect: $f=0.4, f^{2}=0.35$}
\end{tabular}


Table 2

Post-Hoc Power Analyses

\begin{tabular}{llcccc} 
& & Study 1 & Study 2 & Study 3 & Study 4 \\
\hline Hypothesis A & & 0.07 & 0.32 & $0.68^{*}$ & 0.09 \\
Hypothesis B & Step 1 & $1.00^{*}$ & $1.00^{*}$ & $1.00^{*}$ & $0.83^{*}$ \\
& Step 2 & 0.08 & $0.41^{*}$ & 0.08 & 0.10 \\
Hypothesis C & Step 1 & 0.10 & $1.00^{*}$ & $0.73^{*}$ & 0.07 \\
& Step 2 & $0.32^{*}$ & $1.00^{*}$ & $0.85^{*}$ & 0.06 \\
& Step 3 & $1.00^{*}$ & $1.00^{*}$ & $1.00^{*}$ & $0.75^{*}$ \\
& Step 4 & $1.00^{*}$ & $1.00^{*}$ & $1.00^{*}$ & $0.59^{*}$ \\
\hline
\end{tabular}

${ }^{*}$ Indicates a significant finding 
Table 3

All Pilot Descriptives

\begin{tabular}{|c|c|c|c|c|c|c|c|}
\hline \multirow{3}{*}{ Gender } & & \multicolumn{2}{|c|}{ Pilot 1} & \multicolumn{2}{|c|}{ Pilot 2} & \multicolumn{2}{|c|}{ Pilot 3} \\
\hline & & $\mathbf{N}$ & \multirow{2}{*}{$\begin{array}{c}\% \\
52\end{array}$} & \multirow{2}{*}{$\frac{\mathbf{N}}{100}$} & \multirow{2}{*}{$\frac{\%}{63}$} & \multirow{2}{*}{$\frac{\mathbf{N}}{121}$} & \multirow{2}{*}{$\frac{\%}{64}$} \\
\hline & Man & 50 & & & & & \\
\hline & Woman & 38 & 40 & 55 & 34 & 62 & 33 \\
\hline & Nonbinary & 2 & 2 & 2 & 2 & 1 & 1 \\
\hline & Declined & 1 & 1 & 1 & 1 & 1 & 1 \\
\hline Race / & Black & 11 & 11 & 9 & 6 & 16 & 8 \\
\hline \multirow[t]{7}{*}{ Ethnicity } & Asian & 4 & 4 & 14 & 9 & 17 & 9 \\
\hline & Native American & 1 & 1 & 1 & 1 & 0 & 0 \\
\hline & Pacific Islander & 0 & 0 & 0 & 0 & 0 & 0 \\
\hline & White & 70 & 73 & 121 & 76 & 130 & 69 \\
\hline & Latino/a/x & 4 & 4 & 7 & 4 & 12 & 6 \\
\hline & Multiracial & 2 & 2 & 7 & 4 & 11 & 6 \\
\hline & Other/Declined & 1 & 1 & 1 & 1 & 1 & 1 \\
\hline \multirow[t]{9}{*}{ Education } & $<$ High School & 2 & 2 & 0 & 0 & 0 & 0 \\
\hline & High school & 9 & 9 & 26 & 16 & 16 & 8 \\
\hline & Some College & 19 & 20 & 28 & 18 & 43 & 23 \\
\hline & Trade School & 1 & 1 & 1 & 1 & 2 & 1 \\
\hline & Associates & 8 & 8 & 16 & 10 & 13 & 7 \\
\hline & Bachelors & 37 & 39 & 73 & 46 & 83 & 44 \\
\hline & Some Grad Ed & 2 & 2 & 1 & 1 & 1 & 1 \\
\hline & Grad Degree & 14 & 14 & 15 & 9 & 28 & 15 \\
\hline & Declined & 1 & 1 & 0 & 0 & 1 & 1 \\
\hline \multirow[t]{6}{*}{ Employment } & Full Time & 59 & 61 & 119 & 74 & 134 & 71 \\
\hline & Part time & 11 & 11 & 13 & 8 & 23 & 12 \\
\hline & Homemaker & 5 & 5 & 3 & 2 & 5 & 3 \\
\hline & Student & 2 & 2 & 2 & 1 & 8 & 4 \\
\hline & Retired/ None & 11 & 11 & 15 & 10 & 11 & 6 \\
\hline & Other/Declined & 5 & 5 & 8 & 6 & 6 & 4 \\
\hline
\end{tabular}




\begin{tabular}{|c|c|c|c|c|c|c|c|}
\hline & & \multicolumn{2}{|c|}{ Pilot 1} & \multicolumn{2}{|c|}{ Pilot 2} & \multicolumn{2}{|c|}{ Pilot 3} \\
\hline & & $\mathbf{N}$ & $\%$ & $\mathbf{N}$ & $\%$ & $\mathbf{N}$ & $\%$ \\
\hline Marital & Single & 32 & 33 & 68 & 43 & 82 & 43 \\
\hline \multirow[t]{6}{*}{ Status } & Partnered & 9 & 9 & 18 & 11 & 17 & 9 \\
\hline & Married & 47 & 49 & 60 & 38 & 78 & 41 \\
\hline & Separated & 0 & 0 & 1 & 1 & 2 & 1 \\
\hline & Divorced & 2 & 2 & 10 & 6 & 7 & 4 \\
\hline & Widowed & 2 & 2 & 0 & 0 & 0 & 0 \\
\hline & Declined & 1 & 1 & 3 & 2 & 1 & 1 \\
\hline \multirow[t]{10}{*}{ Income } & $<\$ 25,000$ & 12 & 13 & 33 & 21 & 20 & 11 \\
\hline & $\$ 25 \mathrm{k}-\$ 35 \mathrm{k}$ & 15 & 16 & 19 & 12 & 20 & 11 \\
\hline & $\$ 35 \mathrm{k}-\$ 50 \mathrm{k}$ & 16 & 17 & 25 & 16 & 32 & 17 \\
\hline & $\$ 50 \mathrm{k}-\$ 75 \mathrm{k}$ & 23 & 24 & 32 & 20 & 50 & 26 \\
\hline & $\$ 75 \mathrm{k}-\$ 100 \mathrm{k}$ & 13 & 14 & 21 & 13 & 32 & 17 \\
\hline & $\$ 100 \mathrm{k}-\$ 150 \mathrm{k}$ & 10 & 10 & 19 & 12 & 24 & 13 \\
\hline & $\$ 150 \mathrm{k}-\$ 200 \mathrm{k}$ & 3 & 3 & 5 & 3 & 5 & 3 \\
\hline & $>\$ 200,000$ & 0 & 0 & 2 & 1 & 3 & 2 \\
\hline & Unsure & 0 & 0 & 2 & 1 & 0 & 0 \\
\hline & Declined & 1 & 1 & 2 & 1 & 1 & 1 \\
\hline Sexual & Straight & 79 & 82 & 142 & 89 & 164 & 87 \\
\hline \multirow[t]{4}{*}{ Orientation } & Gay/Lesbian & 4 & 4 & 4 & 3 & 7 & 4 \\
\hline & $\mathrm{Bi} /$ pansexual & 7 & 7 & 11 & 7 & 11 & 6 \\
\hline & Queer/Multiple & 2 & 2 & 1 & 1 & 4 & 2 \\
\hline & Other/Declined & 1 & 1 & 2 & 1 & 1 & 1 \\
\hline
\end{tabular}


Table 4

All Study Descriptives

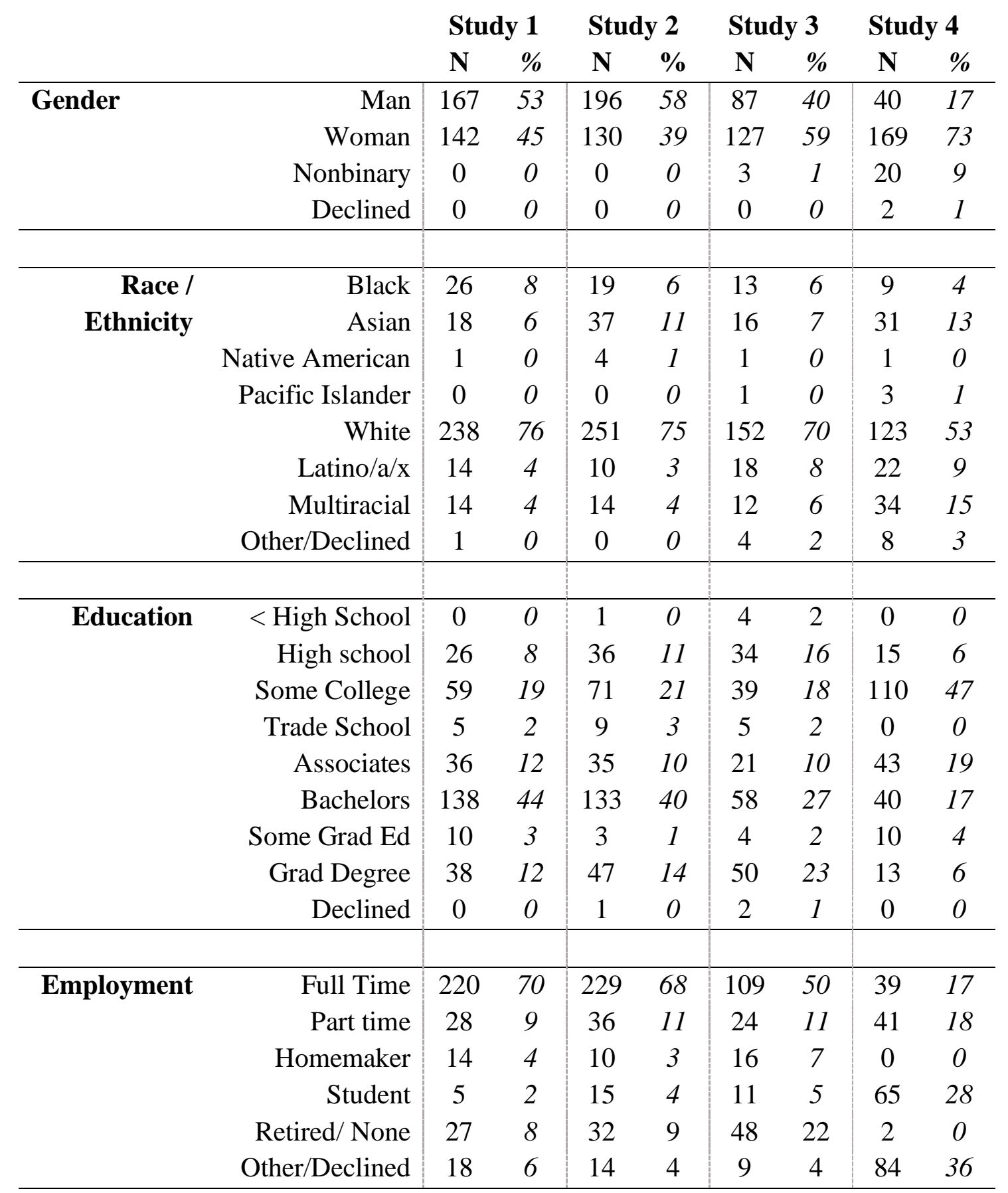




\begin{tabular}{|c|c|c|c|c|c|c|c|c|c|}
\hline & & \multicolumn{2}{|c|}{ Study 1} & \multicolumn{2}{|c|}{ Study 2} & \multicolumn{2}{|c|}{ Study 3} & \multicolumn{2}{|c|}{ Study 4} \\
\hline & & $\mathbf{N}$ & $\%$ & $\mathbf{N}$ & $\%$ & $\mathbf{N}$ & $\%$ & $\mathbf{N}$ & $\%$ \\
\hline Marital & Single & 125 & 40 & 136 & 40 & 61 & 28 & 159 & 69 \\
\hline \multirow[t]{6}{*}{ Status } & Partnered & 42 & 13 & 33 & 10 & 17 & 8 & 49 & 21 \\
\hline & Married & 123 & 39 & 130 & 39 & 117 & 54 & 15 & 6 \\
\hline & Separated & 3 & 1 & 6 & 2 & 4 & 2 & 1 & 0 \\
\hline & Divorced & 15 & 5 & 27 & 8 & 13 & 6 & 3 & 1 \\
\hline & Widowed & 3 & 1 & 4 & 1 & 3 & 1 & 2 & 0 \\
\hline & Declined & 1 & 0 & 0 & 0 & 2 & 1 & 2 & 0 \\
\hline \multirow[t]{10}{*}{ Income } & $<\$ 25,000$ & 38 & 12 & 51 & 15 & 19 & 9 & 105 & 45 \\
\hline & $\$ 25 \mathrm{k}-\$ 35 \mathrm{k}$ & 44 & 14 & 33 & 10 & 23 & 11 & 28 & 12 \\
\hline & $\$ 35 \mathrm{k}-\$ 50 \mathrm{k}$ & 54 & 17 & 45 & 13 & 35 & 16 & 16 & 7 \\
\hline & $\$ 50 \mathrm{k}-\$ 75 \mathrm{k}$ & 79 & 25 & 82 & 24 & 39 & 18 & 10 & 4 \\
\hline & $\$ 75 \mathrm{k}-\$ 100 \mathrm{k}$ & 45 & 14 & 59 & 18 & 31 & 14 & 9 & 4 \\
\hline & $\$ 100 \mathrm{k}-\$ 150 \mathrm{k}$ & 31 & 10 & 36 & 11 & 29 & 13 & 9 & 4 \\
\hline & $\$ 150 \mathrm{k}-\$ 200 \mathrm{k}$ & 10 & 3 & 16 & 5 & 21 & 10 & 2 & 0 \\
\hline & $>\$ 200,000$ & 6 & 2 & 10 & 3 & 10 & 5 & 4 & 2 \\
\hline & Unsure & 2 & 1 & 0 & 0 & 3 & 1 & 30 & 13 \\
\hline & Declined & 3 & 1 & 4 & 1 & 7 & 3 & 18 & 8 \\
\hline Sexual & Straight & 265 & 85 & 297 & 88 & 179 & 82 & 112 & 48 \\
\hline \multirow[t]{4}{*}{ Orientation } & Gay/Lesbian & 14 & 5 & 11 & 3 & 5 & 2 & 14 & 6 \\
\hline & $\mathrm{Bi} /$ pansexual & 23 & 7 & 20 & 6 & 20 & 9 & 45 & 19 \\
\hline & Queer/Multiple & 8 & 3 & 7 & 2 & 11 & 4 & 53 & 23 \\
\hline & Other/Declined & 1 & 0 & 1 & 0 & 2 & 1 & 7 & 3 \\
\hline
\end{tabular}


Table 5

Pilot 1 Descriptives and Correlations

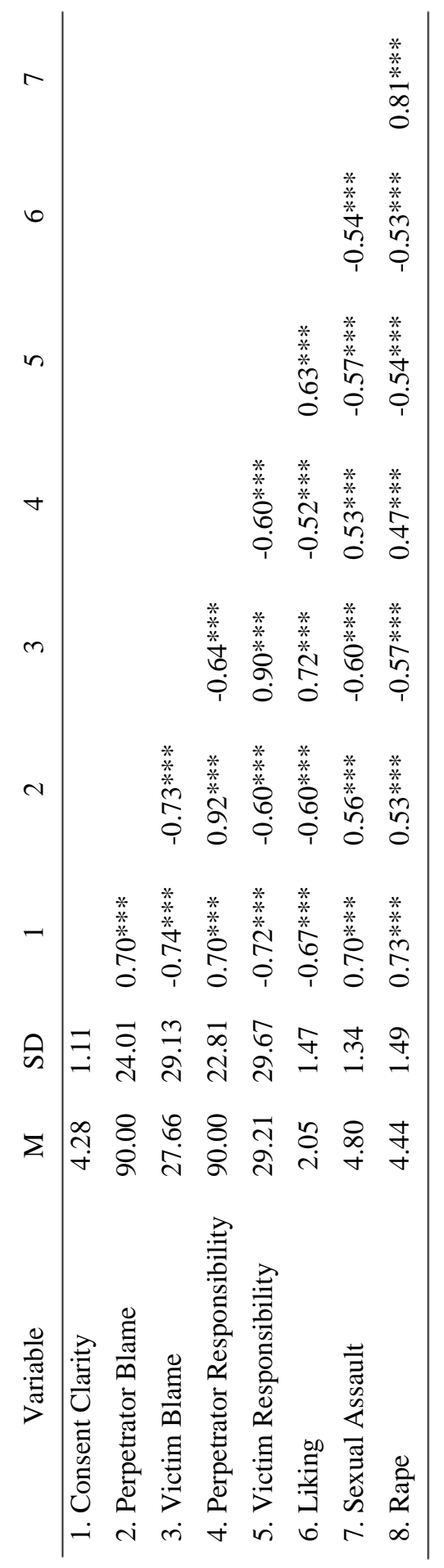


Table 6

Pilot 2 Descriptives and Correlations

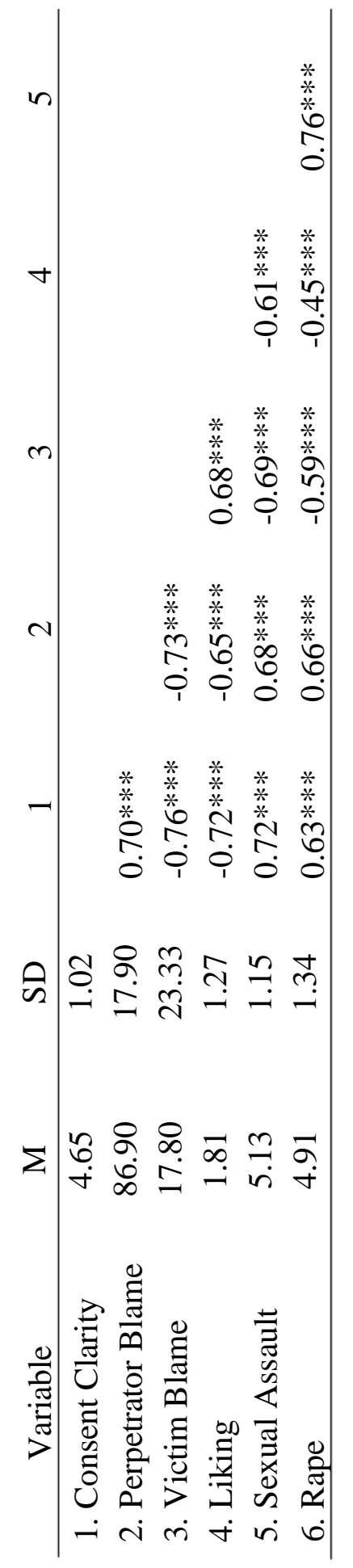


Table 7

Pilot 3 Descriptives and Correlations

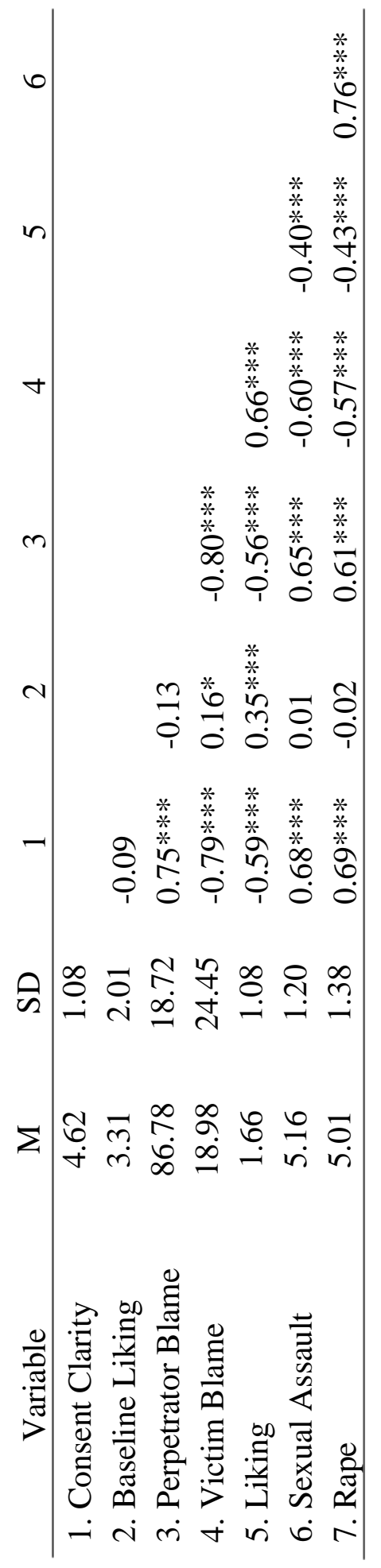


Table 8

Study 1 Descriptives and Correlations

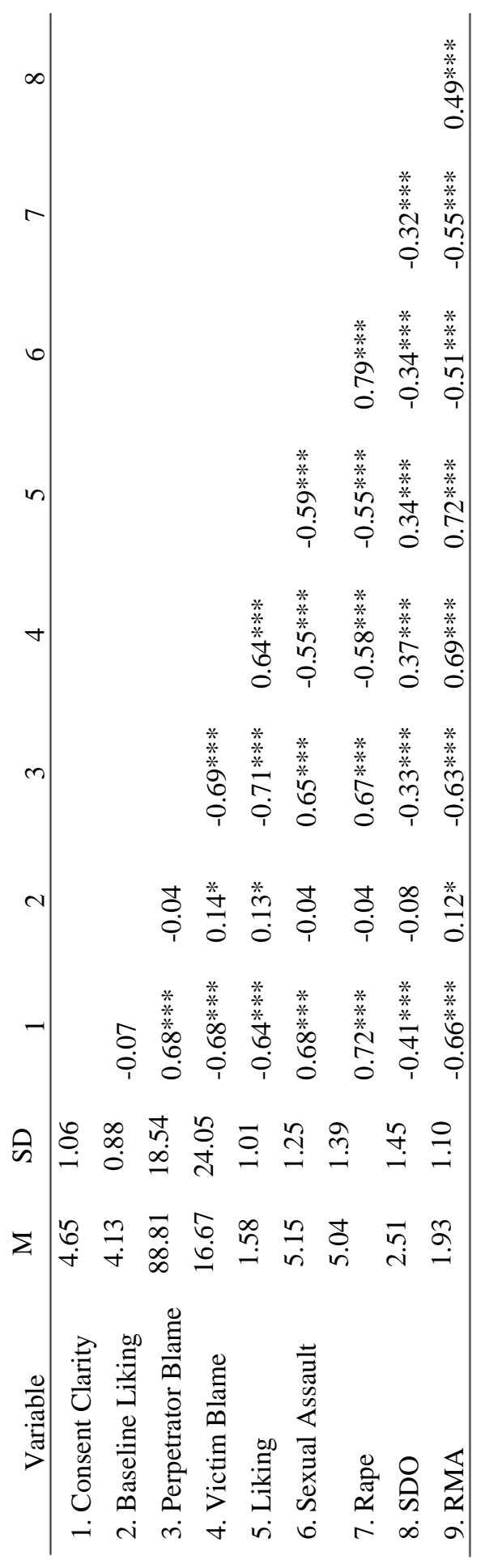


Table 9

Study 2 Descriptives and Correlations

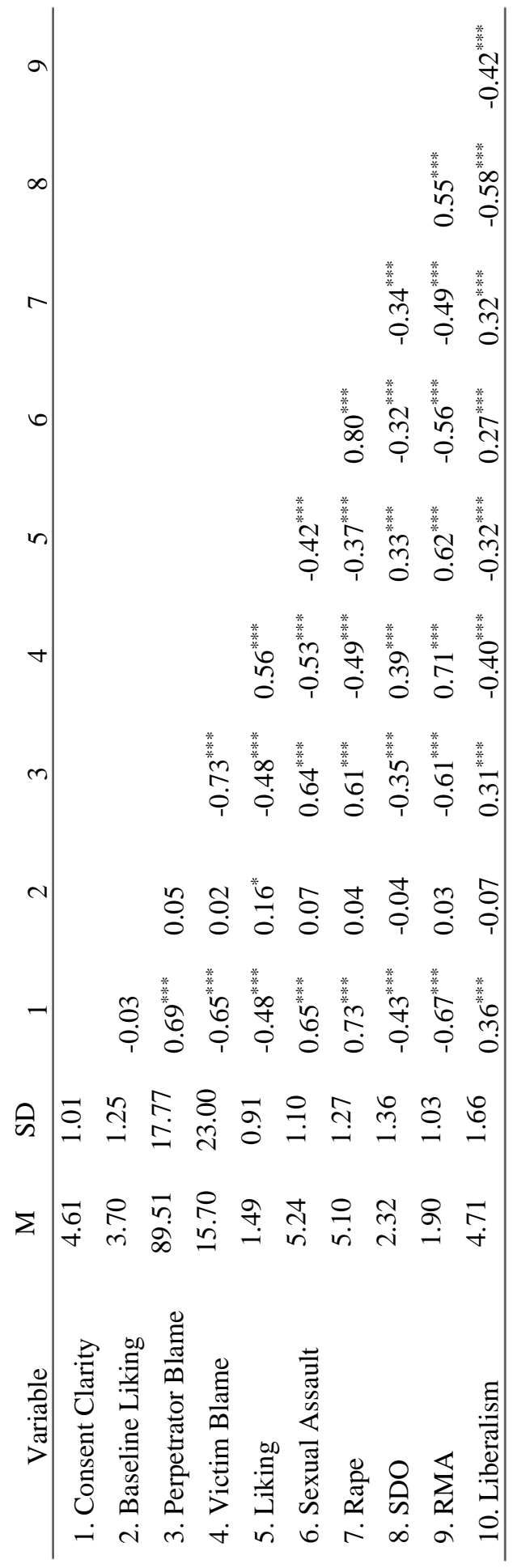


Table 10

Study 3 Descriptives and Correlations

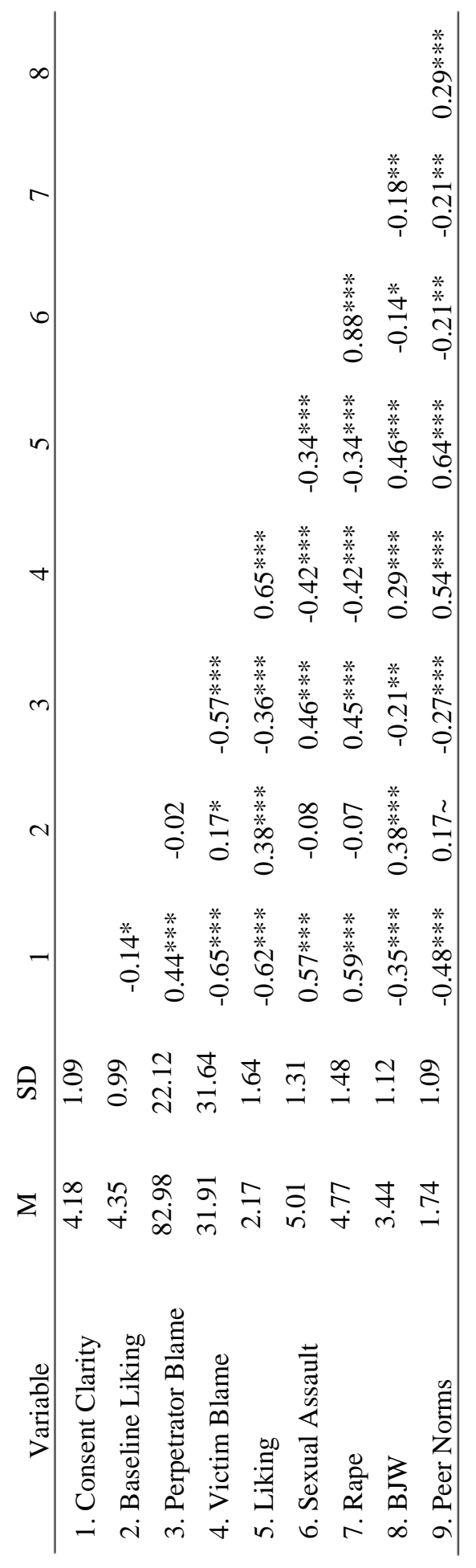


Table 11

Study 4 Descriptives and Correlations

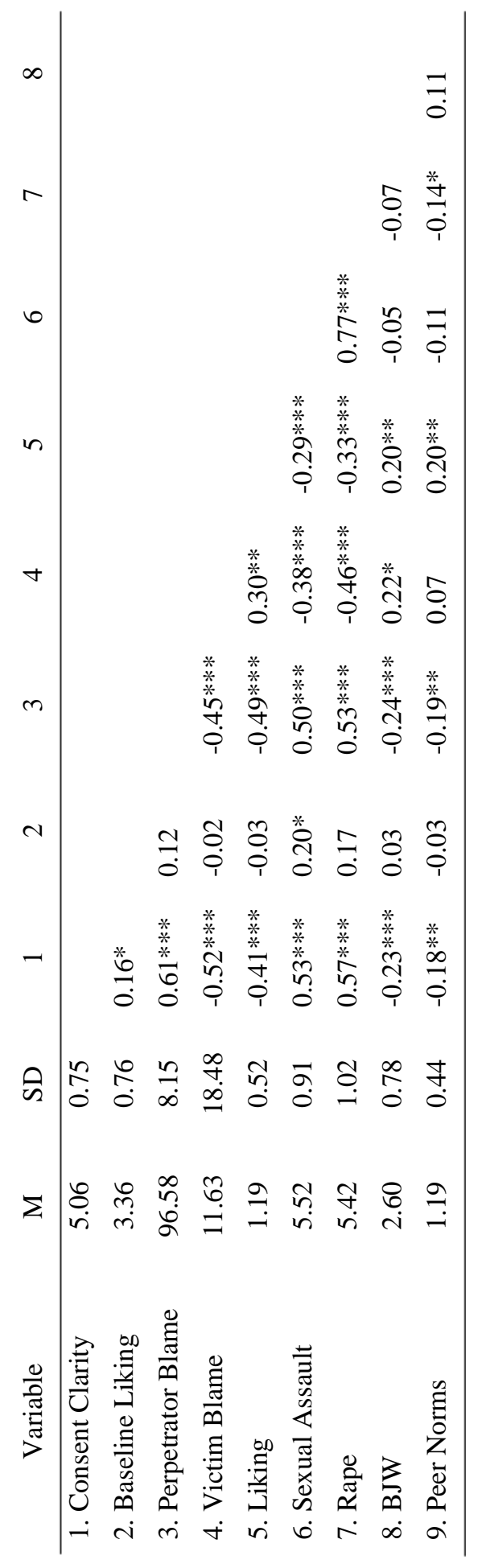


Table 12

\section{All Studies Overview}

\begin{tabular}{|c|c|c|c|c|}
\hline Material & Study 1 & Study 2 & Study 3 & Study 4 \\
\hline Manipulation & $\begin{array}{l}\text { Minimal group } \\
\text { - Ingroup } \\
\text { - No group } \\
\text { - Outgroup }\end{array}$ & $\begin{array}{l}\text { Political group } \\
\text { - Ingroup } \\
\text { - No group } \\
\text { - Outgroup }\end{array}$ & $\begin{array}{l}\text { Minimal group } \\
\text { - Ingroup } \\
\text { - Outgroup }\end{array}$ & $\begin{array}{l}\text { University group } \\
\text { - Ingroup } \\
\text { - No group } \\
\text { - Outgroup }\end{array}$ \\
\hline Measures* & $\begin{array}{l}\text { Social } \\
\text { dominance } \\
\text { orientation } \\
\text { - } \begin{array}{l}\text { Rape myth } \\
\text { acceptance }\end{array}\end{array}$ & $\begin{array}{ll}\text { - } & \begin{array}{l}\text { Social } \\
\text { dominance } \\
\text { orientation }\end{array} \\
\text { - } & \text { Rape myth } \\
\text { acceptance } \\
\text { - }\end{array}$ & 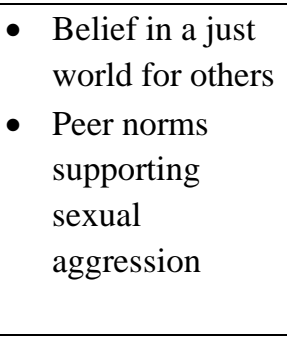 & 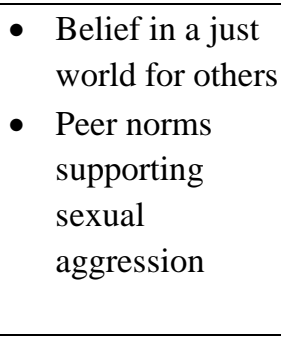 \\
\hline \multicolumn{5}{|c|}{ Preliminary Analyses } \\
\hline $\begin{array}{l}\text { Condition }> \\
\text { Liking }\end{array}$ & $\begin{array}{l}\text { Significant } \\
\text { direction) }\end{array}$ & Significant & Significant & Not Significant \\
\hline $\begin{array}{l}\text { r(Liking, } \\
\text { Consent) }\end{array}$ & Not Significant & Not Significant & Significant & $\begin{array}{l}\text { Significant } \\
\text { direction) }\end{array}$ \\
\hline \multicolumn{5}{|c|}{ Hypothesis Tests } \\
\hline Hypothesis A & Not Significant & Not Significant & Significant & Not Significant \\
\hline Hypothesis B & Not Significant & Not Significant & Not Significant & Not Significant \\
\hline Hypothesis C & Not Significant & Not Significant & Significant & Not Significant \\
\hline
\end{tabular}

* In addition to core measures 
Figure 1

Hypothesis C Model

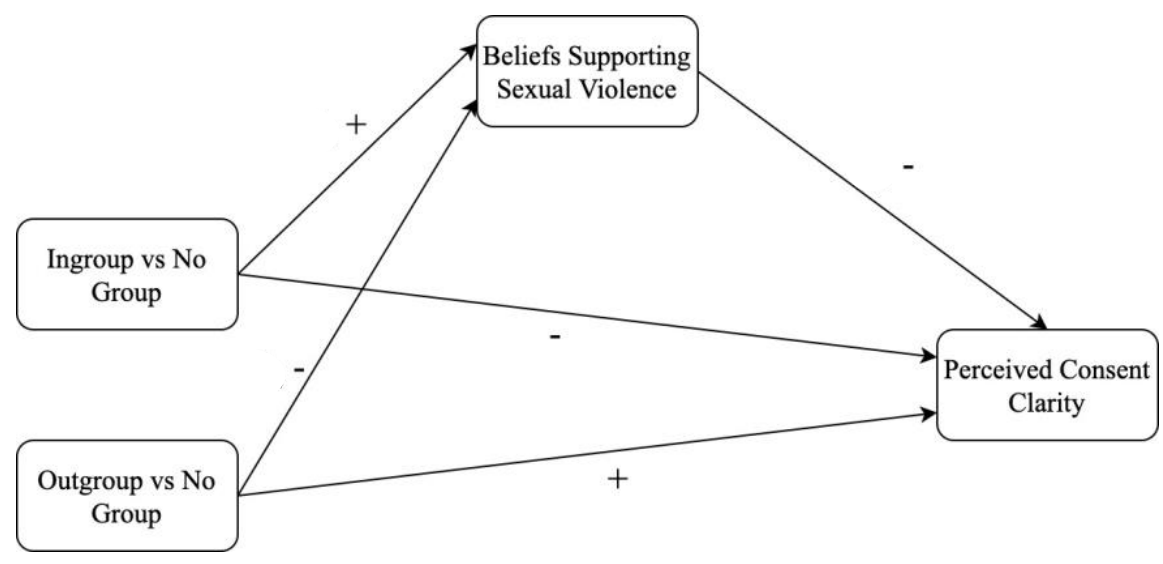


Figure 2

Survey Order \& Overview

\begin{tabular}{|c|c|}
\hline $\begin{array}{l}\text { Informed } \\
\text { Consent }\end{array}$ & $\begin{array}{l}\text { Project Title: Perceptions of Sexual Activity Survey } \\
\text { The reasons for doing this research are to examine how you will react to a paragraph } \\
\text { describing sexual activity based on the people and actions in the paragraph. }\end{array}$ \\
\hline Moderator & $\begin{array}{l}\text { S1\&S2: Social Dominance Orientation: Some groups of people must be kept in their place } \\
\text { S3\&S4: Belief in a Just World for Others: Ifeel that people get what they deserve }\end{array}$ \\
\hline $\begin{array}{l}\text { Group } \\
\text { Assignment }\end{array}$ & $\begin{array}{l}\text { No group } \\
\text { No group mentioned }\end{array}$ \\
\hline $\begin{array}{c}\text { Baseline } \\
\text { Liking }\end{array}$ & $\begin{array}{l}\text { Single item assessment of liking of the perpetrator pre-vignette } \\
\text { "I like Alan." }\end{array}$ \\
\hline Vignette & $\begin{array}{l}\text { Participants then read a vignette describing an alcohol mediated acquaintance rape } \\
\text { perpetrated by Alan. All participants read the same vignette. }\end{array}$ \\
\hline $\begin{array}{l}\text { Auxiliary } \\
\text { Measures }\end{array}$ & \multirow{2}{*}{$\begin{array}{l}\text { Blame: Please indicate what percent of the blame for what happened you would give... } \\
\text { Liking: I like Alan from this story } \\
\text { Trust: I think that Alan is someone who should not be trusted }\end{array}$} \\
\hline$\downarrow$ & \\
\hline $\begin{array}{c}\text { Consent } \\
\text { Clarity }\end{array}$ & \multirow{2}{*}{$\begin{array}{l}\text { Perceived Consent Clarity: Sandy clearly communicated that she did not want to have } \\
\text { sex with Alan [Key Outcome] } \\
\text { Included attention check: If you are reading this please leave this question blank }\end{array}$} \\
\hline$\downarrow$ & \\
\hline$\underbrace{\text { Manipulation }}_{\downarrow}$ Check & $\begin{array}{l}\text { S1\&S3: Are you and Alan from the earlier story the same type of thinker? } \\
\text { S2: Do you and Alan from the earlier story usually agree with the same political party? } \\
\text { S4: Do you and Alan from the earlier story attend the same university? }\end{array}$ \\
\hline Mediator & $\begin{array}{l}\text { S1\&S2: Rape Myth Acceptance: Many women secretly desire to be raped } \\
\text { S3\&S4: Peer Norms Supporting Sexual Aggression: How much would your friends } \\
\text { approve offorcing someone to have sex? }\end{array}$ \\
\hline $\begin{array}{c}\text { Rape/Sexual } \\
\text { Assault \& } \\
\text { Qualitative } \\
\end{array}$ & $\begin{array}{l}\text { Rape/Sexual Assault: What Alan did to Sandy was sexual assault/rape } \\
\text { Qualitative: Please provide a brief explanation of why you feel that this instance was or } \\
\text { was not sexual assault or rape }\end{array}$ \\
\hline Demographics & $\begin{array}{l}\text { Gender, race, education, age, employment, marital status, income, sexual orientation } \\
\text { These items were asked before the moderator in S2 and included political orientation }\end{array}$ \\
\hline Debrief & $\begin{array}{l}\text { At the beginning of this research, we told you that a test you took indicated that you had a } \\
\text { certain way of thinking. This was not true. The test that you took does not provide us any } \\
\text { information about your thinking style. In fact, every participant was shown the same result }\end{array}$ \\
\hline
\end{tabular}


References

Abbey, A., McAuslan, P., Zawacki, T., Clinton, A. Monique., \& Buck, P. O. (2001). Attitudinal, experiential, and situational predictors of sexual assault perpetration. Journal of Interpersonal Violence, 16(8), 784-807. https://doi.org/10.1177/088626001016008004

Abrams, D., Randsley de Moura, G., \& Travaglino, G. A. (2013). A double standard when group members behave badly: Transgression credit to ingroup leaders. Journal of Personality and Social Psychology, 105(5), 799-815. https://doi.org/10.1037/a0033600

Ahrens, C. E. (2006). Being silenced: The impact of negative social reactions on the disclosure of rape. American Journal of Community Psychology, 38(3-4), 31-34. https://doi.org/10.1007/s10464-006-9069-9

Balliet, D., Wu, J., \& De Dreu, C. K. W. (2014). Ingroup favoritism in cooperation: A meta-analysis. Psychological Bulletin, 140(6), 1556-1581. https://doi.org/10.1037/a0037737

Barends, A. J., \& de Vries, R. E. (2019). Noncompliant responding: Comparing exclusion criteria in MTurk personality research to improve data quality. Personality and Individual Differences, 143, 84-89. https://doi.org/10.1016/j.paid.2019.02.015

Baron, R. M., \& Kenny, D. A. (1986). The moderator-mediator variable distinction in social psychological research: Conceptual, strategic, and statistical considerations. Journal of Personality and Social Psychology, 51(6), 1173-1182. https://doi.org/10.1037//0022-3514.51.6.1173 
Bay-Cheng, L. Y., \& Eliseo-Arras, R. K. (2008). The making of unwanted sex: Gendered and neoliberal norms in college women's unwanted sexual experiences. Journal of Sex Research, 45(4), 386-397. https://doi.org/10.1080/00224490802398381

Beres, M. A. (2007). 'Spontaneous' sexual consent: An analysis of sexual consent literature. Feminism \& Psychology, 17(1), 93-108. https://doi.org/10.1177/0959353507072914

Beres, M. A. (2010). Sexual miscommunication? Untangling assumptions about sexual communication between casual sex partners. Culture, Health \& Sexuality, 12(1), 1-14. https://doi.org/10.1080/13691050903075226

Beres, M. A. (2014). Rethinking the concept of consent for anti-sexual violence activism and education. Feminism \& Psychology, 24(3), 373-389. https://doi.org/10.1177/0959353514539652

Beres, M. A., Senn, C. Y., \& McCaw, J. (2014). Navigating ambivalence: How heterosexual young adults make sense of desire differences. The Journal of Sex Research, 51(7), 765-776. https://doi.org/10.1080/00224499.2013.792327

Berkowitz, A. (2010). Fostering healthy norms to prevent violence and abuse: The social norms approach. In K. L. Kaufman (Ed.), The Prevention of Sexual Violence: A Practitioner's Sourcebook. NEARI Press.

Bonomi, A. E., Anderson, M. L., Rivara, F. P., \& Thompson, R. S. (2007). Health outcomes in women with physical and sexual intimate partner violence exposure. Journal of Women's Health, 16(7), 987-997.

https://doi.org/10.1089/jwh.2006.0239 
Borges, A. M., Banyard, V. L., \& Moynihan, M. M. (2008). Clarifying consent: Primary prevention of sexual assault on a college campus. Journal of Prevention \& Intervention in the Community, 36(1-2), 75-88. https://doi.org/10.1080/10852350802022324

Borja, S. E., Callahan, J. L., \& Long, P. J. (2006). Positive and negative adjustment and social support of sexual assault survivors. Journal of Traumatic Stress, 19(6), 905-914. https://doi.org/10.1002/jts.20169

Bruchmann, K., Koopmann-Holm, B., \& Scherer, A. (2018). Seeing beyond political affiliations: The mediating role of perceived moral foundations on the partisan similarity-liking effect. PLOS ONE, 13(8), 1-20. https://doi.org/10.1371/journal.pone.0202101

Burkett, M., \& Hamilton, K. (2012). Postfeminist sexual agency: Young women's negotiations of sexual consent. Sexualities, 15(7), 815-833. https://doi.org/10.1177/1363460712454076

Campbell, R. (2008). The psychological impact of rape victims' experiences with the legal, medical, and mental health systems. American Psychologist, 63(8), 702717. https://doi.org/10.1037/0003-066X.63.8.702

Cantor, D., Fisher, B., Chibnall, S., Townsend, R., Lee, H., Bruce, C., \& Thomas, G. (2015). Report on the AAU Campus Climate Survey on Sexual Assault and Sexual Misconduct. Association of American Universities.

Chapleau, K. M., \& Oswald, D. L. (2010). Power, sex, and rape myth acceptance: Testing two models of rape proclivity. Journal of Sex Research, 47(1), 66-78. https://doi.org/10.1080/00224490902954323 
Chapleau, K. M., \& Oswald, D. L. (2014). A system justification view of sexual violence: Legitimizing gender inequality and reduced moral outrage are connected to greater rape myth acceptance. Journal of Trauma \& Dissociation, 15(2), 204-218. https://doi.org/10.1080/15299732.2014.867573

Chen, L. P., Murad, M. H., Paras, M. L., Colbenson, K. M., Sattler, A. L., Goranson, E. N., Elamin, M. B., Seime, R. J., Shinozaki, G., Prokop, L. J., \& Zirakzadeh, A. (2010). Sexual abuse and lifetime diagnosis of psychiatric disorders: Systematic review and meta-analysis. Mayo Clinic Proceedings, 85(7), 618-629. https://doi.org/10.4065/mcp.2009.0583

Chmielewski, M., \& Kucker, S. C. (2020). An MTurk crisis? Shifts in data quality and the impact on study results. Social Psychological and Personality Science, 11(4), 464-473. https://doi.org/10.1177/1948550619875149

Coker, A. L., Hopenhayn, C., DeSimone, C. P., Bush, H. M., \& Crofford, L. (2009). Violence against women raises risk of cervical cancer. Journal of Women's Health, 18(8), 1179-1185. https://doi.org/10.1089/jwh.2008.1048

Dardis, C. M., Murphy, M. J., Bill, A. C., \& Gidycz, C. A. (2016). An investigation of the tenets of social norms theory as they relate to sexually aggressive attitudes and sexual assault perpetration: A comparison of men and their friends. Psychology of Violence, 6(1), 163-171. https://doi.org/10.1037/a0039443

Deming, M. E., Covan, E. K., Swan, S. C., \& Billings, D. L. (2013). Exploring rape myths, gendered norms, group processing, and the social context of rape among college women: A qualitative analysis. Violence Against Women, 19(4), 465-485. https://doi.org/10.1177/1077801213487044 
Ellison, L., \& Munro, V. E. (2008). Reacting to rape: Exploring mock jurors' assessments of complainant credibility. British Journal of Criminology, 49(2), 202-219. https://doi.org/10.1093/bjc/azn077

Ellsberg, M., Jansen, H. A., Heise, L., Watts, C. H., \& Garcia-Moreno, C. (2008). Intimate partner violence and women's physical and mental health in the WHO multi-country study on women's health and domestic violence: An observational study. The Lancet, 371(9619), 1165-1172. https://doi.org/10.1016/S01406736(08)60522-X

Emmers-Sommer, T. (2014). Adversarial sexual attitudes toward women: The relationships with gender and traditionalism. Sexuality \& Culture, 18(4), 804817. https://doi.org/10.1007/s12119-014-9222-9

Fabiano, P. M., Perkins, W., Berkowitz, A., Linkenbach, J., \& Stark, C. (2003). Engaging men as social justice allies in ending violence against women: Evidence for a social norms approach. Journal of American College Health, 53(2), 105-112.

Fleischer, A., Mead, A. D., \& Huang, J. (2015). Inattentive responding in MTurk and other online samples. Industrial and Organizational Psychology, 8(02), 196-202. https://doi.org/10.1017/iop.2015.25

Fousiani, K., Yzerbyt, V., Kteily, N., \& Demoulin, S. (2019). Justice reactions to deviant ingroup members: Ingroup identity threat motivates utilitarian punishments. British Journal of Social Psychology, 58(4), 869-893. https://doi.org/10.1111/bjso.12312

García-Moreno, C., Pallitto, C., Devries, K., Stöckl, H., Watts, C., \& Abrahams, N. (2013). Global and regional estimates of violence against women: Prevalence 
and health effects of intimate partner violence and non-partner sexual violence. World Health Organization.

Gausel, N., \& Brown, R. (2012). Shame and guilt — do they really differ in their focus of evaluation? Wanting to change the self and behavior in response to ingroup immorality. The Journal of Social Psychology, 152(5), 547-567. https://doi.org/10.1080/00224545.2012.657265

Glace, A. M., \& Dover, T. L. (2020, February). Labeling and reporting sexual violence: Stigma as a barrier for trauma survivors [Poster Presentation]. Society for Personality and Social Psychology Annual Conference, New Orleans, LA.

Glace, A. M., Zatkin, J. G., \& Kaufman, K. L. (2020). Moving toward a new model of sexual consent: The development of the Process-Based Consent Scale. Violence Against Women, 27. https://doi.org/10.1177/1077801220952159

Grubb, A., \& Turner, E. (2012). Attribution of blame in rape cases: A review of the impact of rape myth acceptance, gender role conformity and substance use on victim blaming. Aggression and Violent Behavior, 17(5), 443-452. https://doi.org/10.1016/j.avb.2012.06.002

Gunby, C., Carline, A., \& Beynon, C. (2013). Regretting it after? Focus group perspectives on alcohol consumption, nonconsensual sex and false allegations of rape. Social \& Legal Studies, 22(1), 87-106. https://doi.org/10.1177/0964663912459293

Halabi, S., Statman, Y., \& Dovidio, J. F. (2015). Attributions of responsibility and punishment for ingroup and outgroup members: The role of just world beliefs. 
Group Processes \& Intergroup Relations, 18(1), 104-115.

https://doi.org/10.1177/1368430214546067

Halstead, V., Williams, J. R., \& Gonzalez-Guarda, R. (2017). Sexual violence in the college population: A systematic review of disclosure and campus resources and services. Journal of Clinical Nursing, 26(15-16), 2137-2153. https://doi.org/10.1111/jocn.13735

Hammond, E. M., Berry, M. A., \& Rodriguez, D. N. (2010). The influence of rape myth acceptance, sexual attitudes, and belief in a just world on attributions of responsibility in a date rape scenario. Legal and Criminological Psychology, 16, 242-252. https://doi.org/10.1348/135532510X499887

Hansen, S., O’Byrne, R., \& Rapley, M. (2010). Young heterosexual men's use of the miscommunication model in explaining acquaintance rape. Sexuality Research and Social Policy, 7(1), 45-49. https://doi.org/10.1007/s13178-010-0003-4

Hayes, R. M., Lorenz, K., \& Bell, K. A. (2013). Victim blaming others: Rape myth acceptance and the just world belief. Feminist Criminology, 8(3), 202-220. https://doi.org/10.1177/1557085113484788

Hickman, S. E., \& Muehlenhard, C. L. (1999). "By the semi-mystical appearance of a condom": How young women and men communicate sexual consent in heterosexual situations. The Journal of Sex Research, 36(3), 258-272. https://doi.org/10.1080/00224499909551996

Hirsch, J. S., Khan, S. R., Wamboldt, A., \& Mellins, C. A. (2018). Social dimensions of sexual consent among cisgender heterosexual college students: Insights from 
ethnographic research. Journal of Adolescent Health, 64(1), 26-35.

https://doi.org/10.1016/j.jadohealth.2018.06.011

Ho, A. K., Sidanius, J., Kteily, N., Sheehy-Skeffington, J., Pratto, F., Henkel, K. E., Foels, R., \& Stewart, A. L. (2015). The nature of social dominance orientation: Theorizing and measuring preferences for intergroup inequality using the new SDO-7 scale. Journal of Personality and Social Psychology, 109(6), 1003-1028. https://doi.org/10.1037/pspi0000033

Jina, R., \& Thomas, L. S. (2013). Health consequences of sexual violence against women. Best Practice \& Research Clinical Obstetrics \& Gynaecology, 27(1), 1526. https://doi.org/10.1016/j.bpobgyn.2012.08.012

Jozkowski, K. N. (2015). Barriers to affirmative consent policies and the need for affirmative sexuality. The University of the Pacific Law Review, 47, 741-772.

Jozkowski, K. N., Marcantonio, T. L., \& Hunt, M. E. (2017). College students's sexual consent communication and perceptions of sexual double standards: A qualitative investigation. Perspectives on Sexual and Reproductive Health, 49(4), 237-244. https://doi.org/10.1363/psrh.12041

Jozkowski, K. N., \& Peterson, Z. D. (2013). College students and sexual consent: Unique insights. Journal of Sex Research, 50(6), 517-523.

https://doi.org/10.1080/00224499.2012.700739

Kahn, A. S., Mathie, V. A., \& Torgler, C. (1994). Rape scripts and rape acknowledgment. Psychology of Women Quarterly, 18(1), 53-66. https://doi.org/10.1111/j.14716402.1994.tb00296.x 
Kelly, A. J., Dubbs, S. L., \& Barlow, F. K. (2015). Social dominance orientation predicts heterosexual men's adverse reactions to romantic rejection. Archives of Sexual Behavior, 44(4), 903-919. https://doi.org/10.1007/s10508-014-0348-5

Kennedy, A. C., \& Prock, K. A. (2018). "I still feel like I am not normal”: A review of the role of stigma and stigmatization among female survivors of child sexual abuse, sexual assault, and intimate partner violence. Trauma, Violence, \& Abuse, 19(5), 512-527. https://doi.org/10.1177/1524838016673601

Kitzinger, C., \& Frith, H. (1999). Just say no? The use of conversation analysis in developing a feminist perspective on sexual refusal. Discourse \& Society, 10(3), 293-316. https://doi.org/10.1177/0957926599010003002

Lambert, A. J., \& Raichle, K. (2000). The role of political ideology in mediating judgments of blame in rape victims and their assailants: A test of the just world, personal responsibility, and legitimization hypotheses. Personality and Social Psychology Bulletin, 26(7), 853-863. https://doi.org/10.1177/0146167200269010

Landström, S., Strömwall, L. A., \& Alfredsson, H. (2016). Blame attributions in sexual crimes: Effects of belief in a just world and victim behavior. Nordic Psychology, 68(1), 2-11. https://doi.org/10.1080/19012276.2015.1026921

Lipkus, I., Dalbert, C., \& Siegler, I. (1996). The importance of distinguishing the belief in a just world for self versus for others: Implications for psychological well-being. Personality and Social Psychology Bulletin, 22(7). https://doi.org/10.1177/0146167296227002 
Litman, L., Robinson, J., \& Abberbock, T. (2017). TurkPrime.com: A versatile crowdsourcing data acquisition platform for the behavioral sciences. Behavior Research Methods, 49(2), 433-442. https://doi.org/10.3758/s13428-016-0727-z

Mason, G. E., Ullman, S., Long, S. E., Long, L., \& Starzynski, L. (2009). Social support and risk of sexual assault revictimization. Journal of Community Psychology, 37(1), 58-72. https://doi.org/10.1002/jcop.20270

Muehlenhard, C. L., Humphreys, T. P., Jozkowski, K. N., \& Peterson, Z. D. (2016). The complexities of sexual consent among college students: A conceptual and empirical review. The Journal of Sex Research, 53(4-5), 457-487. https://doi.org/10.1080/00224499.2016.1146651

O’Byrne, R., Hansen, S., \& Rapley, M. (2008). “If a girl doesn’t say 'no'...”: Young men, rape and claims of 'insufficient knowledge.' Journal of Community \& Applied Social Psychology, 18(3), 168-193. https://doi.org/10.1002/casp.922

O’Byrne, R., Rapley, M., \& Hansen, S. (2006). 'You couldn’t say “no”, could you?': Young men's understandings of sexual refusal. Feminism \& Psychology, 16(2), 133-154. https://doi.org/10.1177/0959-353506062970

Page, D., \& Whitt, S. (2020). Confronting wartime sexual violence: Public support for survivors in Bosnia. Journal of Conflict Resolution, 64(4), 674-702. https://doi.org/10.1177/0022002719867473

Payne, D. L., Lonsway, K. A., \& Fitzgerald, L. F. (1999). Rape myth acceptance: Exploration of its structure and its measurement using the Illinois Rape Myth Acceptance Scale. Journal of Research in Personality, 33(1), 27-68. https://doi.org/10.1006/jrpe.1998.2238 
Peterson, Z. D., \& Muehlenhard, C. L. (2004). Was it rape? The function of women's rape myth acceptance and definitions of sex in labeling their own experiences. Sex Roles, 51(3/4), 129-144. https://doi.org/10.1023/B:SERS.0000037758.95376.00

Planty, M., Langton, L., Krebs, C., Berzofsky, M., \& Smiley-McDonald, H. (2013). Female Victims of Sexual Violence, 1994-2010. Bureau of Justice Statistics.

Shafer, A., Ortiz, R. R., Thompson, B., \& Huemmer, J. (2018). The role of hypermasculinity, token resistance, rape myth, and assertive sexual consent communication among college men. Journal of Adolescent Health, 62(3), S44S50. https://doi.org/10.1016/j.jadohealth.2017.10.015

Smith, S. G., Chen, J., Basile, K. C., Gilbert, L. K., Merrick, M. T., Patel, N., Walling, M., \& Jain, A. (2017). The National Intimate Partner and Sexual Violence Survey: 2010-2012 State Report (p. 272). National Center for Injury Prevention and Control, Centers for Disease Control and Prevention.

Ståhl, T., Eek, D., \& Kazemi, A. (2010). Rape victim blaming as system justification: The role of gender and activation of complementary stereotypes. Social Justice Research, 23(4), 239-258. https://doi.org/10.1007/s11211-010-0117-0

Stephens, T., Kamimura, A., Yamawaki, N., Bhattacharya, H., Mo, W., Birkholz, R., Makomenaw, A., \& Olson, L. M. (2016). Rape myth acceptance among college students in the United States, Japan, and India. SAGE Open, 6(4), 2158244016675015.

Tajfel, H., \& Turner, J. C. (1986). The social identity theory of intergroup behavior. In S. Worchol \& W. G. Austin (Eds.), Psychology of Intergroup Relations (2nd ed., p. 10). Nelson-Hall. 
Tingley, D., Yamamoto, T., Hirose, K., Keele, L., \& Imai, K. (2014). Mediation: R package for causal mediation analysis. Journal of Statistical Software, 59(5). https://doi.org/10.18637/jss.v059.i05

Ullman, S. E., \& Peter-Hagene, L. (2014). Social reactions to sexual assault disclosure, coping, perceived control, and PTSD symptoms in sexual assault victims: Social reactions and PTSD. Journal of Community Psychology, 42(4), 495-508. https://doi.org/10.1002/jcop.21624

Ullman, S. E., Townsend, S. M., Filipas, H. H., \& Starzynski, L. L. (2007). Structural models of the relations of assault severity, social support, avoidance coping, selfblame, and PTSD among sexual assault survivors. Psychology of Women Quarterly, 31(1), 23-37. https://doi.org/10.1111/j.1471-6402.2007.00328.x van den Bos, K., \& Maas, M. (2009). On the psychology of the belief in a just world: Exploring experiential and rationalistic paths to victim blaming. Personality and Social Psychology Bulletin, 35(12), 1567-1578. https://doi.org/10.1177/0146167209344628

Vladutiu, C. J., Martin, S. L., \& Macy, R. J. (2011). College- or university-based sexual assault prevention programs: A review of program outcomes, characteristics, and recommendations. Trauma, Violence, \& Abuse, 12(2), 67-86. https://doi.org/10.1177/1524838010390708

Walker, W. D., Rowe, R. C., \& Quinsey, V. L. (1993). Authoritarianism and sexual aggression. Journal of Personality and Social Psychology, 65(5), 1036-1045. https://doi.org/10.1037/0022-3514.65.5.1036 
Warren, P., Swan, S., \& Allen, C. T. (2015). Comprehension of sexual consent as a key factor in the perpetration of sexual aggression among college men. Journal of Aggression, Maltreatment \& Trauma, 24(8), 897-913. https://doi.org/10.1080/10926771.2015.1070232

Wells, D., \& Taylor, W. (2003). Guidelines for medico-legal care for victims of sexual violence. World Health Organization. 


\section{Appendix A - Study Materials}

\section{Vignettes}

\section{Vignette 1}

Alan met Sandy at a party when he brought her a drink. After talking for a while, Alan asked Sandy if she wanted to keep hanging out. Sandy said yes, so Alan drove them both to his house. They sat on the couch, and Alan kissed Sandy. She pulled away a bit, so Alan stopped. Sandy looked at the ground, and Alan grabbed her hand. They talked a bit more, then Alan pulled her close and kissed her again. Sandy tried to pull away, but Alan was holding her too tightly. Sandy told Alan he was moving too fast, but Alan told her he would be gentle. Alan kept kissing her, and Sandy froze. They had sex while Sandy just laid still.

\section{Vignette 2}

Alan met Sandy at a party when he brought her a drink. After talking for a while, Alan asked Sandy if she wanted to keep hanging out. Sandy said yes, so Alan drove them both to his house. They sat on the couch, and Alan kissed Sandy. She pulled away a bit, so Alan stopped. Sandy looked at the ground, and Alan grabbed her hand. They talked a bit more, then Alan pulled her close and kissed her again. Sandy tried to pull away, but Alan was holding her too tightly. Sandy told Alan he was moving too fast, but Alan told her he would be gentle. Alan kept kissing her, and Sandy froze. They had sex while Sandy just laid still. Later, Sandy called her friend and said that she was upset about what Alan did. 
Vignette 3

Alan met Sandy at a party when he brought her a drink. After talking for a while, Alan asked Sandy if she wanted to keep hanging out. Sandy said yes, so Alan drove them both to his house. They sat on the couch, and Alan kissed Sandy. She pulled away a bit, so Alan stopped. Sandy looked at the ground, and Alan grabbed her hand. They talked a bit more, then Alan pulled her close and kissed her again. Sandy tried to pull away, but Alan was holding her too tightly. Sandy told Alan he was moving too fast, but Alan told her he would be gentle. Alan kept kissing her, and Sandy froze. They had sex while Sandy just laid still. Later, Sandy called her friends and warned them to stay away from Alan because of what he did to her.

\section{Vignette 4}

Alan met Sandy at a party when he brought her a drink. They both had a few more drinks while they talked. After a while, Alan asked Sandy if she wanted to keep hanging out. Sandy said yes, so Alan drove them both to his house. They sat on the couch, and Alan kissed Sandy. She pulled away a bit, so Alan stopped. Sandy looked at the ground, and Alan grabbed her hand. They talked a bit more, then Alan pulled her close and kissed her again. Sandy tried to pull away but she felt dizzy and Alan was holding her too tightly. Sandy told Alan he was moving too fast, but Alan told her he would be gentle. Alan kept kissing her, and Sandy froze. They had sex while Sandy just laid still. Later, Sandy called her friend and said that she was upset about what Alan did. 


\section{Perceived Consent Clarity Scale}

Please rate how much you agree or disagree with the following statements.

1 - Strongly Disagree

2 - Disagree

3 - Somewhat Disagree

4 - Somewhat Agree

5 - Agree

6 - Strongly Agree

1. Sandy should have been clearer when telling Alan what she wanted.

2. Sandy clearly communicated that she did not want to have sex with Alan.

3. It would be unfair to expect Alan to know what Sandy wanted.

4. If Sandy did not want to have sex with Alan, she should have been more direct.

5. Alan ignored clear signs that Sandy did not want to have sex with him.

6. It makes sense that Alan would think that Sandy wanted to have sex.

7. Alan knew that he was violating Sandy's consent.

8. There was no way for Alan to know if Sandy did not really want to have sex. 


\title{
Social Dominance Orientation (SDO-7)
}

Show how much you favor or oppose each idea below by selecting a number from 1 to 7 on the scale below. You can work quickly; your first feeling is generally best.

\author{
1 - Strongly Oppose \\ 2 - Somewhat Oppose \\ 3 - Slightly Oppose \\ 4 - Neutral \\ 5 - Slightly Favor \\ 6 - Somewhat Favor \\ 7 - Strongly Favor
}

1. Some groups of people must be kept in their place.

2. It's probably a good thing that certain groups are at the top and other groups are at the bottom.

3. An ideal society requires some groups to be on top and others to be on the bottom.

4. Some groups of people are simply inferior to other groups.

5. Groups at the bottom are just as deserving as groups at the top. [R]

6. No one group should dominate in society. [R]

7. Groups at the bottom should not have to stay in their place. [R]

8. Group dominance is a poor principle. [R]

9. We should not push for group equality.

10. We shouldn't try to guarantee that every group has the same quality of life. 
11. It is unjust to try to make groups equal.

12. Group equality should not be our primary goal.

13. We should work to give all groups an equal chance to succeed. [R]

14. We should do what we can to equalize conditions for different groups. [R]

15. No matter how much effort it takes, we ought to strive to ensure that all groups have the same chance in life. [R]

16. Group equality should be our ideal. [R] 


\section{Illinois Rape Myth Acceptance Scale - Short Form}

Please indicate the extent to which you agree or disagree with the following items.

1 - Not at all agree

2 - Not agree

3 - Somewhat not agree

4 - Neutral

5 - Somewhat agree

6 - Agree

7 - Very much agree

1. If a woman is raped while she is drunk, she is at least somewhat responsible for letting things get out of control.

2. Although most women wouldn't admit it, they generally find being physically forced into sex a real "turn-on."

3. If a woman is willing to "make out" with a guy, then it's no big deal if he goes a little further and has sex.

4. Many women secretly desire to be raped.

5. Most rapists are not caught by the police. [filler item]

6. If a woman doesn't physically fight back, you can't really say that it was rape.

7. Men from nice middle-class homes almost never rape.

8. Rape accusations are often used as a way of getting back at men.

9. All women should have access to self-defense classes. [filler item] 
10. It is usually only women who dress suggestively that are raped.

11. If the rapist doesn't have a weapon, you really can't call it a rape.

12. Rape is unlikely to happen in the woman's own familiar neighborhood.

13. Women tend to exaggerate how much rape affects them.

14. A lot of women lead a man on and then they cry rape.

15. It is preferable that a female police officer conduct the questioning when a woman reports a rape. [filler item]

16. A woman who "teases" men deserves anything that might happen.

17. When women are raped, it's often because the way they said "no" was ambiguous.

18. Men don't usually intend to force sex on a woman, but sometimes they get too sexually carried away.

19. A woman who dresses in skimpy clothes should not be surprised if a man tries to force her to have sex.

20. Rape happens when a man's sex drive gets out of control. 


\title{
Belief in a Just World for Others Scale
}

Please think of how much each statement applies to people other than yourself.

\author{
1 - Strongly Disagree \\ 2 - Disagree \\ 3 - Somewhat Disagree \\ 4 - Somewhat Agree \\ 5 - Agree \\ 6 - Strongly Agree
}

1. I feel that the world treats people fairly.

2. I feel that people get what they deserve.

3. I feel that people treat each other fairly in life.

4. I feel that people earn the rewards and punishments they get.

5. I feel that people treat each other with the respect that they deserve.

6. I feel that people get what they are entitled to have.

7. I feel that a person's efforts are noticed and rewarded

8. I feel that when people meet with misfortune, they have brought it on themselves. 


\section{Peer Norms Supporting Sexual Aggression Scale}

$1-$ Not at all

$2-$ Not really

3 - Undecided

4 - Somewhat

5 - Very Much

1. How much would your friends approve of getting someone drunk to have sex with them?

2. How much would your friends approve of lying to someone to have sex with them?

3. How much would your friends approve of forcing someone to have sex?

4. How much would your friends approve of someone having sex they were uncomfortable with due to a pledge, bet, or dare?

5. How much would your friends approve of someone having sex with someone who they didn't want to have sex with? 


\section{Other Study Items}

\section{Evaluations of the Perpetrator and Survivor}

[Shown before Vignette] Please indicate how much you agree or disagree with each statement

1 - Strongly Disagree

2 - Disagree

3 - Somewhat Disagree

4 - Somewhat Agree

5 - Agree

6 - Strongly Agree

1. I think that I would be friends with Alan.

2. I think that I would like Alan if we met in person.

3. I think that Alan makes bad decisions.

4. I think that Alan is someone who should not be trusted.

5. I think that Alan will be successful in the future.

6. I think that Alan is someone who is like me.

7. I like Alan. ${ }^{4}$

\footnotetext{
${ }^{4}$ This item was used as the measure of baseline liking of perpetrator
} 
Please indicate what percent of the blame (responsibility) for what happened you would give each person.

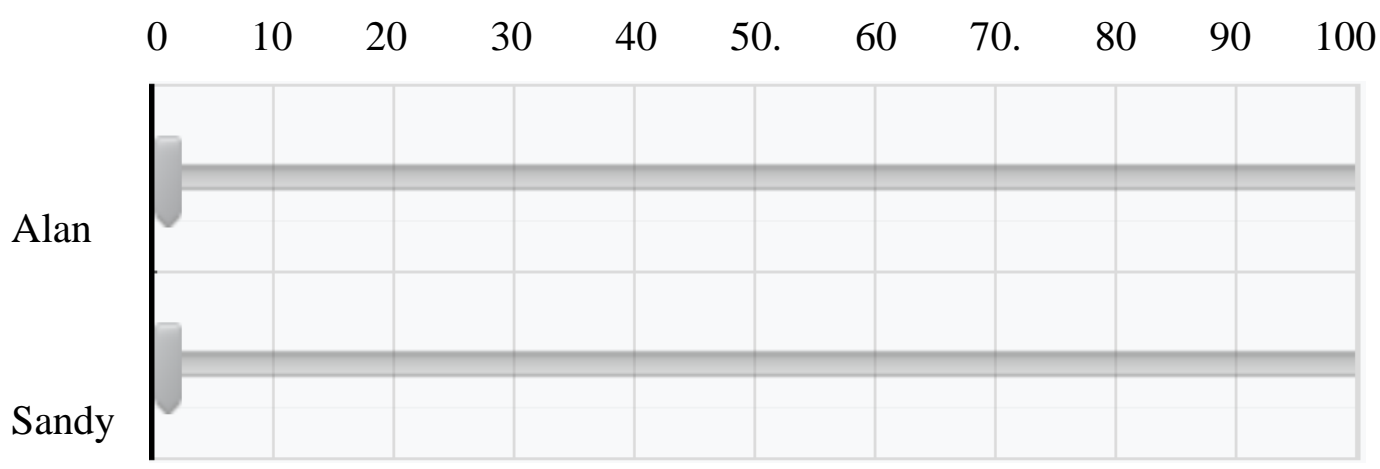

Please indicate how much you agree or disagree with each statement

1 - Strongly Disagree

2 - Disagree

3 - Somewhat Disagree

4 - Somewhat Agree

5 - Agree

6 - Strongly Agree

1. I like Alan from this story

2. I like Sandy from this story

3. What Alan did in this story is okay.

4. What Sandy did in this story is okay. 
Please indicate how much you agree or disagree with each statement

1 - Strongly Disagree

2 - Disagree

3 - Somewhat Disagree

4 - Somewhat Agree

5 - Agree

6 - Strongly Agree

1. I think that I would be friends with Alan

2. I think that I would like Alan if we met in person.

3. I think that Alan makes bad decisions.

4. I think that Alan is someone who should not be trusted.

5. I think that Alan will be successful in the future.

6. I think that Alan is someone who is like me. 
Please indicate how much you agree or disagree with each statement

1 - Strongly Disagree

2 - Disagree

3 - Somewhat Disagree

4 - Somewhat Agree

5 - Agree

6 - Strongly Agree

1. What Alan did to Sandy was sexual assault.

2. What Alan did to Sandy was rape.

Please provide a brief explanation of why you feel that this instance was or was not sexual assault/rape

\section{Manipulation Checks}

[Minimal Group Manipulation] Which type of thinker was Alan from the earlier story?

- $\quad$ A LOGICAL thinker

- $\quad$ A VISUAL thinker

- It was never stated

- Unsure 
[Minimal Group Manipulation] Are you and Alan from the earlier story the same type of thinker?

- $\quad$ Yes

- $\quad$ No

- $\quad$ Alan's thinking type was never stated

- $\quad$ Unsure

\section{Demographics}

What is your gender? (check all that apply)

- $\quad$ Man

- Woman

- $\quad$ Nonbinary

- $\quad$ Genderqueer

- $\quad$ Genderfluid

- $\quad$ Other: (please specify)

- $\quad$ I prefer not to say

Are you transgender?

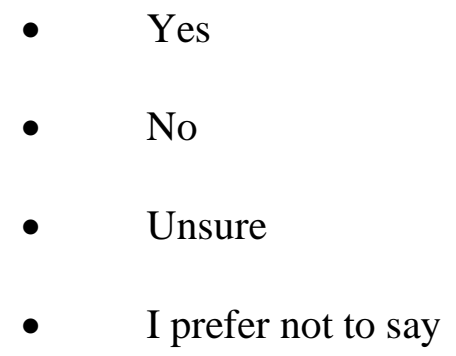


How would you describe yourself? (check all that apply)

- $\quad$ Black or African American

- Asian or Asian American

- $\quad$ Native American, American Indian, or Alaska Native

- $\quad$ Native Hawaiian or Pacific Islander

- White or European

- $\quad$ Hispanic, Latino/a/x, or Spanish Origin

- $\quad$ Other: (please specify)

- I prefer not to say 
What is the highest level of education you have completed?

- $\quad$ Grade school

- $\quad$ Some high school

- $\quad$ High school diploma/GED

- $\quad$ Some college

- $\quad$ Trade school

- $\quad$ Associate's degree

- Bachelor's degree

- $\quad$ Some graduate school

- $\quad$ Master's degree

- $\quad$ Professional degree

- $\quad$ Doctoral degree

- I prefer not to say

What is your age in years: 
What is your current employment status? (check all that apply)

- $\quad$ Employed full-time

- $\quad$ Employed part-time

- $\quad$ Homemaker

- $\quad$ Student

- $\quad$ Military

- $\quad$ Retired

- $\quad$ Not currently employed

- $\quad$ Other: (please specify)

- I prefer not to say

What is your marital status?

- $\quad$ Single (never married)

- $\quad$ Partnered/Cohabitating

- $\quad$ Married

- $\quad$ Separated

- Divorced

- Widowed

- I prefer not to say 
What is your total yearly household income before taxes?

- $\quad$ Less than $\$ 25,000$

- $\quad \$ 25,000$ to $\$ 34,999$

- $\quad \$ 35,000$ to $\$ 49,999$

- $\quad \$ 50,000$ to $\$ 74,999$

- $\quad \$ 75,000$ to $\$ 99,999$

- $\quad \$ 100,000$ to $\$ 149,999$

- $\quad \$ 150,000$ to $\$ 199,999$

- $\$ 200,000$ or more

- Unsure

- I prefer not to say 
What is your sexual orientation? (check all that apply)

- Heterosexual/straight

- Gay

- Lesbian

- Bisexual

- Pansexual

- Asexual/Asexual Spectrum

- Queer

- Questioning

- $\quad$ Other: (please specify)

- I prefer not to say

[Only if Asexual is selected] Do you engage in relationships that are romantic, sexual, and/or queerplatonic?

- I do not engage in any romantic, sexual, or queerplatonic relationships

- I engage in romantic or queerplatonic relationships that do not include sex

- I engage in romantic or queerplatonic relationships that do include sex 
[Only if Asexual is selected] With which gender(s) do you form these relationships?

- I form these relationships only with people of the opposite binary gender

- I form these relationships only with people of the same/a similar gender to me

- I form these relationships with people of any gender

- $\quad$ Other: (please specify)

The rest of these items were only included in Study 2, the political update.

How would you describe your political beliefs?

- $\quad$ Very Conservative

- Conservative

- Somewhat Conservative

- $\quad$ Moderate

- $\quad$ Somewhat Liberal

- Liberal

- $\quad$ Very Liberal 
Are your registered to vote in the US?

- Yes, I am a registered Republican

- $\quad$ Yes, I am a registered Democrat

- $\quad$ Yes, I am registered with a third party or as an independent

- $\quad$ No, I am eligible to vote in the US but I have not registered

- $\quad$ No, I am not eligible to vote in the US

Which major US political party do you most often agree with?

- Democratic party

- $\quad$ Republican party

Please indicate how strongly you feel about your support of the party you selected.

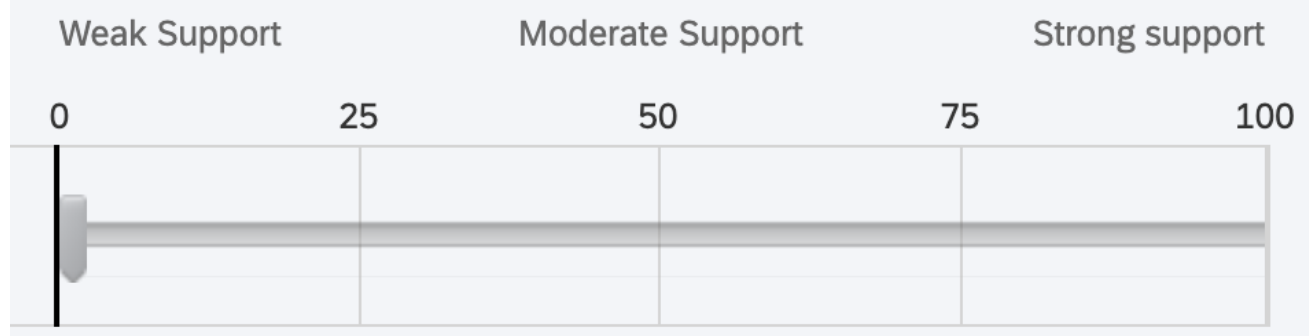


When thinking about why you tend to agree with this political party, please select the issue that is the MOST important to you.

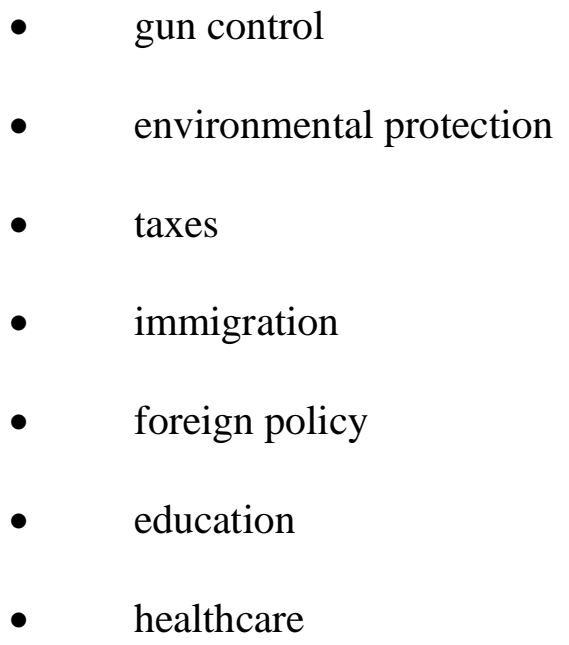


Subset of the Spatial Reasoning Instrument

Two plans of Victoria hospital are shown below.

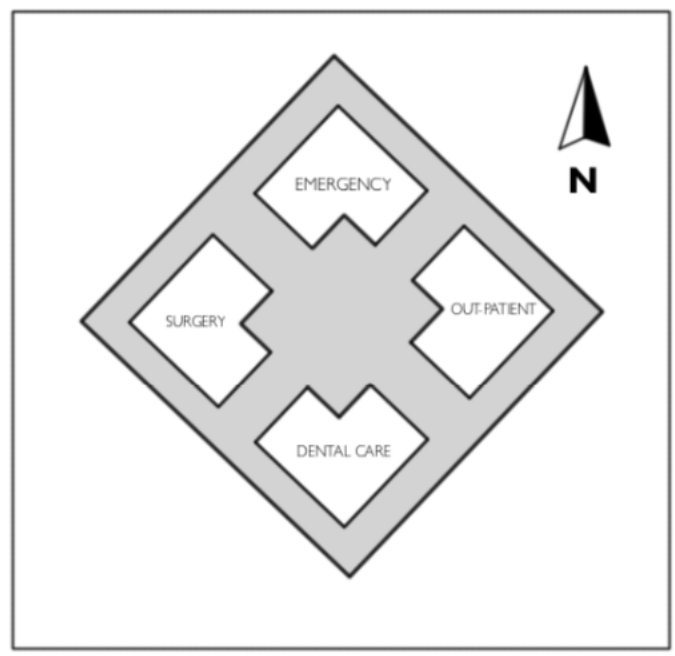

VICTORIA HOSPITAL - BUILDING MAP

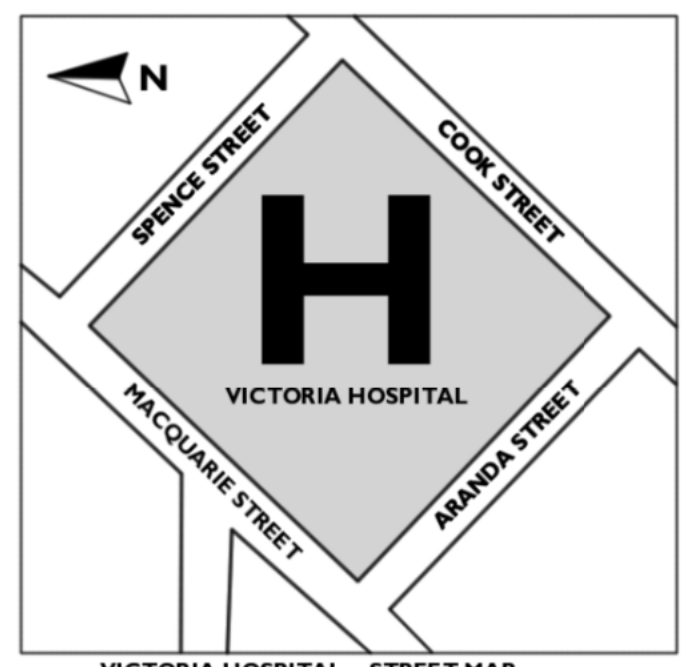

VICTORIA HOSPITAL - STREET MAP

Which building is on the corner of Aranda street and Macquarie street?

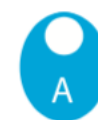

EMERGENCY

OUT-PATIENT

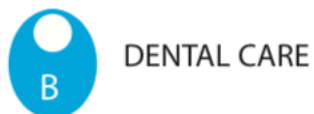

SURGERY 
The diagram below represents a model made out of cubes.

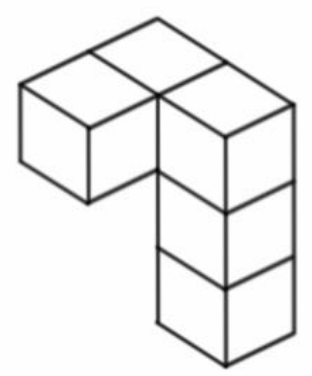

Which of the following is the same as the model above?
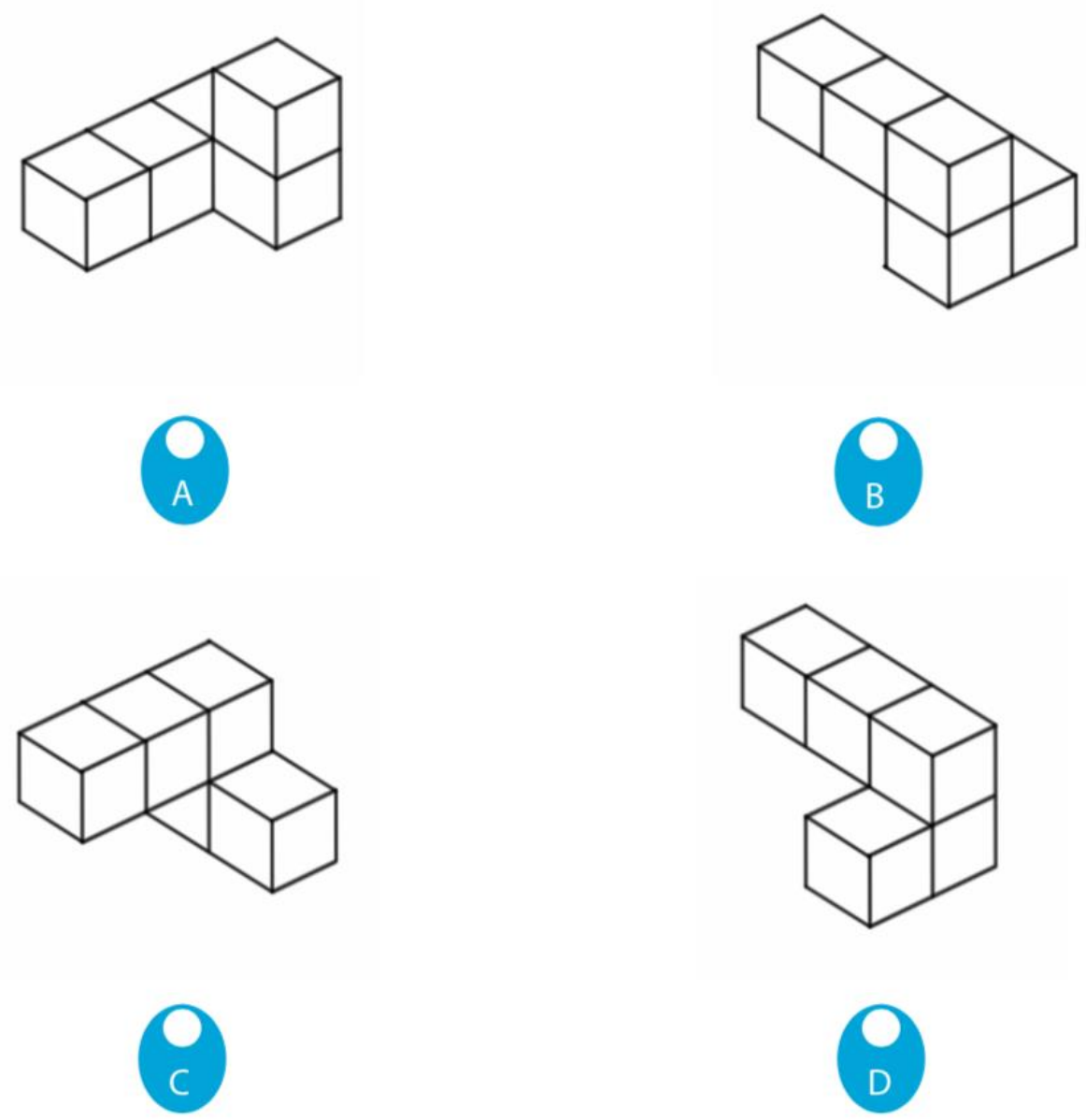
This is the net of a cube.

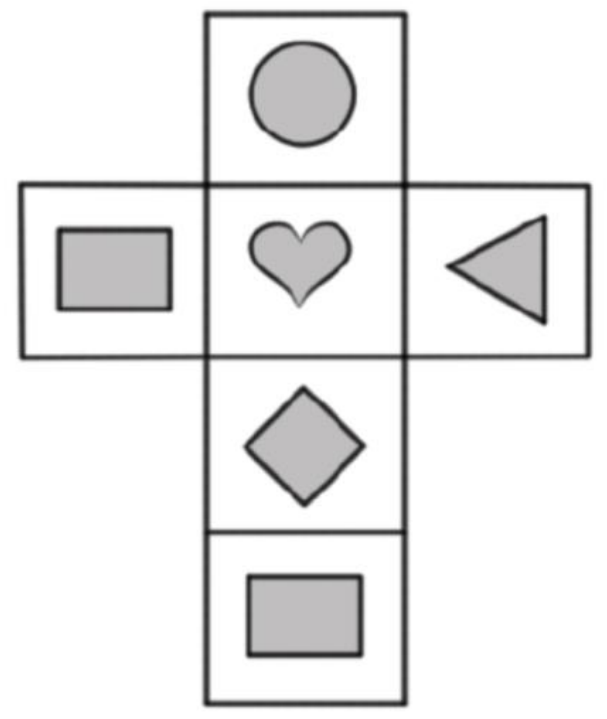

Which one of the following cubes could be made by folding the net?
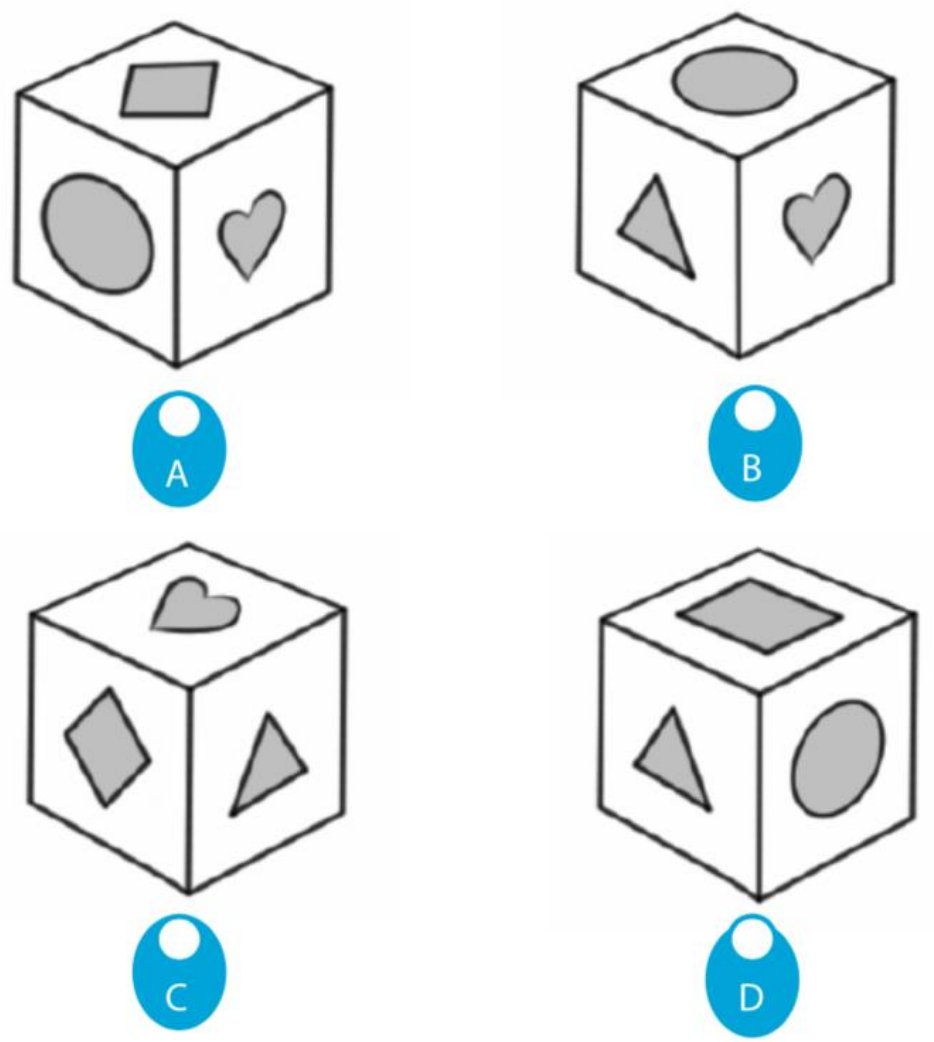
The diagram below represents a model made out of cubes.

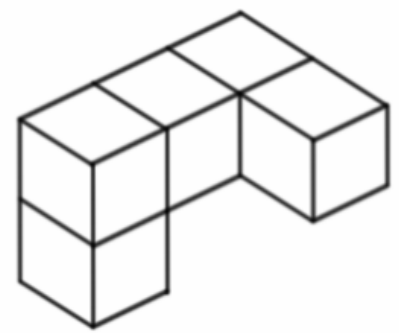

Which of the following is the same as the model above?

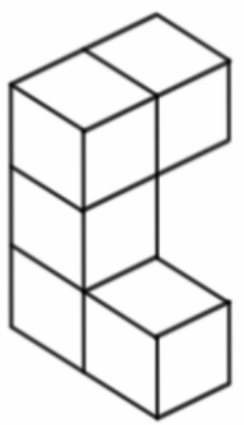

\section{$O$ \\ A}

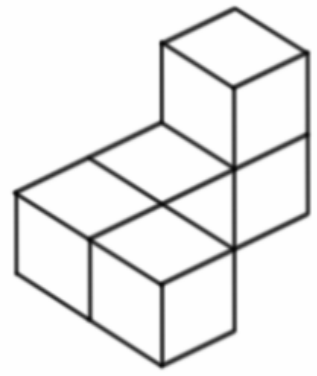

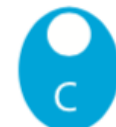

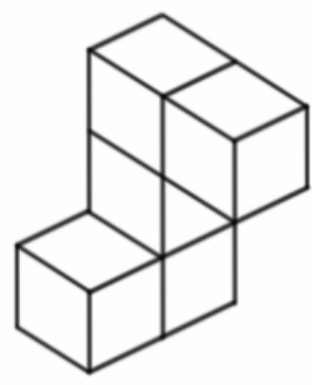

B

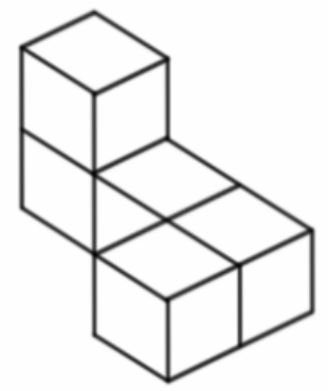


The diagram below represents a model made of cube blocks.

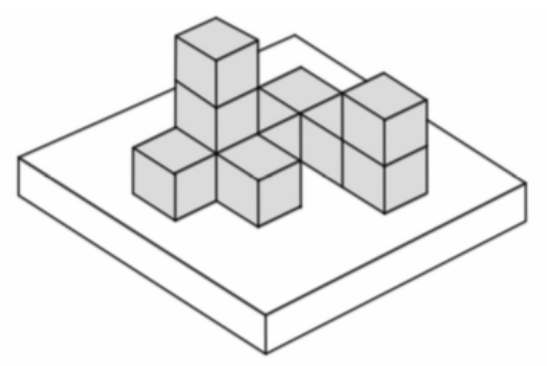

Which one of the following represents the model when viewed from above?
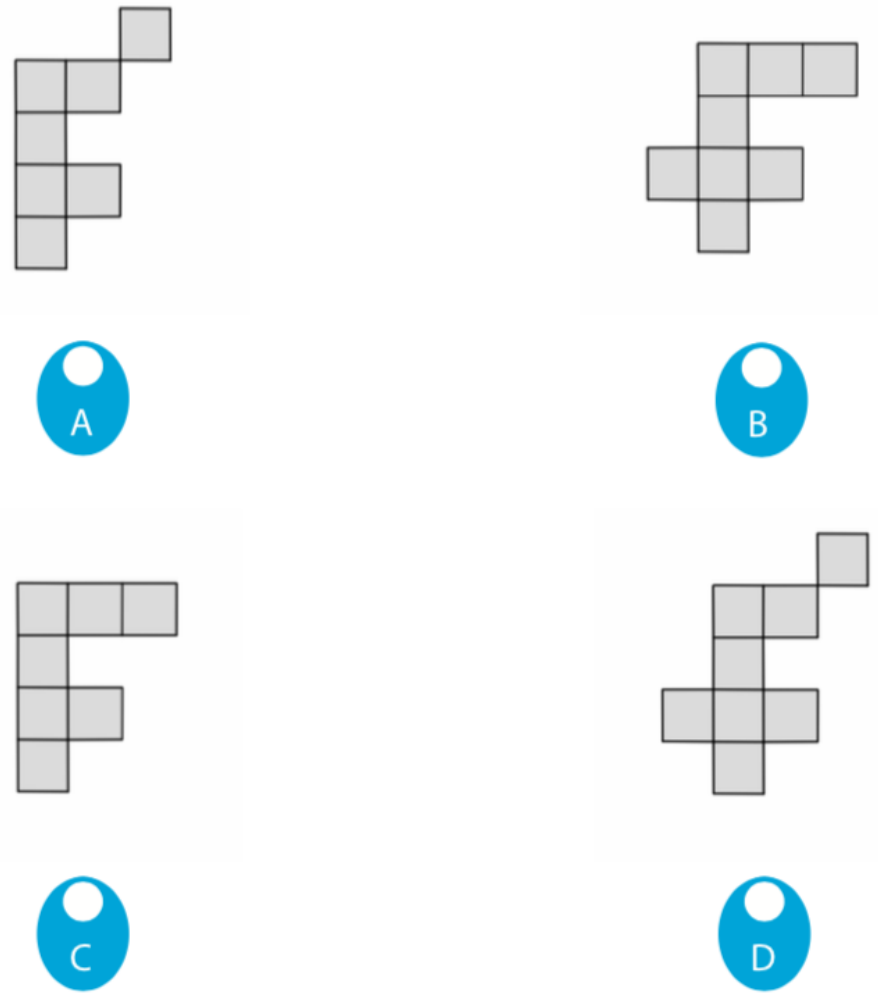


\section{Appendix B - Tests of Model Assumptions}

\section{Pilot 1 - Vignette Test}

Levene's test of homogeneity of variances indicated that the variance of consent clarity did not differ significantly by vignette $[F(2,90)=1.00, \mathrm{p}=0.37]$. The Shapiro-Wilk test of normality indicated that the residuals may not be normally distributed [W = $0.96, \mathrm{p}$-value $=0.01]$

\section{Pilot 2 - Manipulation Check}

Levene's test of homogeneity of variances indicated that the variance of consent clarity did not differ significantly by condition $[F(1,155)=0.25, \mathrm{p}=0.62]$. The Shapiro-Wilk test of normality indicated that the residuals may not be normally distributed [W = 0.95, p-value $<0.001]$.
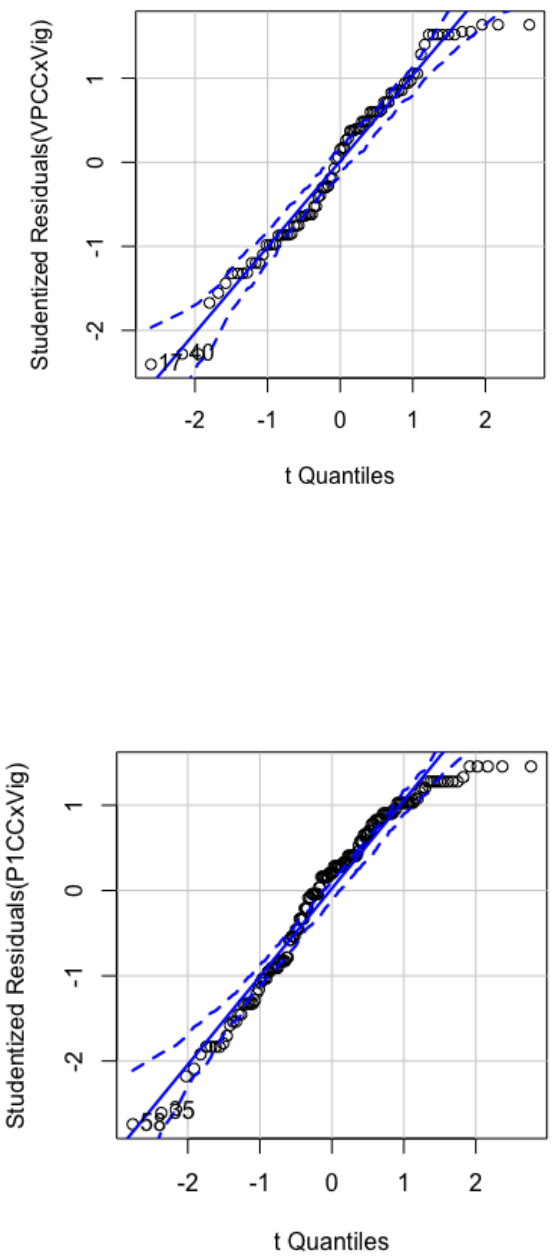


\section{Pilot 3 - Updated Manipulation Check}

Preliminary Analyses

Levene's test of homogeneity of variances indicated that the variance of baseline liking did not differ significantly by condition $[F(1,186)=0.74, \mathrm{p}=0.39]$. The Shapiro-Wilk test of normality indicated that the residuals may not be normally distributed [W = 0.86, p-value $<0.001]$

\section{$\underline{\text { Main Analyses }}$}

Levene's test of homogeneity of variances indicated that the variance of consent clarity did not differ significantly by condition $[F(1,185)=1.37, \mathrm{p}=0.24]$. The Shapiro-Wilk test of normality indicated that the residuals may not be normally distributed $[\mathrm{W}=$ 0.94, p-value $<0.001]$
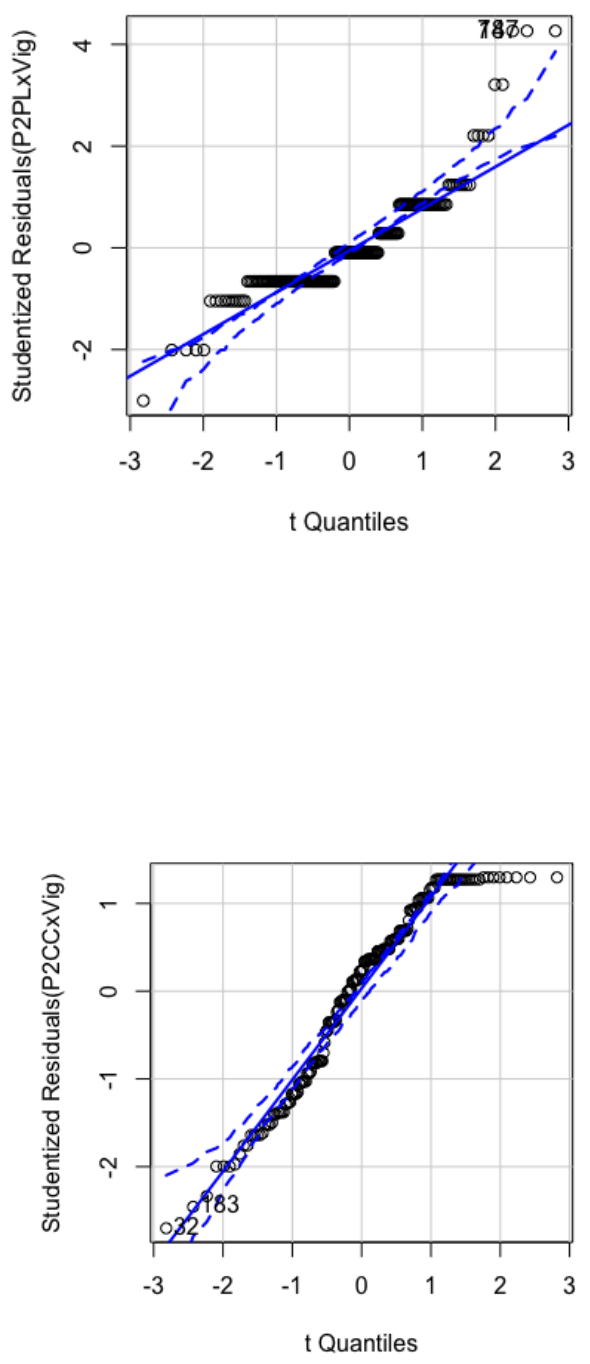


\section{Study 1}

Preliminary Analyses - ANOVA (Baseline liking x $\underline{\text { condition) }}$

Levene's test of homogeneity of variances indicated that the variance of baseline liking did not differ significantly by condition $[F(2,310)=1.26, \mathrm{p}=0.29]$. The Shapiro-Wilk test of normality indicated that the residuals may not be normally distributed [W = 0.92, p-value $<0.001]$

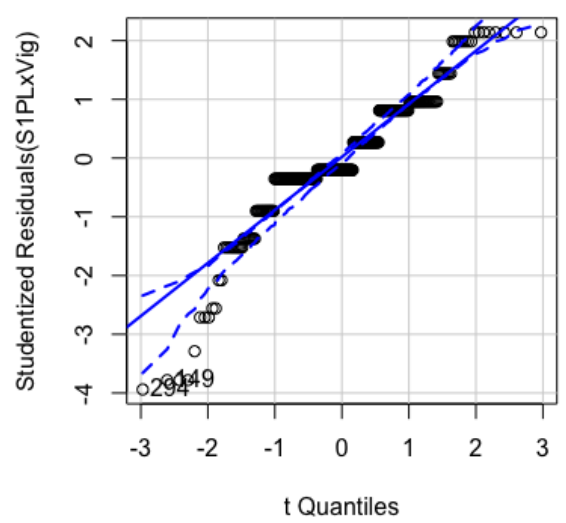

Main Analyses - ANOVA (Consent clarity x $\underline{\text { condition) }}$

Levene's test of homogeneity of variances indicated that the variance of consent clarity did not differ significantly by condition $[F(2,309)=0.16, \mathrm{p}=0.85]$. The Shapiro-Wilk test of normality indicated that

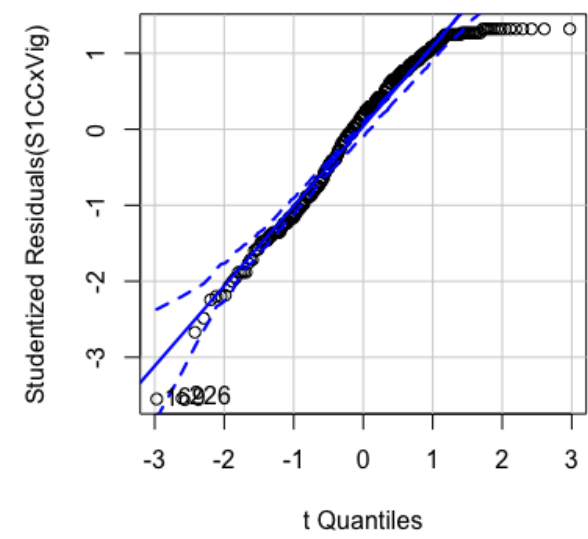
the residuals may not be normally distributed $[\mathrm{W}=$ 0.94, p-value $<0.001]$ 
$\underline{\text { Main Analyses - Multiple Regression (Moderated }}$ by Social Dominance Orientation)

The Breusch-Pagan test indicated homoscedasticity for the full model $(\mathrm{BP}=8.69, \mathrm{df}=5, \mathrm{p}$-value $=$ 0.12). The Shapiro-Wilk test of normality indicated that the residuals may not be normally distributed

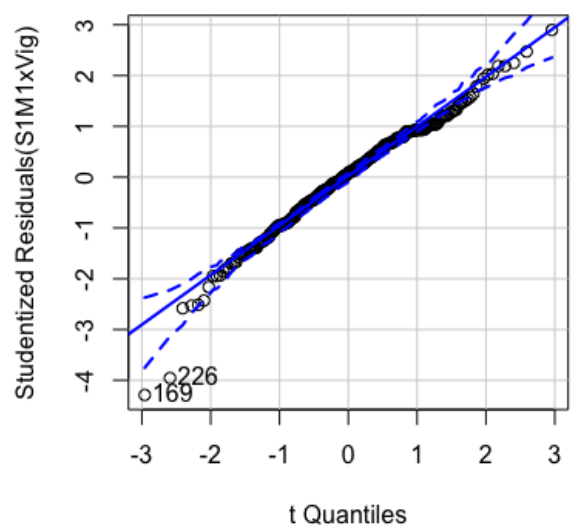
$[\mathrm{W}=0.98, \mathrm{p}$-value $<0.001]$

Main Analyses - Multiple Regression (Mediated by $\underline{\text { Rape Myth Acceptance) }}$

The Breusch-Pagan test indicated homoscedasticity for the full model $(\mathrm{BP}=3.89, \mathrm{df}=3, \mathrm{p}$-value $=$ 0.27). The Shapiro-Wilk test of normality indicated that the residuals may not be normally distributed

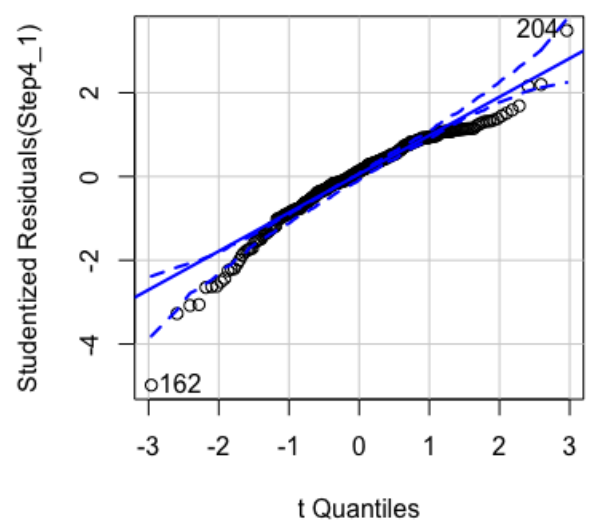
$[\mathrm{W}=0.95, \mathrm{p}$-value $<0.001]$

\section{Study 2 - Political Update}

$\underline{\text { Preliminary Analyses - Baseline Liking x Condition }}$ The Breusch-Pagan test indicated heteroscedasticity for the full model $(\mathrm{BP}=33.66, \mathrm{df}=4, \mathrm{p}$-value $<$ 0.001). The Shapiro-Wilk test of normality indicated that the residuals may not be normally distributed $[\mathrm{W}=0.98, \mathrm{p}$-value $<0.001]$.

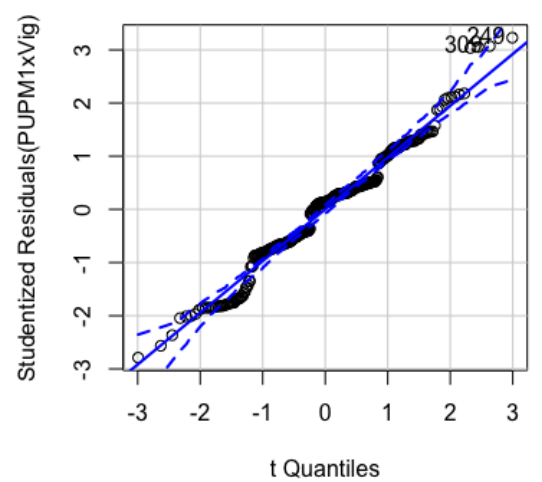


$\underline{\text { Main Analyses - Consent Clarity x Condition }}$

The Breusch-Pagan test indicated homoscedasticity for the full model $(\mathrm{BP}=6.1, \mathrm{df}=4, \mathrm{p}$-value $=0.19)$.

The Shapiro-Wilk test of normality indicated that the residuals may not be normally distributed $[\mathrm{W}=$ 0.97, p-value $<0.001]$

Main Analyses - Moderated by Social Dominance

\section{$\underline{\text { Orientation }}$}

The Breusch-Pagan test indicated homoscedasticity for the full model $(\mathrm{BP}=9.71, \mathrm{df}=7, \mathrm{p}$-value $=$ 0.21). The Shapiro-Wilk test of normality indicated that the residuals may not be normally distributed [W $=0.98, \mathrm{p}$-value $<0.001]$.

Main Analyses - Multiple Regression (Mediated by

\section{Rape Myth Acceptance)}

The Breusch-Pagan test indicated heteroscedasticity for the full model $(\mathrm{BP}=17.35, \mathrm{df}=5, \mathrm{p}$-value $=$ 0.001). The Shapiro-Wilk test of normality indicated that the residuals may not be normally distributed $[\mathrm{W}=0.98, \mathrm{p}$-value $=0.001]$.
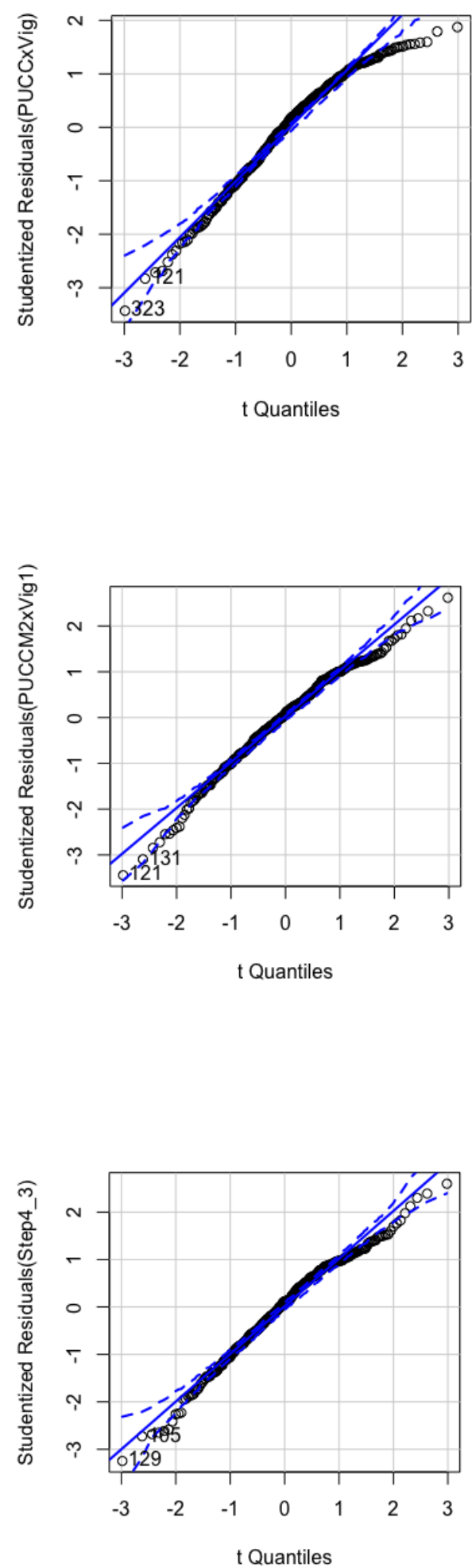


\section{Study 3 - Alternative Data Collection}

Preliminary Analyses - Baseline Liking x Condition

Levene's test of homogeneity of variances indicated that the variance of baseline liking did differ significantly by condition $[F(1,215)=18.91$, $\mathrm{p}<0.001]$. The Shapiro-Wilk test of normality

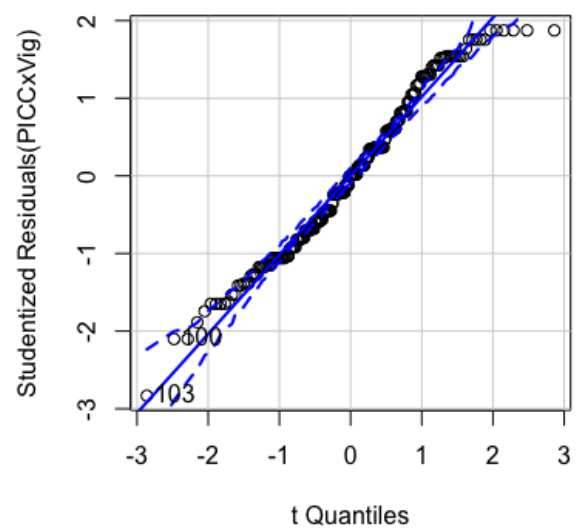
indicated that the residuals may not be normally distributed $[\mathrm{W}=0.91, \mathrm{p}$-value $<0.001]$.

\section{Main Analyses - Consent Clarity x Condition}

Levene's test of homogeneity of variances indicated that the variance of consent clarity did not differ significantly by condition $[F(1,214)=1.46, \mathrm{p}=0.23]$. The Shapiro-Wilk test of normality indicated that the residuals may not be normally distributed $[\mathrm{W}=$ 0.98$, p-value $=0.001]$

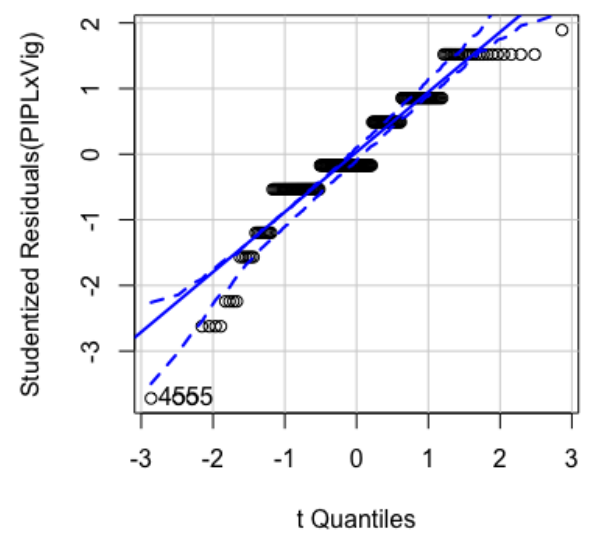


$\underline{\text { Main Analyses - Moderation by Belief in a Just }}$

\section{World}

The Breusch-Pagan test indicated heteroscedasticity for the full model $(\mathrm{BP}=11.27, \mathrm{df}=3, \mathrm{p}$-value $=$ 0.01). The Shapiro-Wilk test of normality indicated that the residuals are normally distributed $[\mathrm{W}=$

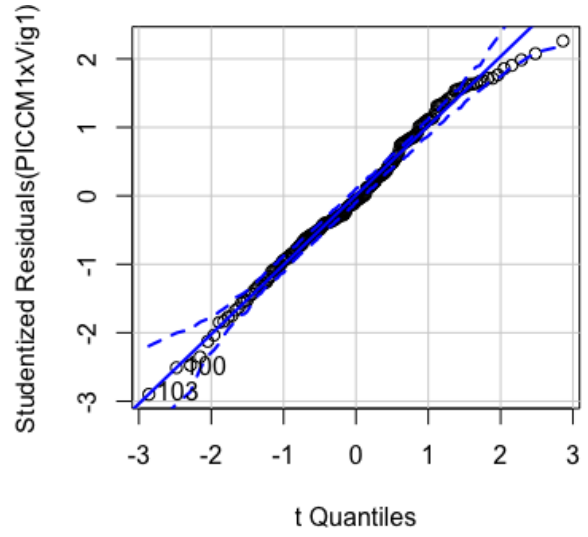

0.99, p-value $=0.14]$.

\section{Main Analyses - Mediation by Rape Supportive}

\section{$\underline{\text { Peer Norms }}$}

The Breusch-Pagan test indicated heteroscedasticity for the full model $(\mathrm{BP}=9.03, \mathrm{df}=2, \mathrm{p}$-value $=$ 0.01). The Shapiro-Wilk test of normality indicated

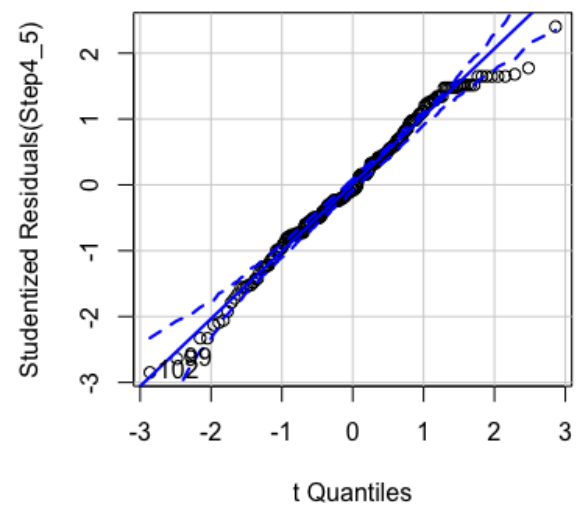
that the residuals may not be normally distributed $[\mathrm{W}=0.99, \mathrm{p}$-value $=0.02]$ 


\section{Study 4 - Actual Group Iteration}

Preliminary Analyses - Baseline Liking x Condition

Levene's test of homogeneity of variances indicated that the variance of baseline liking did not differ significantly by condition $[F(2,219)=0.007$, $\mathrm{p}=0.99]$. The Shapiro-Wilk test of normality

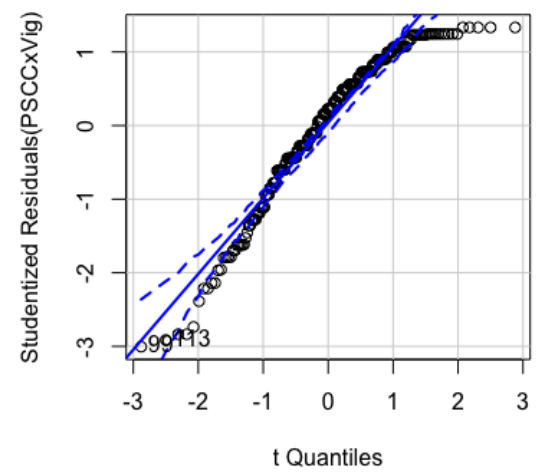

indicated that the residuals may not be normally distributed $[\mathrm{W}=0.9, \mathrm{p}$-value $<0.001]$.

\section{Main Analyses - Consent Clarity x Condition}

Levene's test of homogeneity of variances indicated that the variance of consent clarity did not differ significantly by condition $[F(2,226)=0.22, \mathrm{p}=0.8]$. The Shapiro-Wilk test of normality indicated that the residuals may not be normally distributed [W =

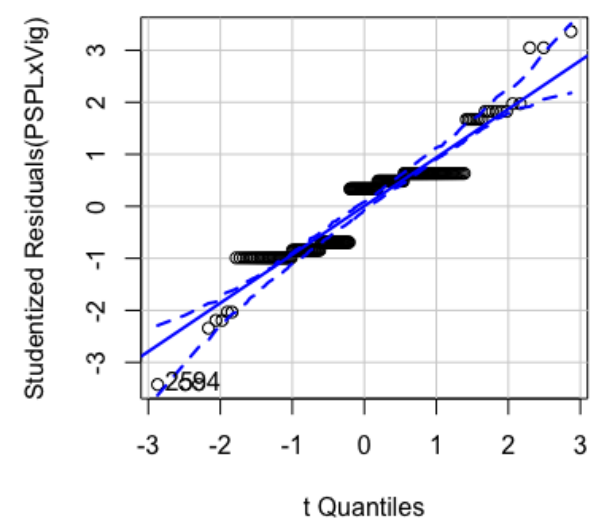
0.93, p-value $<0.001]$. 
$\underline{\text { Main Analyses - Moderation by Belief in a Just }}$

\section{World}

The Breusch-Pagan test indicated homoscedasticity for the full model $(\mathrm{BP}=7.97, \mathrm{df}=5, \mathrm{p}$-value $=$ 0.16). The Shapiro-Wilk test of normality indicated that the residuals may not be normally distributed $[\mathrm{W}=0.95, \mathrm{p}$-value $<0.001]$.

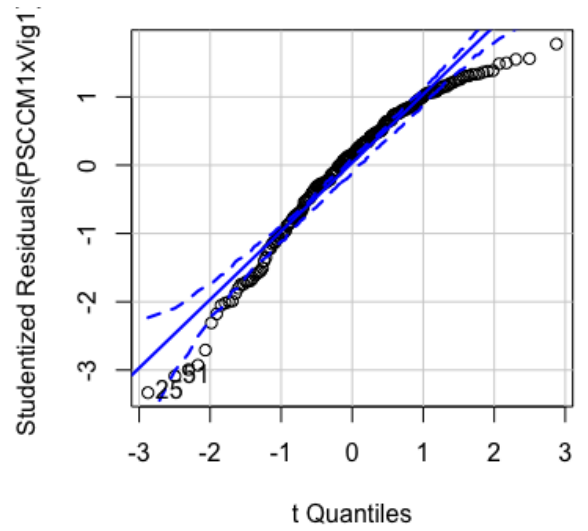

$\underline{\text { Main Analyses - Mediation by Rape Supportive }}$

\section{$\underline{\text { Peer Norms }}$}

The Breusch-Pagan test indicated homoscedasticity for the full model $(\mathrm{BP}=1.02, \mathrm{df}=3, \mathrm{p}$-value $=0.8)$ The Shapiro-Wilk test of normality indicated that the residuals may not be normally distributed [W =

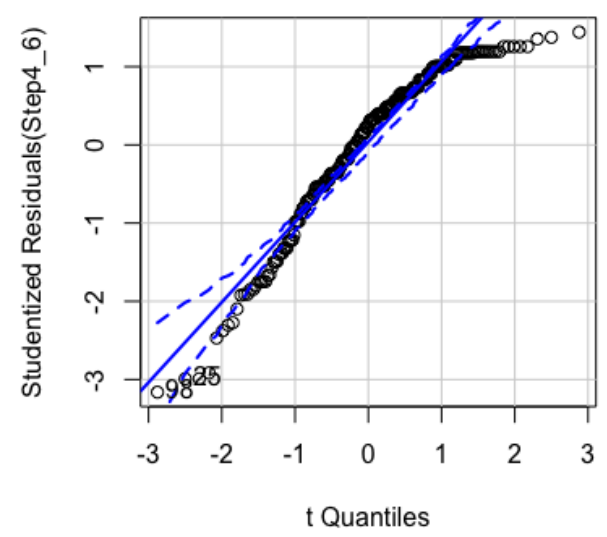
0.93, p-value $<0.001]$ 